Juliana Silva Agostinetto

\title{
SISTEMATIZAÇÃO DO PROCESSO DE DESENVOLVIMENTO DE PRODUTOS, MELHORIA CONTÍNUA E DESEMPENHO: O CASO DE UMA EMPRESA DE AUTOPEÇAS
}

Dissertação apresentada à Escola de Engenharia de São Carlos da Universidade de São Paulo, para a obtenção do Título de Mestre em Engenharia de Produção.

Área de Concentração: Engenharia de Produção

Orientador: Prof. Dr. Daniel Capaldo Amaral 
AUTORIZO A REPRODUÇÃO E DIVULGAÇÃO TOTAL OU PARCIAL DESTE TRABALHO, POR QUALQUER MEIO CONVENCIONAL OU ELETRÔNICO, PARA FINS DE ESTUDO E PESQUISA, DESDE QUE CITADA A FONTE.

Agostinetto, Juliana Silva

Sistematizaça do processo de desenvolvimento de produtos, melhoria continua e desempenho : o caso de uma empresa de autopecas / Juliana Silva Agostinetto; orientador Daniel Capaldo Amaral. -- São Carlos, 2006.

Dissertaçào \{Mestrado\} - Programa de Pós-Graduacăo e Area de Concentraça em Engenharia Mecânica -- Escola de Engenharia de Säo Carlos da Universidade de Săo Paulo.

1. Melhoria continua. 2. Sistematizacăo. 3. Processo de desenvolvimento de produtos. I. Titulo. 
Dissertação defendida e julgada em 20-10-2006 perante a Comissão Julgadora:

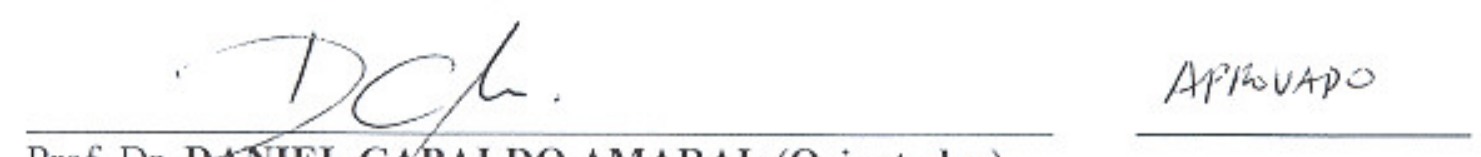

Prof. Dr. DANIEL CAPALDO AMARAL (Orientador)

(Escola de Engenharia de São Carlos/USP)

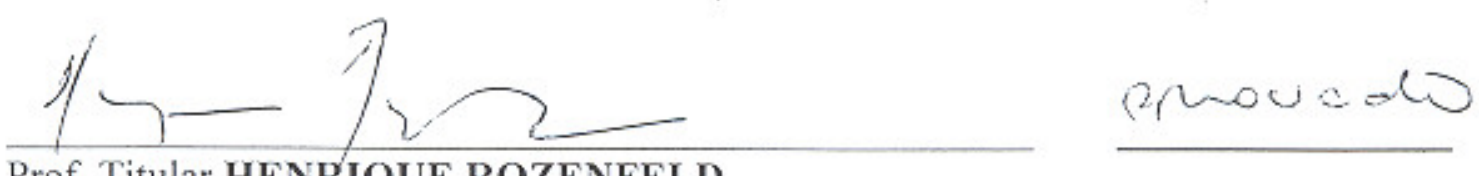

Prof. Titular HENRIQUE ROZENFELD

(Escola de Engenharia de São Carlos/USP)
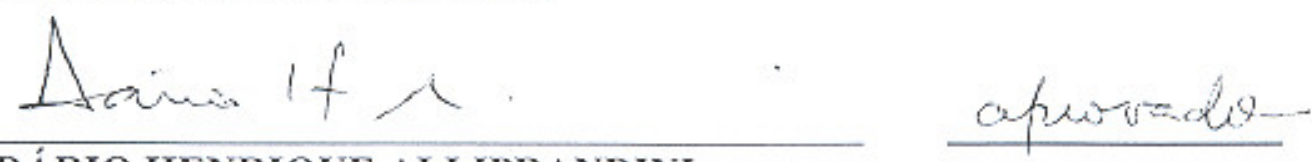

Prof. Dr. DÁRIO HENRIQUE ALLIPRANDINI

(Faculdade ETAPA)

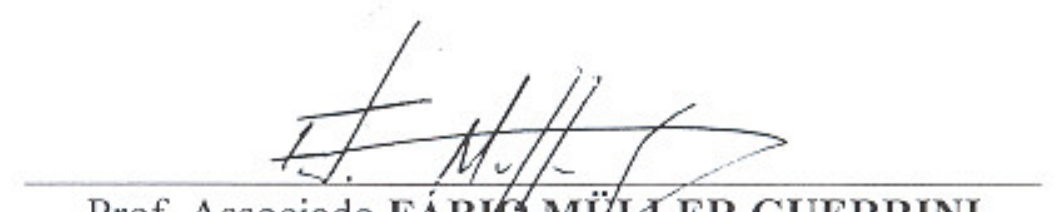

Prof. Associado FÁBJO M"̈LLER GUERRINI

Coordenador do Programa de Pós-Graduação em em Engenharia de Produção

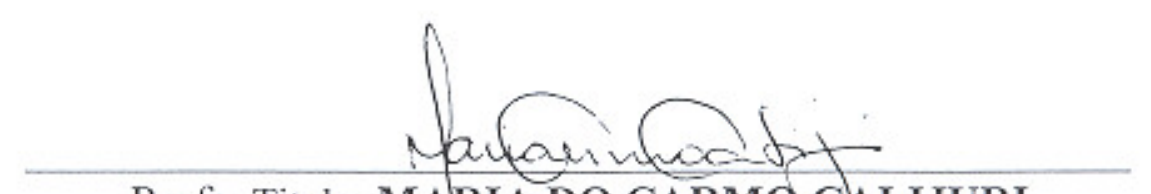

Profa. Titular MARIA DO CARMO CALIJURI

Presidente da Comissão de Pós-Graduação da EESC 


\section{Resumo}

AGOSTINETTO, J.S. Sistematização do processo de desenvolvimento de produtos, melhoria contínua e desempenho: o caso de uma empresa de autopeças. Dissertação (Mestrado) - Escola de Engenharia de São Carlos, Universidade de São Paulo, São Carlos, 2006.

O processo de desenvolvimento de produtos (PDP) tem recebido especial atenção por ser reconhecido como fonte de ganhos competitivos. Através da sua sistematização as empresas reduzem custos, aumentam a qualidade dos seus produtos e diminuem os tempos de desenvolvimento. Para que essa sistematização seja efetiva é preciso que o PDP seja melhorado continuamente, de modo que acompanhe a constante necessidade de aprimoramento dos produtos a serem lançados. Quando comparado a outros processos, o PDP apresenta características que tornam o gerenciamento da sua melhoria contínua (MC) mais complexo, devido às características de criatividade e intangibilidade inerentes a este processo. Poucos trabalhos analisam como a melhoria contínua pode auxiliar na sistematização do PDP, uma vez que a discussão a cerca da MC ainda foca os processo de fabricação e a discussão sobre a sistematização do PDP discute apenas a melhoria das atividades pertencentes a este processo. $\mathrm{O}$ objetivo deste trabalho foi identificar as atividades que contribuem para a MC do PDP e avaliar o impacto destas atividades na sua sistematização para o caso de implementação deste processo em uma empresa de autopeças. Incluiu-se no levantamento as atividades pertencentes ao PDP que fomentam melhorias deste processo e aquelas pertencentes ao processo de melhoria contínua (PMC) e que apóiam a melhoria dos demais processos, incluindo o de desenvolvimento de produtos. Foram levantados dados atuais do desempenho da empresa e histórico das mudanças ocorridas para que a identificação destas atividades e dos resultados reais desta sistematização fosse possível. Para análise da efetividade da MC aplicada ao PDP foram selecionados seis projetos de desenvolvimentos de produtos já concluídos, executados em diferentes períodos de tempo, e comparados seus resultados a partir de indicadores de desempenho pré-definidos. Os resultados demonstram a eficácia da sistematização do PDP na empresa, a partir de atividades executadas durante os desenvolvimentos. Como contribuições, o trabalho apresenta um levantamento da literatura sobre a relação entre a MC e o PDP e a caracterização das atividades relacionadas à MC realizadas em um caso prático de sistematização. O trabalho apresenta uma discussão acerca dos resultados obtidos com a sistematização. Foi possível compreender - através da coleta e análise de indicadores de desempenho dos projetos, entrevistas e estudo da sistematização na empresa - como estas atividades interferiram positivamente nos resultados dos projetos, quais foram os benefícios que elas trouxeram e as lacunas que esta sistematização ainda apresenta.

Palavras-chave: Melhoria Contínua. Sistematização. Processo de Desenvolvimento de Produtos. 


\begin{abstract}
AGOSTINETTO, J.S. Systematization of product development process, continuous improvement and performance: a case-study of an automotive company. M.Sc. (Dissertation) - Escola de Engenharia de São Carlos, Universidade de São Paulo, São Carlos, 2006.
\end{abstract}

Product development process (PDP) has received special attention from companies due to it is recognized as a source of competitive profits. Through its systematization companies can reduce their costs and development time and increase their product quality. To get and effective systematization it is necessary to continuously improve the PDP so that it can follow the continuous necessity of develop better products to be launched to the market. When compared with other process the PDP presents special characteristics such as creativity and non-measurable activities that become its continuous improvement (CI) management more complex. The number of researches that discuss how CI can help the PDP systematization is too small once this discussion still focuses production process into companies and the discussion of the PDP systematization only discusses the improvement of activities that belong to PDP. It is not clear to define activities of CI when they are part of PDP subjects. The main goal of this research was to identify which activities can contribute with CI of PDP and to analyze the impact of these activities on its systematization, studying a case of an automotive company. It was included on the case survey all activities that belongs to PDP and can contribute with its CI and also activities that belongs to the CI process and can be applied to PDP as a support of other processes to get their improvement, including the PDP. During the case research it was collected recent data of company performance and history information regarding changes on its PDP model and practices; this research into the company allowed us to identify CI activities on PDP and the results of the implementation of these activities. To analyze the effectiveness of CI activities applied on PDP it was selected six concluded product development projects which were developed on different periods of time and then it was compared their results through some key performance indicators defined previously for the research. Those results demonstrate the effectiveness of the PDP systematization due to CI activities done during the evaluation of the product development projects in that automotive company. This research presents as contributions a survey from the literature about the relation between CI and PDP and the characterization of the activities executed in a practical case of systematization. The research presents a discussion regarding the results obtained by that company with the PDP systematization. It was possible to understand - using project performance indicators, interviews and the study of the PDP systematization - how those activities had positively intervened on projects results, which benefits they brought to the company and which gaps the systematization still keeps.

Key words: Continuous Improvement. Systematization. Product Development Process. 
"Não temer o futuro nem idolatrar o passado. O insucesso é apenas uma oportunidade para começar de novo com mais inteligência. O passado só nos serve para mostrar nossas falhas e fornecer informações para o progresso futuro".

Henry Ford 
"Aos meus pais Mauro e Maria Cacilda, pela constante formação crítica. Ao querido Jucá, meu exemplo de dedicação, sabedoria e humildade, fonte de estímulo para a realização deste trabalho". 


\section{Agradecimentos}

A realização deste trabalho só foi possível com a contribuição de diversas pessoas, as quais quero expressar meus sinceros agradecimentos.

À empresa Delphi, representada por Roberto Stein, que fomentou minhas viagens para realizar esta pesquisa e viabilizou minhas ausências, dando-me subsídios e suporte para conjugar minhas responsabilidades na empresa e minha atividade de pesquisa.

Aos meus supervisores, amigos de empresa e aos entrevistados durante esta pesquisa, que trouxeram informações fundamentais para as conclusões aqui apresentadas.

À Raquel Moyses, minha amiga e meu apoio durante esses anos.

Ao Alex Marson, meu amigo e mentor, minha eterna gratidão por me orientar nas minhas escolhas e nas minhas dúvidas, por ter sido um verdadeiro líder me ajudando a traçar e trilhar meus caminhos, e ter grande parte da "culpa" pelo que sou hoje.

Aos meus amigos Jane, Du, Carol, Ti, Fer e Fran, pela compreensão nas tantas vezes que eu disse "Tenho que estudar".

Aos meus irmãos, Maurício e Mariana, que são minha base, e também à Lívia.

A todos os meus colegas do Numa, em especial à Cris e ao Fernandinho, que facilitaram todos os dias o meu trabalho, e às amizades da República Ambev, que permanecem sólidas.

Registro também meus agradecimentos e admiração aos professores que contribuíram para a minha formação durante estes anos de pesquisa. São eles os professores Dário Alliprandini, Henrique Rozenfeld, Edmundo Escrivão, Fábio Guerrini, Sérgio Silva, Márcia Echeveste e Ana Lúcia Torkomian.

Finalmente, agradeço ao meu orientador Daniel Amaral, grande exemplo, a quem tenho profunda admiração e respeito, por ter permitido que minhas primeiras idéias se transformassem neste trabalho, através da sua paciência, competência e dedicação. 


\section{Lista de Figuras}

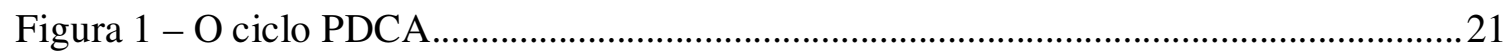

Figura 2 - Fases da estrutura de maturidade em melhoria contínua ........................................28

Figura 3 - O processo de desenvolvimento de produtos …………………….......................... 32

Figura 4 - Diferença entre melhoria de processo e de produto ................................................35

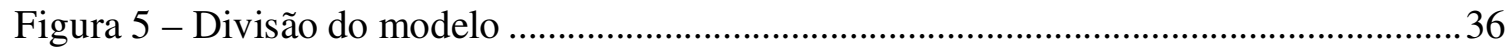

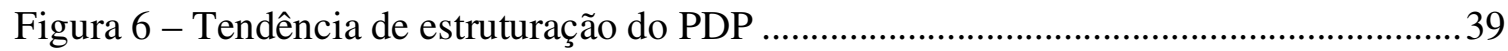

Figura 7 - Fluxo do planejamento da qualidade do produto ....................................................43

Figura 8 - Ciclo AAEM: Aprender, aplicar, ensinar e melhorar ……................................... 44

Figura 9 - Dificuldades encontradas nas atividades de Kaizen ............................................. 47

Figura 10 - Sistemática de Aprovação de Fases para o PDP ….................................................50

Figura 11 - Tipos de projeto de pesquisa de estudo de caso ....................................................56

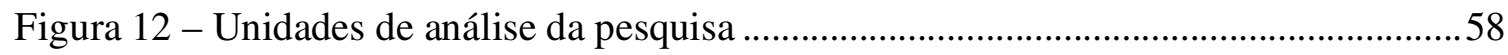

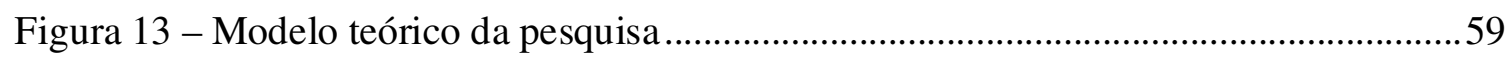

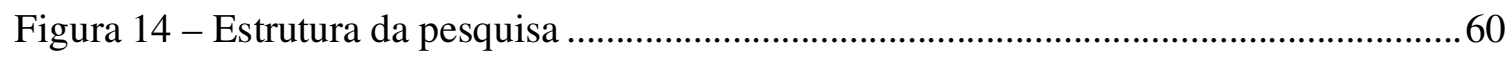

Figura 15 - Auditoria pós-projeto no desenvolvimento de funil …........................................ 70

Figura 16 - Modelo de referência para o PDP na Delphi ......................................................... 77

Figura 17 - Gráfico de controle do portfólio de projetos ativos da unidade ..........................78

Figura 18 - Exemplos de mudanças para a sistematização do PDP na unidade .................... 85 


\section{Lista de Quadros}

Quadro 1 - Habilidades básicas e comportamentos-chave para a MC ..................................30

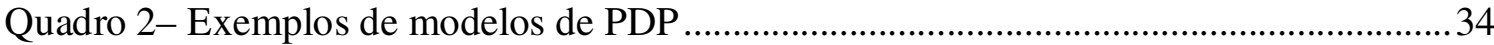

Quadro 3 - MC aplicada ao PDP: diferenças comparadas ao processo de fabricação ..........38

Quadro 4 - Princípios do pensamento enxuto: diferenças entre o PDP e a fabricação .........39

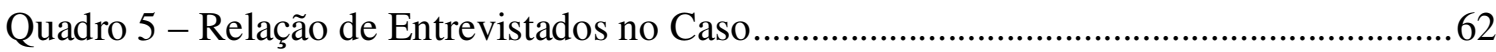

Quadro 6 - Atividades do PDP que contribuem para a MC deste processo...........................67

Quadro 7 - Atividades do PMC que contribuem para a melhoria do PDP ............................ 70

Quadro 8 - Classificação dos Projetos da Empresa de acordo com a Complexidade ...........76

Quadro 9 - Matriz de treinamentos da unidade....................................................................... 87

Quadro 10 - Atividades encontradas nos projetos da linha de produto A..............................8

Quadro 11 - Percentual de atividades encontradas nos projetos da linha de produto A .......89

Quadro 12 - Atividades encontradas nos projetos da linha de produto B ………………......90

Quadro 13 - Percentual de atividades encontradas nos projetos da linha de produto B ......90

Quadro 14 - Atividades encontradas nos projetos da linha de produto C ..............................91

Quadro 15 - Percentual de atividades encontradas nos projetos da linha de produto C ......91

Quadro 16 - Cenário das atividades que contribuem para a MC do PDP do primeiro grupo

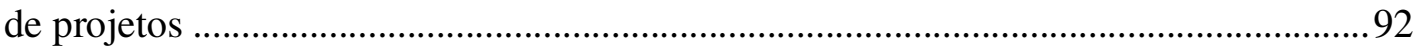

Quadro 17 - Cenário das atividades que contribuem para a MC do PDP do segundo grupo

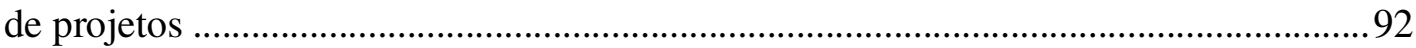

Quadro 18 - Número de atividades por tipo em cada grupo de projetos...............................93

Quadro 19 - Atividades do PDP: Comparativo entre grupos 1 e 2 ….....................................94

Quadro 20 - Atividades do PMC: Comparativo entre grupos 1 e 2 .....................................94 


\section{Lista de Tabelas}

Tabela 1 - Exemplo de detalhamento de atividade do modelo de PDP da empresa..............75

Tabela 2 - Indicadores de desempenho do primeiro grupo de projetos...................................96

Tabela 3 - Indicadores de desempenho do segundo grupo de projetos ..................................97 


\section{Lista de Abreviaturas e Siglas}

$\begin{array}{ll}\text { AAEM } & \begin{array}{l}\text { Modus Operandi - Aprender, Aplicar, Ensinar e Melhorar } \\ \text { APQP }\end{array} \\ \text { 5S } & \begin{array}{l}\text { Manual do Planejamento Avançado da Qualidade do Produto e Plano } \\ \text { Programa de Melhoria Contínua criado pelos Japoneses }\end{array} \\ \text { CIRCA } & \begin{array}{l}\text { Continuous Improvement Research for Competitive Advantage } \\ \text { CMMI }\end{array} \\ \text { Capability Maturity Model Integration } \\ \text { EP } & \text { Desenvolvimento de Produtos } \\ \text { EUA } & \text { Sistema de Gerenciamento do Motor (Engine Management System) } \\ \text { GQT } & \text { Estados Unidos da América } \\ \text { ISO/TS16949 } & \text { Gestão da Qualidade Total } \\ \text { LP } & \text { Especificação Técnica da Gestão da Qualidade das Autopeças } \\ \text { MC } & \text { Linha de Produto } \\ \text { P\&D } & \text { Melhoria Contínua } \\ \text { PDCA } & \text { Pesquisa e Desenvolvimento } \\ \text { PDP } & \text { Ciclo de Planejar, Fazer, Checar e Agir } \\ \text { PDP01 } & \text { Processo de Desenvolvimento de Produtos } \\ \text { PDP01 Source } & \text { Processo de Desenvolvimento de Produtos da Delphi, versão 2001 } \\ \text { Document } & \text { Documento de Consulta sobre Detalhamento das Atividades } \\ \text { PMBoK } & \text { Sugeridas no Modelo de PDP da Empresa } \\ \text { PMC } & \text { Project Management Body of Knowledge } \\ \text { PSO } & \text { Processo de Melhoria Contínua } \\ \text { QS-9000 } & \text { Project Support Office } \\ \text { TQC } & \text { Norma da Gestão da Qualidade das Autopeças } \\ \text { TQM } & \text { Total Quality Control } \\ & \text { Total Quality Management }\end{array}$




\section{Sumário}

RESUMO_............................................................................................................................................... III

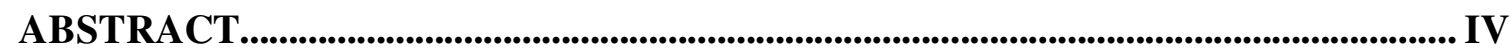

AGRADECIMENTOS …......................................................................................................VII

LISTA DE FIGURAS ...................................................................................................................... VIII

LISTA DE QUADROS ................................................................................................................. IX

LISTA DE TABELAS ....................................................................................................................

LISTA DE ABREVIATURAS E SIGLAS ............................................................................ XI

SUMÁRIO......................................................................................................................................XII

1 INTRODUÇÃO..............................................................................................14

2 MELHORIA CONTÍNUA DO PROCESSO DE DESENVOLVIMENTO DE

PRODUTOS ................................................................................................................................. 18

2.1 DEFINIÇÃO DE MELHORIA CONTÍNUA.................................................................... 18

2.2 EVOLUÇÃO HISTÓRICA DA MELHORIA CONTÍNUA...................................................2

2.2.1 Gerenciamento de Mudanças......................................................................2

2.2.2 Aprendizagem Organizacional ....................................................................24

2.2.3 Modelo de Maturidade em Melhoria Contínua ……………………………......27

2.3 Processo de DesenVolvimento de Produtos ……………………………..........31

2.4 DIFERENÇAS NA APLICAÇÃO DA MC AO PDP E AOS PROCESSOS DE FABRICAÇÃO. 36

2.5 SISTEMATIZAÇÃO DO PDP E MELHORIA CONTÍNUA..................................................4

2.5.1 Mecanismos que podem auxiliar a MC do PDP..........................................4 43

2.5.2 Benchmarking............................................................................................. 44

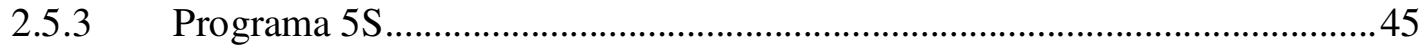

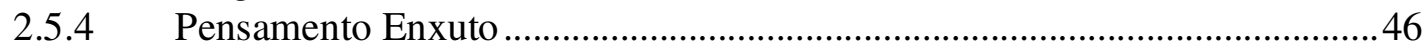

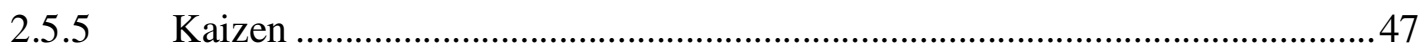

2.5.6 Aprovação de Fases........................................................................................... 48

2.5.7 Inibidores e Facilitadores da MC do PDP .........................................................50

3 METODOLOGIA.......................................................................................................52

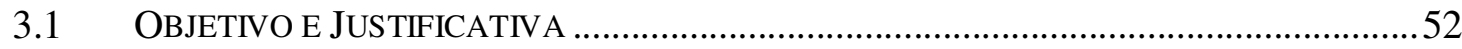

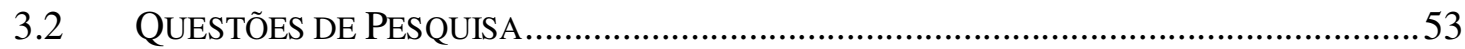

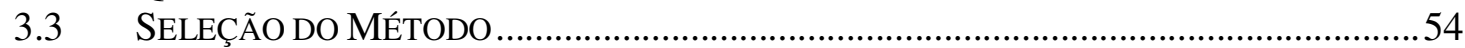

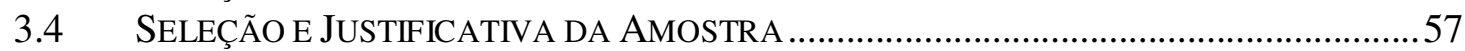

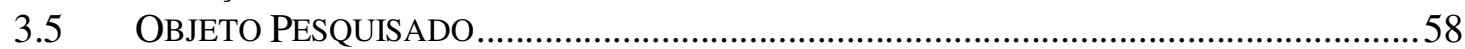

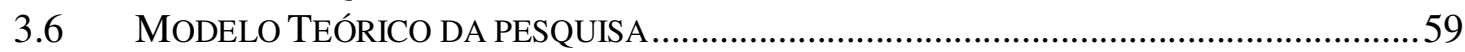

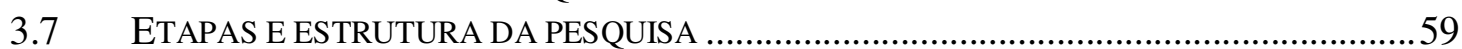

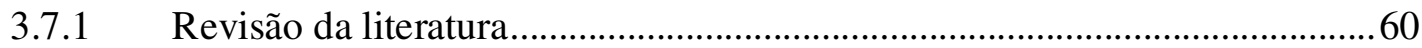

3.7.2 Descrição do modelo de PDP da empresa ........................................................61

3.7.3 Análise do PDP da empresa quanto à aplicação das atividades de MC.........61

3.7.4 Estudo comparativo dos seis projetos de desenvolvimento .............................62 


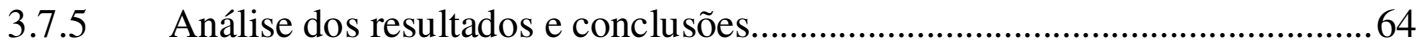

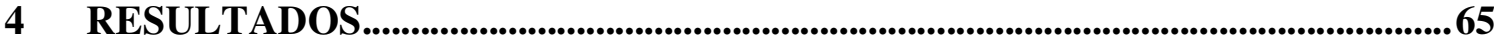

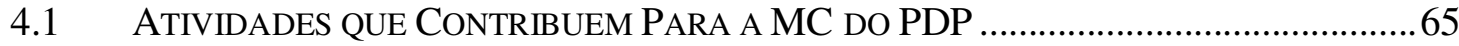

4.2 CARACTERIZAÇÃO DO CASO .............................................................................

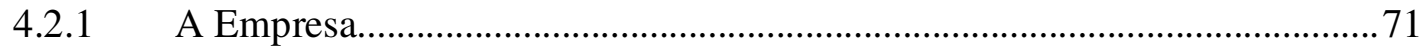

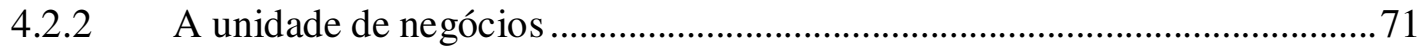

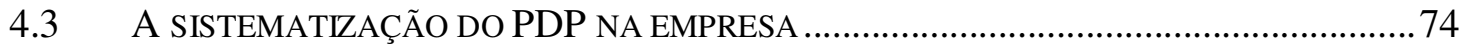

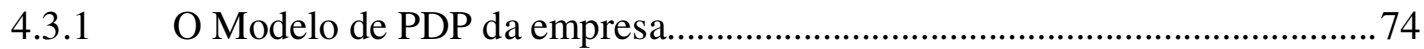

4.3.2 Os Projetos de Desenvolvimentos de Produtos ...................................................77

4.3.3 Histórico da Implementação do Modelo de PDP na Empresa.........................79

4.3.4 Histórico da Implementação do Modelo de PDP na Unidade .........................81

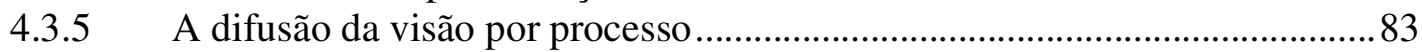

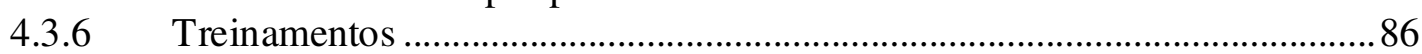

4.4 IDENTIFICAÇÃO DAS ATIVIDADES QUE CONTRIBUEM PARA A MC DO PDP NOS

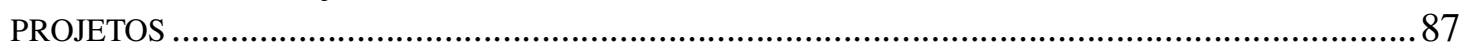

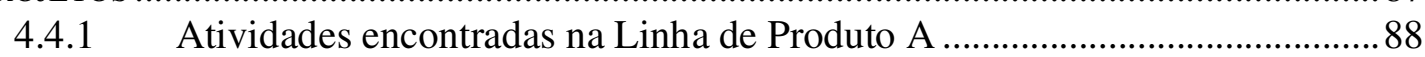

4.4.2 Atividades encontradas na Linha de Produto B ............................................8 89

4.4.3 Atividades encontradas na Linha de Produto C ..............................................91

4.5 SISTEMATIZAÇÃO DO PDP E O DESEMPENHO DOS PROJETOS ...................................96

5 ANÁLISE E CONSIDERAÇÕES FINAIS ......................................................................101

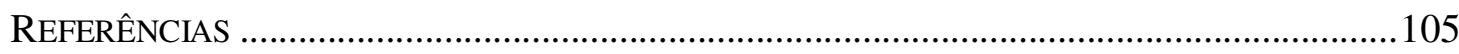

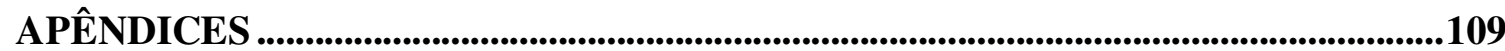

Apêndice A - Roteiro de Entrevistas para Aplicação em Campo .................................109

Apêndice B - Tabela Padrão de Atividades do PDP para Mapeamento dos Projetos 112 Apêndice C - Tabela Padrão de Atividades do PMC para Mapeamento dos Projetos

Apêndice D - Roteiro de Observação para pesquisa em campo.....................................114

Apêndice E - Identificação das atividades de PDP e PMC nos projetos A.1 e A.2 ...115

Apêndice F - Identificação das atividades de PDP e PMC nos projetos B.1 e B.2...117

Apêndice G - Identificação das atividades de PDP e PMC nos projetos C.1 e C.2 ...119 ANEXO 1 - DIAGRAMA DE TARTARUGA UTILIZADO NO MAPEAMENTO DOS PROCESSOS DA UNIDADE ESTUDADA 


\section{Introdução}

A competitividade do atual cenário econômico tem exigido das empresas maior agilidade em processos de negócios que garantam a oferta de produtos ou serviços a preços reduzidos e com qualidade cada vez melhor. Neste contexto, o processo de desenvolvimento de produtos (PDP) nas empresas desponta como comprovada fonte de ganhos competitivos, pois é por meio dele que a empresa pode criar novos produtos em menos tempo para atender à constante evolução do mercado (ROZENFELD et al. 2000). A melhoria deste processo torna-se necessária visto que o que hoje é uma vantagem competitiva, no futuro poderá se tornar um requisito básico do produto ou do próprio processo para que a empresa garanta fatias de mercado, considerando a velocidade das transformações no ambiente atual.

Clark e Wheelwright (1993) afirmam que o PDP deve conjugar eficiência e eficácia para que a empresa ganhe velocidade no desenvolvimento de novos produtos. Para tanto, os autores sugerem a utilização de um modelo para a gestão do PDP que, dentre outros aspectos, destaca a necessidade de melhoria ao longo do tempo das capacidades requeridas nas atividades, pelo desenvolvimento de elementos-chave como: as pessoas e suas habilidades; a estrutura organizacional e seus procedimentos; as estratégicas e as táticas; as ferramentas e os métodos; o próprio processo gerencial.

A eficiência do PDP depende do aprendizado contínuo da equipe e de um aprimoramento constante do processo com base nas experiências adquiridas em cada projeto de novo produto. No entanto, se comparado aos processos tradicionais de fabricação, há aspectos que tornam a melhoria contínua mais complexa e difícil de ser gerenciada no caso de projetos de novos produtos. Um deles é inerente à própria natureza básica da atividade, baseada no ciclo projetar-construir-testar-otimizar. Esta característica faz com que resultados ruins de certas atividades, ou seja, desperdícios, sejam muitas vezes tratados como algo natural, inerente ao processo de desenvolvimento de produtos.

Um erro ocorrido em um desenvolvimento que está sendo executado pela primeira vez deveria ser considerado aprendizado, pois uma vez registrado poderá ser evitado nos próximos desenvolvimentos ou mesmo aproveitado como sugestão para alterar o PDP, trazendo melhoria para o processo. Em contrapartida, quando a falha acontece na última 
etapa do ciclo, ou seja, na nova ação derivada do aprendizado, e o erro é cometido novamente, trata-se de uma ineficiência do processo, ou seja, desperdício.

Embora seja mais complexo identificar o que é desperdício no PDP quando comparado aos processos de fabricação, a situação estável e contínua deste último não traz muitas oportunidades de aprendizado, enquanto que no desenvolvimento de produtos, a característica criativa e inovadora permite que oportunidades de aprendizado apareçam constantemente, fazendo com que a característica não repetitiva das atividades do PDP fomente o aprendizado contínuo. Rozenfeld et al. (2006) afirmam que mesmo com as características de incerteza, baixa previsibilidade e criatividade, é possível e necessário gerenciar o PDP, planejando, executando, controlando, e melhorando as atividades em busca de melhores resultados de desempenho e de aprendizagem.

Como discutido durante este trabalho, a padronização das atividades do PDP (processos, procedimentos, responsabilidades, cadência, treinamentos, etc) facilita a sua melhoria contínua, pois pela padronização estas atividades podem ser executadas repetidas vezes e esta repetibilidade pode facilitar a identificação de oportunidades de melhorias. Desta forma, a padronização não afeta o processo criativo, que é único e não-repetitivo, mas sim a maneira como as atividades acontecem e são armazenadas pela empresa.

A aprendizagem organizacional está diretamente ligada a este processo de melhoria contínua quando a empresa busca, através da utilização de suas lições aprendidas em desenvolvimentos anteriores, melhores níveis de desempenho. Esta aprendizagem organizacional aplica-se ao PDP como em qualquer outro processo da empresa. Diversos autores já discutem a aprendizagem - e a forma de armazenamento do conhecimento adquirido - e serão resumidamente discutidos durantes este trabalho. Para Lynn (1998) o processo de desenvolvimento de produtos visa buscar constantemente atividades de melhoria para se adequar à dinâmica das mudanças do ambiente empresarial, sejam elas de produto ou do próprio processo; além disso, a maneira como as organizações aprendem tem especial importância, pois pode determinar se a organização vai melhorar, quão rápido isso acontecerá, ou se ela está destinada a perder fatias de mercado para competidores que praticam a aprendizagem contínua.

Identificou-se na literatura carência em textos e teorias tratando da sistematização do PDP pela melhoria contínua. Existem trabalhos que discutem esta sistematização, porém 
analisando unicamente atividades pertencentes a este processo. Ainda, a própria identificação do que é melhoria contínua para o PDP não está clara na literatura disponível.

A principal lacuna sobre este assunto está em discutir a melhoria contínua do PDP bem como a sua sistematização - considerando processos de apoio para que esta melhoria aconteça. Este trabalho ocupa-se em discutir principalmente o processo de melhoria contínua (PMC) aplicado ao PDP como suporte a sua efetiva sistematização. Atividades do PMC podem ser aplicadas ao PDP e por elas resultados significativamente melhores podem ser obtidos, como descrito no estudo de caso que esta pesquisa apresenta. Neste contexto, este trabalho também caracteriza estas atividades relacionadas à MC em um caso específico de sistematização do PDP em uma empresa de autopeças, além de analisar os resultados obtidos com esta sistematização.

A categorização das atividades identificadas está dividida em dois grandes grupos de atividades que podem contribuir para a MC do PDP - não claros na literatura disponível -, representados por: a) as atividades pertencentes ao próprio PDP e que fomentam o aprendizado e a identificação de oportunidades de melhoria e; b) as atividades pertencentes ao processo de melhoria contínua (PMC) que apóia os demais processos na empresa (como já consagradas nos processos de fabricação) e para este trabalho são aplicadas ao processo de desenvolvimento de produtos.

O estudo de caso se fez necessário para embasar a discussão teórica acerca do assunto da sistematização do PDP para a obtenção de melhores resultados nos desenvolvimentos. Desta forma, as afirmações acerca da eficácia e dos benefícios da melhoria contínua nos diversos processos de negócios das empresas - para esta pesquisa, no PDP - foram aferidas pelo caso da empresa de autopeças apresentado. Foram utilizados resultados quantitativos de seis projetos de desenvolvimentos de produtos realizados em dois diferentes períodos na empresa. Estes resultados estão representados nos seguintes indicadores de desempenho: orçamento e prazo planejado versus realizado, número de nacionalização de peças em cada desenvolvimento (planejado versus realizado), número de pessoas envolvidas em cada projeto (planejado versus realizado), índice de retorno de peças em campo e número de reclamações formais vindas do cliente.

Como característica do caso, tem-se uma unidade de negócios de uma empresa de autopeças, filial de uma matriz americana, que utiliza hoje um modelo de referência de PDP 
sistematizado e padronizado mundialmente e busca continuamente a melhoria deste processo já implementado em todas as suas unidades. Esta filial teve destaque mundial nos últimos anos pelo aumento da sua autonomia nas atividades de desenvolvimento de produtos, por comprovar eficiência ao liderar as atividades de desenvolvimento.

A metodologia utilizada neste trabalho está fundamentada em uma pesquisa descritivo-exploratória das atividades que contribuem para a MC do PDP disponíveis na literatura, complementada pelo estudo de caso descrito, no qual a coleta dos dados auxiliou na conclusão da pesquisa para as empresas do segmento automotivo, uma vez que verificou a eficácia destas atividades nos resultados dos desenvolvimentos.

Este trabalho está dividido em seis capítulos, incluindo esta introdução que apresenta a pesquisa, contextualiza-a no cenário atual, justifica-a e os objetivos alcançados e o capítulo de referências bibliográficas.

O capítulo dois apresenta a síntese teórica dos principais conceitos utilizados na pesquisa.

O capítulo três trata da metodologia, justificando a escolha do delineamento, da abordagem e do método da pesquisa, com base nos objetivos que foram alcançados.

No capítulo quatro estão descritos os resultados e as contribuições obtidas por esta pesquisa. São também apresentados os passos que a pesquisa seguiu em campo, resumidos por: apresentação do estudo de caso, do histórico da empresa e sua participação no mercado; detalhamento do modelo de referência de PDP utilizado; relação às atividades que contribuem para a melhoria contínua do PDP existentes; apresentação dos indicadores que fundamentaram a pesquisa na identificação dos benefícios da sistematização do PDP pelas atividades de melhoria contínua.

O capítulo cinco traz as conclusões extraídas deste trabalho de pesquisa, bem como as suas considerações finais. 


\section{Melhoria Contínua do Processo de Desenvolvimento}

\section{de Produtos}

\subsection{Definição de melhoria contínua}

O conceito de melhoria contínua (MC) adotado neste trabalho foi extraído de Caffyn e Bessant (1996), que a definem como "um processo, em toda a empresa, focado na inovação incremental e contínua". Por este conceito, os autores sugerem uma abordagem sistemática da melhoria contínua - ou incremental - em todos os níveis da empresa, tendo a sequiência destas atividades como um processo independente que pode permear todos os demais processos da empresa, inclusive o PDP, foco deste trabalho.

A melhoria contínua é vista então, como um processo que atravessa e apóia os demais processos de negócios - e não apenas os processos de fabricação, muito citados na literatura sobre melhoria contínua -, trazendo benefícios pequenos isoladamente e no curto prazo, mas que cumulativamente trazem sensíveis melhorias para as empresas.

O conceito de melhoria aqui proposto acontece continuamente através de passos que podem ser pequenos. Ainda, estas atividades contínuas devem ser parte da cultura da empresa sendo executadas natural e freqüentemente pelos funcionários que buscam melhorar suas práticas rotineiramente, e não um marco de uma transformação.

Caffyn e Grantham (2003) afirmam que em termos de processo, a MC é um esforço contínuo que pode atravessar toda a organização para implementar mudanças, as quais, embora sejam pequenas por elas mesmas, cumulativamente impactam de maneira positiva os objetivos da organização.

A institucionalização das atividades de melhoria contínua em qualquer processo está intimamente ligada à reestruturação destes processos e dos componentes que o integram incluindo as pessoas que o seguem -, na busca pela sua sistematização. Para o PDP, estas mudanças impactam não apenas no processo, mas também no produto que está sendo desenvolvido e no próprio processo de aprendizagem inerente ao PDP. Os resultados da melhoria no processo isoladamente não trazem benefícios para a empresa. É preciso que 
esta melhoria no processo impacte diretamente a qualidade do produto que está sendo desenvolvido, a agilidade com que o desenvolvimento foi executado e o investimento financeiro a ele dedicado.

Para Slack et al. (1997), todas as operações ou processos são passíveis de melhoramentos; os autores afirmam que na MC o mais importante não é o tamanho de cada passo, mas a probabilidade de que a melhoria vai continuar, ou seja, não importa se os melhoramentos sucessivos são pequenos, o que de fato importa é que todo mês (ou semana, ou trimestre, ou qualquer que seja o período) alguma melhoria tenha de fato acontecido.

Embora muitos autores afirmem que a melhoria contínua pode ser aplicada em qualquer processo em uma empresa (CAFFYN, 1997; CAFFYN e GRANTHAM, 2003; RUY, 2002; SILVA, 2004) a teoria sobre MC ainda é principalmente voltada para os processos de fabricação, área que se originou (BERGER, 1997; BESSANT et al., 1993; MESQUITA e ALLIPRANDINI, 2003). Não há claras evidências na literatura de modelos e casos de implementação de MC em processos como o PDP. Alguns autores já discutem modelos de MC que podem ser aplicados ao PDP, como Caffyn (1997). No entanto, estas pesquisas tratam da melhoria contínua como uma mudança "radical" e embora este conceito não esteja explícito em seus trabalhos a maneira como sugerem a condução da implantação da melhoria contínua ao PDP descreve uma transformação grande e pontual nas práticas da empresa, evidenciada através da utilização de líderes dedicados a esta transformação ou dos sugeridos eventos formais para oficializar cada estágio de melhoria alcançado. Contudo, no decorrer desta revisão é apresentado o modelo de referência em melhoria contínua sugerido por estes autores por ser o pioneiro no assunto. Há uma discussão acerca da aplicabilidade deste modelo ao PDP, preservando o escopo desta pesquisa.

Um dos motivos para que a MC seja tão complexa quando aplicada ao PDP pode ser a característica de intangibilidade que distingue o PDP dos processos de fabricação. Além disso, o próprio processo criativo inerente ao PDP entra em discussão quando através da melhoria contínua, sugere-se a padronização deste processo. Há vertentes de que a padronização do PDP pode inibir o processo criativo e que este último é o de maior importância para que resultados obtidos sejam positivos. 
Este trabalho investiga estas questões-chave e discute, dentre outros assuntos, como a melhoria contínua pode ser aplicada ao PDP neste cenário em que mensurar entradas e saídas das atividades e os próprios resultados conclusivos dos desenvolvimentos não é simples quanto dos processos de fabricação, uma vez que os elementos em questão são freqüentemente representados por informações, e não peças ou produtos resultantes de um processo de transformação.

\subsection{Evolução histórica da melhoria contínua}

A discussão sobre as atividades de melhoria contínua (MC) nos diversos processos de negócios das organizações não é recente. Inicialmente demonstrada na experiência japonesa com os eventos kaizen, sob interferência de Edwards Deming, e posteriormente pelas empresas americanas e parte da Europa pelos programas de TQM (Total Quality Management), estas práticas são comumente encontradas nos processos de fabricação das empresas. Estas práticas de melhoria contínua eram no início dos anos 90 requisitos exclusivos das grandes empresas.

Hoje, a realidade demonstrada é de que a sobrevivência de qualquer empresa independentemente do seu porte - está atrelada a melhoria contínua dos seus processos e, para que se mantenham competitivas precisam buscar práticas que garantam esta melhoria em seus processos, especialmente nos processos de fabricação. Bessant et al. (1993); Bessant et al. (1994); Imai (1997); Mesquita e Alliprandini (2003), entre outros discutem a MC neste contexto.

Os primeiros esforços para a implantação da sistemática de melhorias ficaram conhecidos pela difusão do TQC (Total Quality Control), em especial o conceito de ciclo PDCA (planejar, fazer, verificar e agir), central para esta teoria.

As primeiras atividades baseadas no ciclo PDCA foram sugeridas por Walter A. Shewart, na década de 20, e em 1931 foi publicado o primeiro livro sobre este conceito. Shiba; Graham e Walden (1997) e Slack et al. (1997), entre outros autores, fazem referência ao ciclo PDCA ao discutir o conceito de MC. Este ciclo representa um processo sem fim, questionando repetidamente os trabalhos detalhados de um determinado processo. As fases deste ciclo se repetem toda vez que a última delas é alcançada. Desta forma, o 
ciclo PDCA é definido pelos autores como a seqüência de atividades que são percorridas de maneira cíclica para melhorar as práticas das organizações, sejam pertencentes aos processos de fabricação ou aos demais processos de negócios da empresa.

Como demonstra a história, até pouco tempo atrás estes conceitos eram exclusivamente utilizados nos processos de fabricação; hoje as empresas já descobriram que o conceito deste ciclo pode ser utilizado nos diversos processos das empresas, muitas vezes adaptado a cada realidade, fomentando a cultura de busca pela melhoria de cada atividade em toda a empresa.

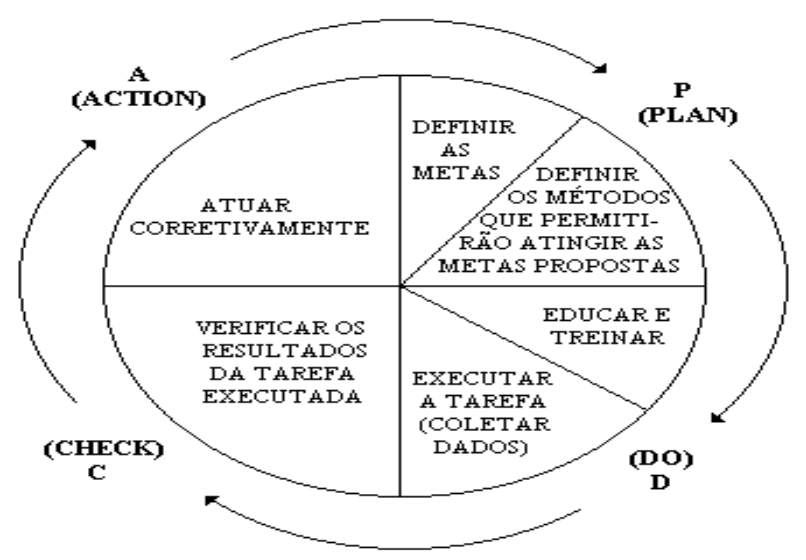

Figura 1 - O ciclo PDCA

Como demonstrado na Figura 1, o ciclo PDCA envolve:

- Plan - Traçar o Plano: é estabelecido de acordo com as diretrizes da empresa; identifica o problema, estabelece os objetivos e as metas, define o método a ser utilizado e analisa risco, custo, prazo e recursos disponíveis;

- Do - Executar o Plano: estabelece treinamentos no método a ser utilizado, estabelece objetivos sobre os itens de controle, coleta dados para verificação do processo e finalmente, educa, treina, motiva e obtém comprometimento das pessoas;

- Check - Verificar os Resultados: verifica se o trabalho está sendo executado de acordo com o padrão definido, se os valores medidos variaram e comparam estes com o padrão e, finalmente, se os itens de controle correspondem com os valores dos objetivos; 
- $\underline{A c t-R e a l i z a r ~ A c ̧ o ̃ e s ~ C o r r e t i v a s: ~ t o m a ~ a c ̧ o ̃ e s ~ p a r a ~ c o r r i g i r ~ t r a b a l h o s ~ q u e ~}$ possam ter desviado do padrão, investiga as causas e toma ações para não repeti-los e melhora o sistema de trabalho e o método.

A fase Plan (Traçar o Plano) do ciclo PDCA demonstra grande similaridade com o processo de desenvolvimento de produtos (PDP) uma vez que as atividades que estão inseridas nesta fase - alinhamento estratégico, definição clara de objetivos e metas, análise antecipada de riscos, prazos, custos e recursos - são semelhantes às atividades requeridas em qualquer desenvolvimento de um novo produto.

Da mesma forma, a fase Act (Realizar Ações Corretivas) está intimamente relacionada ao processo de melhoria contínua (PMC) que apóia os demais processos de negócio, uma vez que tem como propósito corrigir e evitar reincidência de erros nestes processos, buscando melhorar continuamente a eficácia destes.

Pela difusão dos conceitos de melhoria contínua na década de 90 conceitos correlatos passaram a ser também uma preocupação de pesquisadores e empresários, fazendo com que a sistematização da melhoria contínua nos processos de negócios fosse facilitada. Estes conceitos difundidos por consequiência da melhoria contínua especialmente durante a década de 90 - estão representados por: gerenciamento de mudanças, aprendizagem organizacional e modelo de maturidade em melhoria contínua e serão discutidos mais detalhadamente a seguir.

\subsubsection{Gerenciamento de Mudanças}

A evolução dos conceitos de melhoria contínua, junto aos avanços da teoria de planejamento estratégico, fez com que muitos pesquisadores e profissionais unissem estes conceitos, dando origem à teoria de Gerenciamento de Mudanças, difundida pelo termo em inglês Change Management. Embora tenha sido derivada dos conceitos de TQM (Total Quality Management) existe uma diferença fundamental em relação a esta teoria inicial da MC que foi a busca por um processo único, unindo a melhoria incremental com a melhoria radical (breakthrough), com o objetivo de controlar e implementar eficazmente mudanças que trouxessem melhorias aos processos, produtos ou mesmo serviços das empresas, seguindo o planejamento estratégico. Tanto no caso da melhoria incremental quanto da chamada radical, têm-se ciclos alimentados pelo plano estratégico e pelos "gatilhos" (change triggers), ou seja, eventos que iniciam um processo de mudança. 
A gestão de mudança tem sido extremamente utilizada nos processos de fabricação e de desenvolvimento de produtos nas empresas. Esta gestão facilitou o cadenciamento das atividades e das responsabilidades toda vez que uma nova mudança se faz necessária. Algumas empresas já utilizam times multifuncionais já pré-definidos e até sistemas de informação para gerenciar todo o processo de implementação de uma mudança, desde a identificação da sua necessidade. Ainda, é comum encontrar procedimentos padronizados para estas implementações, uma vez que esta padronização traz mais agilidade para o processo.

Pelo conceito difundido, a gestão de mudanças é um processo contínuo de alinhamento de uma organização com o seu mercado, tornando-a mais ágil e eficiente que suas competidoras a partir da identificação de mudanças - pequenas ou não - que podem trazer melhorias aos processos ou aos produtos (BERGER e SIKORA ${ }^{1}, 1994$ apud RENTES, 2000).

Rentes (2000) sugere que "a gestão de mudanças é um processo contínuo, ou seja, após a implementação de um ciclo deve-se seguir um novo ciclo de mudança. Portanto elas são técnicas circulares, onde a definição de novos objetivos e metas e a proposição de novos processos são sempre reinicializadas ao final de cada implementação ou sempre que se julgar necessário. Elas pressupõem um constante retorno ao processo de planejamento inicial”.(p.51)

Nota-se grande semelhança nos objetivos do processo de gestão de mudanças e nos processo de melhoria contínua, uma vez que ambos buscam constantemente formas diferenciadas para melhorar algo que foi implementado. Por esta razão optou-se por descrever esta teoria neste trabalho.

Maiores informações podem ser encontradas em Rentes (2000) que faz uma compilação das abordagens de Change Management, descrevendo ainda as principais dificuldades existentes na implantação de iniciativas de melhorias nos processos incluindo o processo de desenvolvimento de produtos - e as principais ferramentas que

\footnotetext{
${ }^{1}$ BERGER, L.A.; SHIKORA, M.J. (1994). The change management handbook: a road map to corporate transformation. New York: McGraw-Hill. Apud RENTES, A.F. (2000). TransMeth: proposta de uma metodologia para condução de processos de transformação de empresas. 1v. Tese (Livre-docência) - Escola de Engenharia de São Carlos, Universidade de São Paulo, São Carlos, 2000.
} 
podem facilitar a gestão de mudanças nas empresas, sejam elas mudanças incrementais (escopo deste trabalho) ou "radicais".

\subsubsection{Aprendizagem Organizacional}

Outra evolução natural da teoria de $\mathrm{MC}$ foi a teoria de aprendizagem organizacional. A novidade introduzida por estes teóricos está na ênfase ao conceito de aprendizagem e a maneira como ela é conduzida dentro das empresas. A teoria inicial focava principalmente os métodos e técnicas para auxiliar a equipe na identificação dos problemas e escolha das soluções, mas não se preocupava com o registro e o compartilhamento do aprendizado e conhecimento gerados em cada ciclo de melhoria.

Garvin (1993) foi um dos autores da área de qualidade pioneiros na identificação desta necessidade. Ele "cunhou" o termo empresa de aprendizagem (learning organization) para diferenciar as empresas que transformavam as melhorias em aprendizados daquelas que simplesmente mantinham-se realizando mudanças pontuais que não elevavam a competência dos funcionários. Para este autor, a aprendizagem organizacional é a capacidade que habilita uma organização a adquirir e integrar novos processos e novas funções de maneira contínua para elevar o conhecimento e melhorar o processo de tomada de decisão.

Esta definição não era muito operacional, no sentido de entender como implementar estes conceitos, mas na mesma época, metade dos anos 90, surgiu a quinta disciplina, a teoria de Senge (1999), um dos primeiros autores a sistematizar princípios para o processo de aprendizagem organizacional.

Portanto, pode-se considerar que a aprendizagem organizacional é uma evolução da melhoria contínua, cuja inovação foi a adição da preocupação com o processo de aprendizado e a geração do conhecimento.

Também nesta época surge o livro clássico de Nonaka e Takeuchi (1997) que formou as bases da teoria da Gestão do Conhecimento. Esta teoria introduziu novas técnicas e ferramentas para a gestão do conhecimento gerado, o "combustível” para a MC.

Hoje já existem diversas empresas que assimilaram esta necessidade e estão implementando maneiras formais de captura e compartilhamento do aprendizado adquirido em determinada atividade, através de reuniões e até sistemas de informação compartilhados. 
É interessante notar que uma parte expressiva dos exemplos utilizados nos clássicos de Davenport e Prusak (1998); Garvin (1993); Nonaka e Takeuchi (1997); Ruy e Alliprandini (2005) e Senge (1999), está ligada ao desenvolvimento de novos produtos. Por ser o PDP um processo com características de criação e inovação, pode-se se dizer que ele é grande fonte de aprendizado uma vez que, diferentemente dos processos de fabricação, as atividades não são repetitivas, o que permite maior possibilidade de aprendizado. Uma vez aprendido, é preciso gerir o conhecimento adquirido capturando-o e compartilhando-o dentro da organização de maneira sistêmica. Este é atualmente um dos grandes desafios das organizações.

A partir dos trabalhos de CLARK e WHEELWRIGHT, 1993, SNYDER e DUARTE, 1997 e THOMKE e FUJIMOTO, 2000, Ruy e Alliprandini (2005) descrevem um método sistemático para a aprendizagem organizacional aplicada ao processo de desenvolvimento de produtos, representado pelas seguintes etapas:

- Adquirir, filtrar, interpretar e analisar informações sobre eventos críticos;

- Disseminar e compartilhar os resultados analisados;

- Utilizar os resultados para corrigir erros e para mudar a maneira como o desenvolvimento de produtos é executado e;

- Arquivar as informações e gerar conhecimento para a empresa.

As empresas com maior visão estratégica já notaram a necessidade de registrar o que foi aprendido, bem como as melhores práticas de atividades para posterior reutilização, na busca por ganhos competitivos pela maximização da utilização de recursos e esforços e no tempo desprendido para a realização da mesma.

O processo de melhoria contínua de uma organização está diretamente associado à sua capacidade de aprender. Com isso, a habilidade de uma empresa em manter um processo de melhoria contínua sustentada do seu PDP depende da criação de competências específicas deste processo. As organizações que já notaram tal dependência apresentam habilidades como: solução de problemas por métodos sistemáticos, experimentação de novas abordagens, aprendizado com a própria experiência, aprendizado com as melhores práticas alheias e transferência de conhecimentos rápida e eficiente em toda a organização.

No entanto, é importante destacar que nenhuma empresa com estas características se constrói da noite para o dia. O sucesso depende de atitudes contínuas em toda a 
organização, continuamente fomentadas pela alta gerência, de comprometimentos e de processos gerenciais que acumulem resultados claros, gradualmente e com firmeza.

Nonaka e Takeuchi (1997) definiram as empresas criadoras de conhecimento como lugares onde a invenção de novos conhecimentos não é atividade especializada, mas uma forma de comportamento; na verdade, um modo de ser, em que todos são trabalhadores do conhecimento. Desta forma, para que as empresas transformem-se em empresas criadoras de conhecimento é preciso que haja esforços partindo de todos os seus níveis hierárquicos para que a cultura e a forma de pensar e agir das pessoas mude progressivamente.

Não somente a aprendizagem individual, na qual os indivíduos aprendem pela prática ou através de novos conhecimentos, mas também a aprendizagem organizacional. Significa dizer que a organização deve capturar o conhecimento e a aprendizagem dos indivíduos e grupos que a compõem, institucionalizá-los (na forma de sistemas, estruturas, procedimentos, rotinas ou ainda, estratégias) e torná-los disponíveis em uma base ampla, rápida e regular (CROSSAN et al., 1999).

Alliprandini e Ruy (2002) abordam duas questões relativas à aprendizagem organizacional no contexto do PDP. A primeira delas é a compreensão de como uma organização pode aprender a partir de sua experiência concreta em projetos de desenvolvimento individuais, por meio da análise do desempenho do processo e da equipe responsável por sua condução. A segunda questão diz respeito aos métodos durante um projeto específico ou após o seu final (pós-projeto) que podem ser utilizados para facilitar a aprendizagem organizacional. Estes métodos destacam-se por:

- Aprendizagem pós-projeto: uma equipe é definida para analisar e documentar eventos críticos do processo, propondo melhorias. As ações geradas desta atividade são encaminhadas a um departamento que tem por função prover programas de treinamentos e demais tipos de intervenções que se fizerem necessárias (CLARK e WHEELWRIGHT, 1993; SNYDER e DUARTE², 1997 apud ALLIPRANDINI E RUY, 2002)

\footnotetext{
${ }^{2}$ SNYDER, N.; DUARTE, D. (1997). From experience: facilitating global organizational learning in product development at whirpool corporation. Journal of Product Innovation Management, Geneva, v.14, p.48-55. Apud ALLIPRANDINI, D.H.; RUY, M. (2002). Aprendizagem organizacional no processo de desenvolvimento de produtos: estudo de caso em três empresas brasileiras. In: SIMPÓSIO DE GESTÃO DE INOVAÇÃO TECNOLÓGICA, 22., 2002, Salvador. Anais... São Paulo : PGT/USP. 1 CD-Rom
} 
- Sistemática de Stage-Gates: uma forma de estruturar o processo de desenvolvimento de produtos (PDP) na qual grupos se reúnem para, dentre outros assuntos, identificarem as lições aprendidas sobre cada atividade de determinada etapa do desenvolvimento.

- Resolução antecipada de problemas: esta estratégia busca melhorar o desempenho do PDP através da mudança da identificação e resolução de um conjunto de problemas de um dado projeto para as suas fases mais iniciais. Ainda, ela tem o potencial de mover a aprendizagem organizacional e desempenho do processo de desenvolvimento para além dos níveis correntes e, concomitantemente, reduzir os custos e tempos gastos. (THOMKE e FUJIMOTO³ ${ }^{3}, 2000$ apud ALLIPRANDINI e RUY, 2002)

Como conclusão do trabalho, os autores destacaram que a aprendizagem organizacional é um elemento importante na estruturação da gestão do PDP, por permitir a inserção desse processo em um ambiente de melhoria contínua sustentada, tornando a empresa mais competitiva.

\subsubsection{Modelo de Maturidade em Melhoria Contínua}

O modelo de maturidade representa o terceiro conceito difundido na evolução da melhoria contínua nos anos 90, identificado na literatura. Os dois conceitos já citados gerenciamento de mudanças e aprendizagem organizacional - estão mais difundidos na literatura; no entanto, o modelo de maturidade aqui apresentado é referência de grande valia para empresas que querem avaliar e aumentar o nível de maturidade em melhoria contínua em seus processos seja através da mudança de comportamento, da forma de pensar ou da maneira como cada atividade é realizada. Preservando o escopo deste trabalho, o modelo é apresentado considerando o processo de desenvolvimento de produtos.

A definição de modelo de maturidade adotada neste trabalho foi extraída do CAPABILITY MATURITY MODEL INTEGRATION-CMMI (2005) que é definida por

\footnotetext{
${ }^{3}$ THOMKE, S.; FUJIMOTO, T. (2000). The effect of "front-loading"problemsolving on product development performance. Journal of product Innovation Management, Geneva, v.17, p.128-142. Apud ALLIPRANDINI, D.H.; RUY, M. (2002). Aprendizagem organizacional no processo de desenvolvimento de produtos: estudo de caso em três empresas brasileiras. In: SIMPÓSIO DE GESTÃO DE INOVAÇÃO TECNOLÓGICA, 22., 2002, Salvador. Anais... São Paulo : PGT/USP. 1 CD-Rom
} 
"uma coleção estruturada de elementos que descrevem características de um processo efetivo".

O grupo de estudos sobre CIRCA (Continuous Improvement Research for Competitive Advantage) da Universidade de Brighton na Inglaterra, em conjunto com mais de 70 empresas de diferentes segmentos, propôs e aplicou com sucesso um modelo de maturidade em MC (BESSANT e CAFFYN, 1997; CAFFYN e BESSANT, 1995). Por meio de um trabalho de mais de cinco anos, estes pesquisadores buscaram compreender as dificuldades que circundam a implantação e manutenção da melhoria contínua nas empresas em diversos segmentos; por esta atividade de observação e integração com as empresas participantes da pesquisa, foram definidos níveis de maturidade em MC (Figura 2) e habilidades e comportamentos essenciais requeridos para que a melhoria contínua de aconteça (Quadro 1).

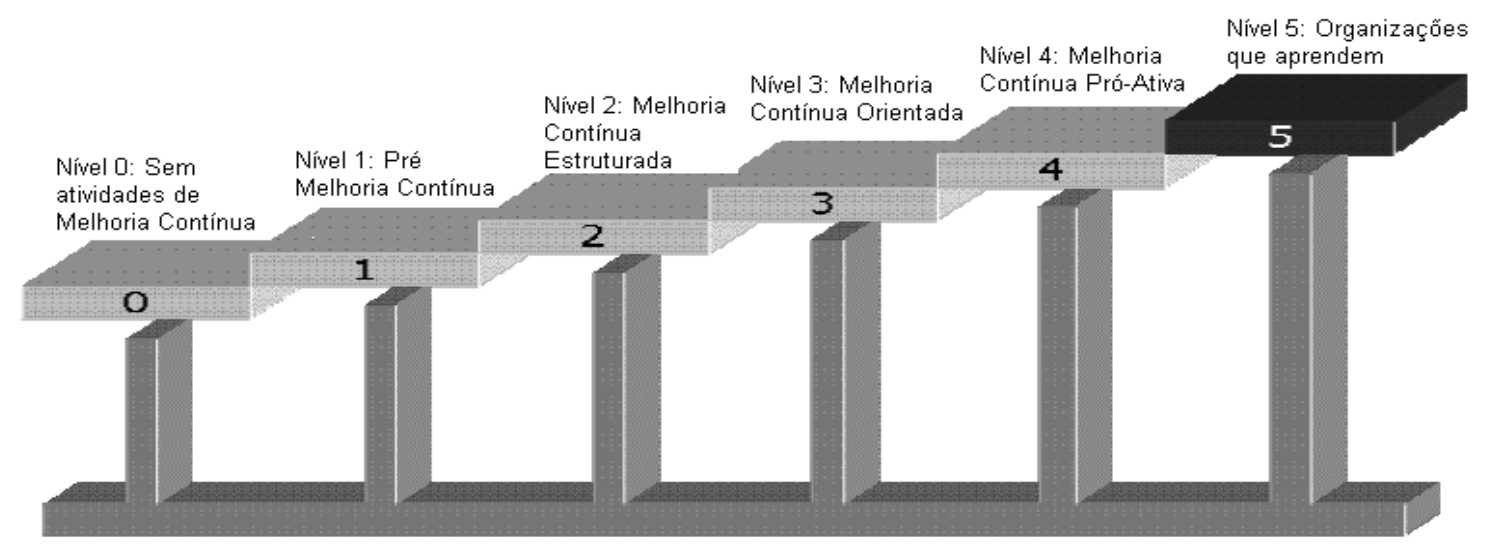

Figura 2 - Fases da estrutura de maturidade em melhoria contínua

Fonte - Bessant e Caffyn ${ }^{4}$ (2000) apud Gonzalez (2004)

O modelo de maturidade descrito na Figura 2 define cada uma das fases da estrutura de maturidade em MC, a serem considerados como seguem (Bessant et al. ${ }^{5}$, 2001 apud Mesquita e Alliprandini, 2003):

\footnotetext{
${ }^{4}$ BESSANT, J.; CAFFYN, S. (2000). Developing strategic continuous improvement capability behavior. Technovation, Amsterdam. Apud GONZALEZ, L.V.D. (2004). Gestão da melhoria contínua aplicada ao modelo de gerenciamento de contratos de prestação de serviços industriais. In: SIMPEP, 2004, Bauru. Anais... [S.1.:s.n.]

${ }^{5}$ BESSANT, J. et al. (2001). A evolutionary model of continuous improvement behaviour. Brighton: Technovation. Apud MESQUITA, M.; ALLIPRANDINI, D.H. (2003). Competências essenciais para melhoria contínua da produção: estudo de caso em empresas da indústria de autopeças. Gestão \& Produção, São Carlos, v.10, n.1, p.17-33.
} 
- Nível 0 - a organização não apresenta atividades de melhoria contínua.

- Nível 1 - a organização não tem nenhuma das habilidades essenciais e nenhum dos comportamentos-chave está presente, mas pode ter alguma atividade de melhoria através de fatos isolados, como a solução de problemas que ocorre ao acaso.

- Nível 2 - há mecanismos capacitadores alocados e evidência de que alguns aspectos dos comportamentos-chave estão começando a serem desempenhados conscientemente. Características comuns são: solução sistemática do problema, treinamento no uso de ferramentas simples de MC e introdução de veículos apropriados para estimular o envolvimento.

- Nível 3 - a organização está segura de suas habilidades e os comportamentos que as suporta tornam-se norma. A solução de problema é direcionada para ajudar a empresa a atingir suas metas e objetivos, havendo monitoramento e sistemas de medição eficientes.

- Nível 4 - a MC é amplamente autodirigida, com indivíduos e grupos fomentando atividades a qualquer momento que uma oportunidade aparece.

- Nível 5 - a organização tem todo o conjunto de habilidades e todos os comportamentos que as reforçam tornam-se rotinas engrenadas. Muitas características atribuídas à "organização de aprendizado" estão presentes.

Nota-se que as empresas mudam ao longo dos níveis sugeridos pelo modelo de maturidade, melhorando suas habilidades e comportamentos para a melhoria contínua. Quando aplicado ao PDP, significa dizer que aumentando os níveis de maturidade em MC ampliam-se as possibilidades de redução de custos e tempo de desenvolvimento, uma vez que a preocupação em identificar oportunidades de melhoria neste processo da empresa será uma constante no trabalho de toda a equipe multidisciplinar, pois quanto maior é o nível de maturidade mais incorporada está a cultura de melhoria contínua às práticas das equipes.

Uma vez definidas as habilidades básicas e os comportamentos-chave para a MC representados no Quadro 1, o grupo de pesquisadores da Universidade de Brighton constatou que nem todas as empresas que dizem praticar atividades de melhoria contínua 
têm sua gestão voltada ao desenvolvimento das competências dos funcionários, fator indispensável para a efetivação destas atividades.

É fato já aceito na literatura que para que as empresas tenham sucesso na incorporação da cultura da melhoria contínua aos seus processos é preciso que este desejo esteja representado pelas estratégias da empresa.

Todos os níveis hierárquicos devem estar envolvidos e comprometidos para que a $\mathrm{MC}$ aconteça, em qualquer que seja o processo.

\begin{tabular}{|c|c|c|}
\hline \multicolumn{3}{|c|}{ Habilidades básicas e normas comportamentais } \\
\hline & Habilidades básicas & Normas Comportamentais \\
\hline A & $\begin{array}{l}\text { Ligar as atividades de MC em todos os } \\
\text { níveis de estratégia da empresa }\end{array}$ & $\begin{array}{l}\text { 1. Indivíduos e grupos usam metas e objetivos estratégicos da } \\
\text { organização para focar e priorizar suas atividades de melhoria }\end{array}$ \\
\hline \multirow[b]{2}{*}{$\mathrm{B}$} & \multirow{2}{*}{$\begin{array}{c}\text { Gerenciar estrategicamente o } \\
\text { desenvolvimento do sistema de MC nas } \\
\text { estruturas da organização }\end{array}$} & 2. Sistema de MC é constantemente monitorado e desenvolvido \\
\hline & & $\begin{array}{l}\text { 3. A avalização progressiva assegura que a estrutura e a infra-estrutura } \\
\text { da organização, bem como o sistema de MC, consistentemente, } \\
\text { reforcem e apóiem um ao outro }\end{array}$ \\
\hline \multirow[t]{2}{*}{$\mathrm{C}$} & \multirow{2}{*}{$\begin{array}{l}\text { Gerar envolvimento sustentado em } \\
\text { inovação incremental }\end{array}$} & $\begin{array}{l}\text { 4. Gerentes de todos os níveis mostram compromisso ativo e liderança } \\
\text { em relação à MC }\end{array}$ \\
\hline & & 5. Participação pró-ativa em melhoria incremental \\
\hline $\mathrm{D}$ & $\begin{array}{l}\text { Trabalhar efetivamente por meio das } \\
\text { divisões internas e externas }\end{array}$ & $\begin{array}{l}\text { 6. Trabalho efetivo de indivíduos e grupos por todos os níveis das } \\
\text { divisões internas e externas }\end{array}$ \\
\hline \multirow{2}{*}{$E$} & \multirow{2}{*}{$\begin{array}{c}\text { Garantir que a aprendizagem ocorra e } \\
\text { seja capturada e compartilhada em todos } \\
\text { os níveis }\end{array}$} & $\begin{array}{l}\text { 7. Aprendizagem por intermédio de experiências próprias e de outros, } \\
\text { tanto positivas como negativas }\end{array}$ \\
\hline & & $\begin{array}{l}\text { 8. A organização articula e desdobra a aprendizagem de indivíduos e } \\
\text { grupos }\end{array}$ \\
\hline $\mathrm{F}$ & $\begin{array}{l}\text { Articular, demonstrar e comunicar os } \\
\text { valores da MC }\end{array}$ & 9. As pessoas "vivem" os valores da MC \\
\hline
\end{tabular}

Quadro 1 - Habilidades básicas e comportamentos-chave para a MC

Fonte: Caffyn e Bessant (1996)

Desta foram, para o sucesso da implementação deste modelo de maturidade em MC nas organizações os pesquisadores do CIRCA descrevem alguns elementos necessários, agrupados em cinco áreas, a saber: estratégia, cultura, infra-estrutura, modelo do processo que sofrerá as interferências e ferramentas. É preciso que a organização tenha um claro plano estratégico, com objetivos e marcos relacionados e que estes sejam eficientemente divulgados e compreendidos em todos os níveis da organização.

O sucesso depende de um gerenciamento estratégico que planeje, monitore e interfira quando necessário, para que a melhoria contínua aconteça. Os pesquisadores afirmam ainda que a cultura, os valores e os comportamentos devem funcionar como suporte às atividades de $\mathrm{MC}$ e acreditam que com o aumento da maturidade, a prática da melhoria contínua parte das rotinas de trabalho dentro das empresas. 
Embora o modelo não seja específico para o processo de desenvolvimento de produtos, alguns pesquisadores do grupo CIRCA estenderam a pesquisa a este processo, publicando artigos que validam o modelo também ao PDP. Destacam-se: Caffyn, 1997; Caffyn, 1998 e Caffyn e Grantham, 2003. Pesquisas especificamente direcionadas ao ramo automotivo não foram encontradas. Vale destacar que estes autores não fazem distinção entre melhoria incremental e melhoria radical no modelo de melhoria contínua proposto, de maneira que a melhoria contínua inclui estas duas formas de melhoria que pode acontecer dentro de uma organização - e para o caso deste trabalho - dentro de uma empresa de autopeças.

\subsection{Processo de Desenvolvimento de Produtos}

$\mathrm{O}$ processo de desenvolvimento de produtos (PDP) deixou de ser um processo composto por atividades isoladas e sob a responsabilidade de áreas funcionais como marketing, fabricação, processo e produto (COOPER, 1993). Wheelwright e Clark (1992) descrevem o PDP como um processo de negócios que une itens comerciais, técnicos e gerenciais. Para eles, o desenvolvimento de produtos é visto como um guia no qual habilidades, competências, processos e procedimentos estão focados e unidos de modo a transformar um conceito (produto ou processo) em um produto comercializável, com a entrega do produto ou serviço eficiente. Os autores ainda afirmam que velocidade, eficiência e qualidade são os imperativos para a competitividade do desenvolvimento de novos produtos.

Clausing (1994) discute o desenvolvimento de produtos como uma abordagem que inclui as necessidades do cliente, a seleção do conceito, a robustez funcional do produto, a integração deste com todo o sistema, as características de re-uso do produto, a facilidade de produção, a mantenabilidade, a prevenção de problemas, o trabalho em equipe, o gerenciamento eficiente e a coerência estratégica. Todos estes elementos devem estar alinhados para atingir o sucesso corporativo em todo o ciclo de vida do produto, e não apenas no seu desenvolvimento.

Neste trabalho adotaremos a definição de PDP proposta por Rozenfeld et al. (2006), no qual um processo é um conjunto de atividades realizadas em uma seqüência lógica com 
o objetivo de produzir um bem ou serviço que tem valor para um grupo específico de clientes. Assim, os autores afirmam que "o processo de desenvolvimento de produtos consiste em um conjunto de atividades por meio das quais busca-se, a partir das necessidades do mercado e das possibilidades e restrições tecnológicas, e considerando as estratégicas competitivas e de produto da empresa, chegar às especificações de projeto de um produto e de seu processo de produção, para que a manufatura seja capaz de produzi1o".

O PDP inclui diversas áreas funcionais da empresa e as atividades necessárias para este projeto demandam grande interação entre estas áreas funcionais.

O PDP está divido em etapas, que podem ser representadas basicamente por: criação e seleção de idéias, projeto, preparação da manufatura, lançamento e retirada do produto do mercado; as atividades inerentes a estas etapas demandam recursos e tempo para serem executadas e transformam dados de entradas em saídas (ex. requisitos do cliente em produto final). A Figura 3 representa este processo.

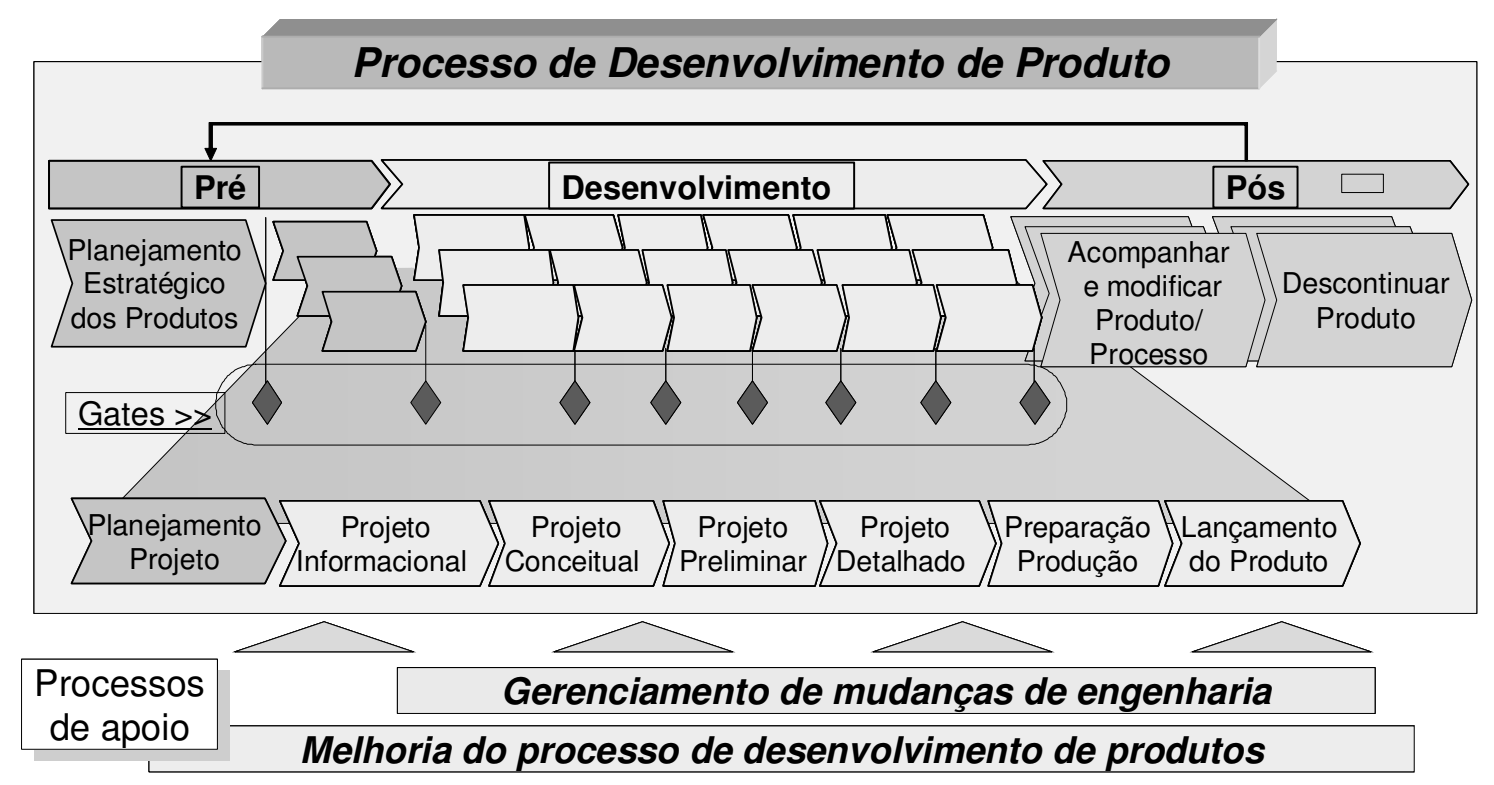

Figura 3 - O processo de desenvolvimento de produtos

Fonte - Rozenfeld et al., 2006

O processo de desenvolvimento de produtos apresentado na Figura 3 aponta o processo de desenvolvimento de produtos envolvendo também as atividades de 
acompanhamento do produto após o seu lançamento no mercado, para que a necessidade de eventuais mudanças nas especificações do produto lançado sejam identificadas e implementadas e para que a descontinuidade do produto também seja uma preocupação da equipe de desenvolvimento do mesmo. Esta vertente é inovadora uma vez que a maioria dos pesquisadores desta área, Clark e Fujimoto, 1991; Wheelwright e Clark, 1992; Toledo, 2002, sugerem que o processo de desenvolvimento de produtos termina com o lançamento do produto ao mercado.

Especialmente para o caso das autopeças, escopo deste trabalho, a necessidade de adoção de modelos de referência justifica-se pela necessidade de atendimento aos requisitos cada vez mais agressivos das montadoras, pela necessidade de maior integração entre as áreas e as atividades para obter vantagens de desempenho e está associada a uma maior valorização desse processo pelas empresas e à difusão da QS-9000 (Norma da gestão da qualidade das autopeças), que exige das empresas um modelo mínimo para desenvolvimento de produtos (TOLEDO et al., 2001). A QS-9000 é, portanto, uma forma de proteção ao cliente, pois assegura que o produto que será ofertado ao mercado automotivo está dentro dos padrões mínimos de qualidade por ele esperado. Vale destacar que nos últimos anos a norma QS-9000 foi reestruturada e alguns requisitos foram adicionados para atender a mais requisitos das montadoras e este novo formato está representado pela especificação técnica ISO-TS16949. As certificações de qualidade requeridas aos fornecedores das grandes montadoras já incluem esta especificação.

O Quadro 2 traz exemplos de modelos de fases do PDP disponíveis na literatura. O próprio modelo de referência descrito no estudo de caso demonstra algumas faltas neste sentido, e é discutido durante o seu detalhamento, no capítulo de resultados. Exemplo desta falta nos modelos apresentados é a descontinuação do produto após o final da sua vida útil; esta etapa já foi incluída no modelo sugerido por Rozenfeld et al., 2006, que será discutido no decorrer deste trabalho. 


\begin{tabular}{|c|c|c|c|c|}
\hline Dickson, 1997 & Pahl \& Beitz, 1996 & Crawford, 2000 & Kotler, 1998 & Kaminski, 2000 \\
\hline Geração de idéias & $\begin{array}{l}\text { Especificação do } \\
\text { projeto }\end{array}$ & $\begin{array}{c}\text { Identificação e } \\
\text { seleção de } \\
\text { oportunidades }\end{array}$ & Geração de idéias & $\begin{array}{l}\text { Especificação técnica } \\
\text { das necessidades }\end{array}$ \\
\hline $\begin{array}{c}\begin{array}{c}\text { Desenvolvimento e } \\
\text { conceito }\end{array} \\
\end{array}$ & Projeto conceitual & Geração de conceito & Triagem de idéias & Estudo de viabilidade \\
\hline $\begin{array}{c}\text { Plano de } \\
\text { desenvolvimento } \\
\end{array}$ & Projeto preliminar & \begin{tabular}{|c|} 
Avaliação de conceito \\
/ projeto
\end{tabular} & $\begin{array}{c}\text { Desenvolvimento e } \\
\text { teste de conceito }\end{array}$ & Projeto básico \\
\hline $\begin{array}{c}\text { Desenvolvimento e } \\
\text { teste }\end{array}$ & Projeto detalhado & $\begin{array}{l}\text { Desenvolvimento } \\
\text { técnico }\end{array}$ & $\begin{array}{c}\text { Desenvolvimento e } \\
\text { estratégia de } \\
\text { marketing }\end{array}$ & Projeto executivo \\
\hline \multirow[t]{4}{*}{ Lançamento } & & Lançamento & Análise comercial & $\begin{array}{c}\text { Planejamento da } \\
\text { produção }\end{array}$ \\
\hline & & & $\begin{array}{l}\text { Desenvolvimento do } \\
\text { produto }\end{array}$ & Execução \\
\hline & & & Testes de mercado & \\
\hline & & & Comercialização & \\
\hline
\end{tabular}

Quadro 2- Exemplos de modelos de PDP

Fonte - Buss (2002)

Poucos autores, porém, incluem formalmente nos modelos a melhoria contínua ou investigam "pontos de retorno", isto é, momentos e atividades específicas para transformar o aprendizado obtido com os projetos de desenvolvimento de produtos em sugestões de melhorias para o processo e para sua efetiva implantação.

O trabalho de Rozenfeld et al. (2006) apresenta-se como pioneiro na representação da melhoria contínua como um processo de apoio ao processo de desenvolvimento de produtos, como representado na Figura 3. Os autores identificam as diferenças entre a melhoria do processo - foco deste trabalho - e a melhoria do produto, a que se referem como "mudança" de produto e enfatizam que ambas podem ocorrer durante o desenvolvimento de um novo produto. Inclusive, classificam a melhoria contínua como um dos processos de apoio ao PDP. Portanto, estes autores propõem que tanto o PDP como a Melhoria Contínua e o Gerenciamento de Mudanças sejam sistematizados de maneira complementar dentro das empresas. A Figura 4 representa esta diferenciação em detalhe. 


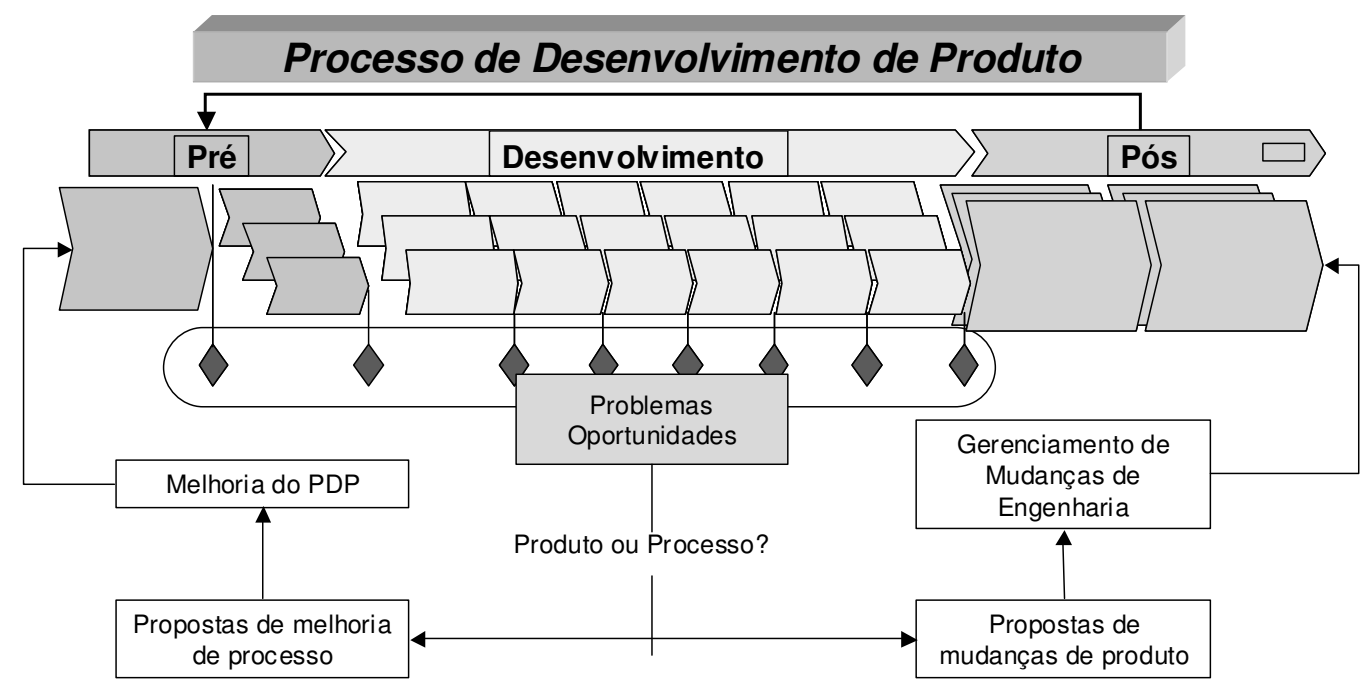

Figura 4 - Diferença entre melhoria de processo e de produto

Fonte - Rozenfeld et al. (2006)

O modelo referenciado nesta revisão é composto por três partes distintas, como seguem:

1. modelo de referência do PDP: descreve as melhores práticas para a gestão do processo de desenvolvimento de produto, apresentando e relacionando fases e atividades às diversas técnicas e métodos disponíveis na área;

2. modelo de maturidade do PDP: serve para apoiar a identificação do nível de evolução que a empresa se encontra. Ele descreve níveis de maturidade e apresenta quais atividades devem estar formalizadas e implementadas em cada um destes níveis. A descrição mostra, portanto, uma hierarquia de prioridade em termos de atividade na medida que os níveis mais altos só podem ser atingidos uma vez que os níveis anteriores tenham sido satisfeitos.

3. processo de transformação do PDP: descreve um processo estrutural para implementar as mudanças necessárias no PDP, visando a elevação do nível de maturidade, por meio de projetos de transformação.

A Figura 5 representa esquematicamente cada um destes modelos e mostra o relacionamento entre eles. 


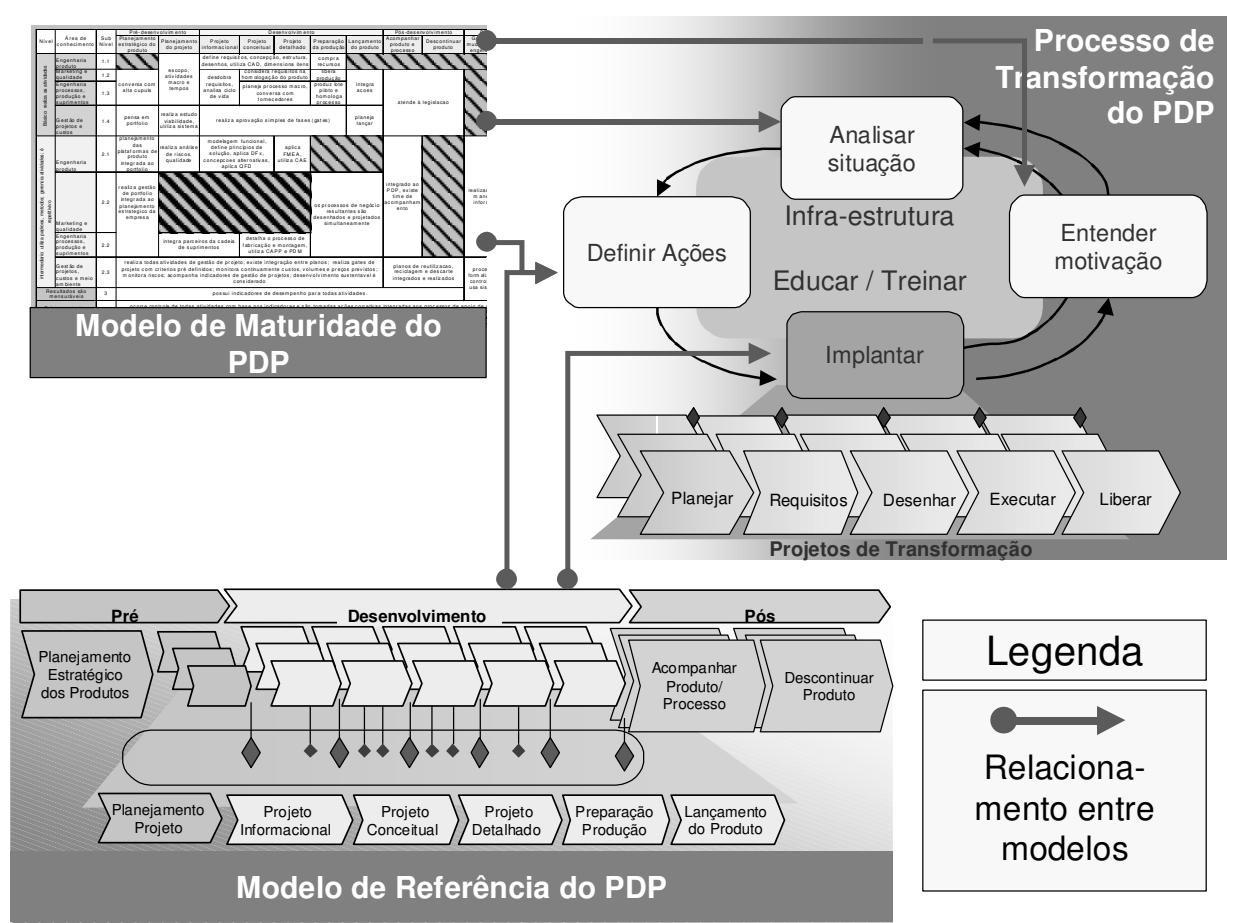

Figura 5 - Divisão do modelo

Fonte - Amaral (2006) (comunicação pessoal) ${ }^{6}$

Além disso, no modelo apresentado pelos autores há ainda a diferenciação entre o processo de melhoria contínua e outro processo, denominado de transformação do PDP, composto pelas atividades de mudança radical descritos pelos teóricos que discutem a melhoria contínua.

Embora os autores proponham o modelo acima citado, não há evidências de casos de utilização deste modelo e sua eficácia ou necessidade.

\subsection{Diferenças na aplicação da MC ao PDP e aos processos de}

\section{fabricação}

Como descrito anteriormente, a origem da melhoria contínua se deu nos processos de fabricação das empresas. O fato de que a melhoria contínua ainda hoje é principalmente

\footnotetext{
${ }^{6}$ Figura fornecida por Daniel C.Amaral, em São Carlos,em julho de 2006
} 
voltada para estes processos pode ser compreendido pelas dificuldades da sua aplicação ao PDP, dadas as características que distinguem o PDP dos processos de fabricação.

Caffyn (1997) lista estas diferenças no Quadro 3, que se justificam por:

- O PDP é um processo iterativo. Isto faz com que exista um ciclo natural, projetar-construir-testar-otimizar, necessário para o aprimoramento das soluções. Por isso, é difícil identificar se um evento negativo que aconteceu foi um desperdício ou um aprendizado que agregou valor à organização;

- A intangibilidade das atividades do processo de desenvolvimento de produtos desponta como fator crítico na busca por sua melhoria, visto que é mais difícil medir os resultados destas atividades.

- Para o processo de fabricação, uma vez executada uma atividade de melhoria é possível visualizar o seu resultado, uma vez que a melhoria foi feita em algo que está fisicamente na linha de produção, como maquinário, peça ou pessoa;

- Para o processo de desenvolvimento de produtos, o resultado (ou entrega) da atividade de melhoria nem sempre é claramente definido, considerando que a melhoria pode estar relacionada a algo subjetivo, como por exemplo, ao treinamento de uma pessoa em determinada função;

- As atividades do processo de desenvolvimento de produtos geralmente possuem durações mais longas, de modo que os resultados muitas vezes não são rapidamente percebidos.

- A cultura existente no PDP que é mais voltada à criação e, portanto, menos padronizada, tornando mais difícil a identificação do que é desperdício frente ao tempo gasto para execução de determinada atividade de criação.

- O método de avaliação da eficácia do processo. No processo de fabricação, os dados coletados para análise de valor agregado à determinada atividade de melhoria contínua são numéricos, pois consideram elementos tangíveis. Já no processo de desenvolvimento de produtos (PDP) medir a qualidade do processo não depende exclusivamente de dados numéricos, pois o valor agregado em cada atividade pode não ser explícito; esforços recentes apontam indicadores de desempenho tangíveis para avaliar o PDP, fazendo 
com que esta diferença seja minimizada e possivelmente num futuro próximo, eliminada das características que distinguem estes dois processos.

- A tendência de se medir dados facilmente observáveis, como exemplo dados de tempo, o que muitas vezes pode não aferir um resultado real ou suficiente para conclusão da qualidade do processo.

Melhoria Contínua aplicada ao PDP: diferenças comparadas ao processo de fabricação Diferenças-chave

Tangibilidade

PDP é um processo menos tangivel que o processo de fabricação

$\mathrm{Na}$ linha de produção, a melhoria se faz em algo que está fisicamente lá

É mais difícil definir qual é a saida/entrega da atividade de melhoria contínua

Características do Processo

PDP possui escalas de tempo mais longas

PDP é um processo iterativo

A cultura no PDP é diferente do processo de fabricação, por dois aspectos: o criativo e o estruturado

Modelos de Avaliação

Dificuldade de medir a qualidade do processo

Tendências de medir coisas que são facilmente medidas (ex. tempo) e podem não ser obrigatoriamente necessárias para aferir resultados

Dificuldade em medir o que é realmente valor no processo

Quadro 3 - MC aplicada ao PDP: diferenças comparadas ao processo de fabricação

Fonte - Caffyn (1997)

McManus (2004) também sugere diferenças entre o PDP e o processo de fabricação, focando o conceito do pensamento enxuto (lean thinking). No Quadro 4 estão representadas as principais diferenças sugeridas pelo autor entre o PDP e os processos de fabricação, baseadas neste conceito. Para ele, existem dificuldades para a implantação de melhorias do PDP em virtude destas diferenças. No entanto, o autor afirma que este argumento não é válido para justificar a não existência de um fluxo de melhorias do PDP.

$\mathrm{O}$ autor propõe uma metodologia para a implantação do pensamento enxuto no processo de desenvolvimento de produtos. Para este trabalho, esta metodologia é considerada um mecanismo para a $\mathrm{MC}$, uma vez que sugere a máxima utilização dos recursos disponíveis, eliminando tudo o que é considerado desperdício, ou seja, aquilo que não agrega valor para o cliente.

Observa-se que como Caffyn (1997), o autor considera fatores como intangibilidade, característica criativa do processo e repetições planejadas como atividades 
que podem agregar valor ao PDP, diferentemente dos processos de fabricação, no qual repetições são desperdícios e o valor de uma atividade pode ser medido e visualizado na cadeia de valor, onde os tempos devem ser curtos e os erros devem ser sempre eliminados, em qualquer ponto que ele venha ocorrer.

\begin{tabular}{|c|c|c|}
\hline \multicolumn{2}{|c|}{ Princípios do pensamento "enxuto" - diferenças entre o desenvolvimento de produtos e a fabricação } \\
\hline & Fabricação & Desenvolvimento de Produtos \\
\hline Valor & Visível a cada passo & Mais difícil de enxergar, objetivos emergentes \\
\hline Cadeia de Valor & Peças e materiais & Informação e conhecimento \\
\hline Fluxo & Repetições são desperdícios & Repetições planejadas devem ser eficientes \\
\hline Produção "Puxada" & Dirigida pelo "takt time" & Dirigida pelas necessidades do negócio \\
\hline Perfeição & Processo repetitivo sem erros & Processo permite melhorias nos negócios \\
\hline
\end{tabular}

Quadro 4 - Princípios do pensamento enxuto: diferenças entre o PDP e a fabricação

Fonte - Traduzido de McManus (2004)

Amaral (1997) afirma que o desenvolvimento e lançamento de um produto, para a grande maioria das organizações, não são atividades rotineiras como compras ou fabricação, mas sim um processo ad-hoc, ou seja, que acontece de maneira aleatória e não repetitiva, que pode durar anos. Segundo o autor cada desenvolvimento é diferente dos outros, pois possui suas dificuldades, problemas e requisitos particulares.

Em contrapartida, Rosenau Jr. (2000) afirma que o PDP vem sofrendo uma reestruturação fazendo com que a característica criativa deste processo dê lugar à estruturada, como representado na Figura 6. Desta forma, a melhoria do PDP é representada pela sistematização das atividades e respectivos fluxos, buscando ganhos em eficiência pela padronização, como já acontece nas demais áreas da empresa, em especial nos processos de fabricação.

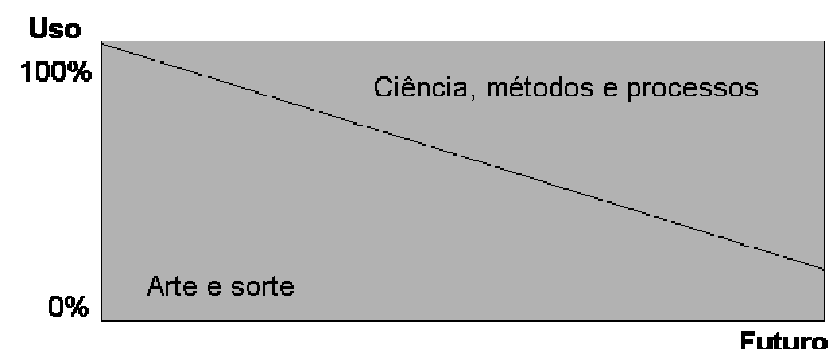

Figura 6 - Tendência de estruturação do PDP

Fonte - Rosenau Jr. (2000) 
Mais recentemente Rozenfeld et al. (2006) comparam o PDP aos demais processos de negócio das empresas, distinguindo-o de todos os outros uma vez que possui características particulares. São elas:

- Elevado grau de incertezas e riscos das atividades e resultados;

- Decisões importantes devem ser tomadas no início do processo, quando as incertezas são ainda maiores;

- Dificuldade de mudar as decisões iniciais;

- As atividades básicas seguem um ciclo iterativo do tipo: Projetar-ConstruirTestar-Otimizar;

- Manipulação e geração de alto volume de informações;

- As informações e atividades provêm de diversas fontes e áreas da empresa e da cadeia de suprimentos;

- Multiplicidade de requisitos a serem atendidos pelo processo, considerando todas as fases do ciclo de vida do produto e seus clientes.

Os autores acreditam que essas características fazem com que a natureza do PDP seja diferente dos demais processos de negócio das empresas, o que condicionará os modelos e práticas de gestão adequadas ao processo, além do perfil e das capacitações requeridas dos profissionais que atuam neste processo.

Como descrito e exemplificado, a literatura demonstra que existem diferenças entre as características essenciais do processo de desenvolvimento de produtos (PDP) e do processo de fabricação (bem como dos demais processos) nas empresas. Essas diferenças devem ser consideradas quando a empresa busca implementar atividades de melhoria contínua no PDP, visto que os fatores que inibirão e aqueles que facilitarão esta implantação no PDP serão também diferentes.

\subsection{Sistematização do PDP e Melhoria Contínua}

Para que seja efetivamente sistematizado, o PDP precisa ser reformulado nas empresas. Neste contexto, as atividades que contribuem para a melhoria contínua desse processo apresentam-se como fatores de fomento a esta sistematização, uma vez que favorecem a organização cadenciada das atividades, a organização das entradas e saídas de cada etapa do processo, a padronização de como cada atividade será executada, a 
eliminação das atividades consideradas desperdícios - que não representam valor para o cliente -, entre outros fatores. Ainda, algumas atividades pertencentes ao próprio processo de desenvolvimento de produtos podem também fomentar a melhoria contínua deste processo, e por estão razão estão discutidas como escopo deste trabalho.

Àquelas organizações que já descobriram as vantagens da aplicação da melhoria contínua também ao PDP, nota-se uma ênfase na necessidade de aumento das competências organizacionais. Em outras palavras, significa dizer que essas empresas estão preocupadas em aumentar as habilidades e melhorar os comportamentos das pessoas que a compõem. O sucesso das montadoras japonesas por suas práticas de melhoria contínua serve como exemplo deste tipo de empresa.

Leonard-Barton (1995) afirma que o crescimento das competências se dá pelas das ações dos próprios funcionários da empresa e mostra como eles podem nortear o desenvolvimento das competências, estimulando as pessoas a compartilharem soluções de problemas, integrando novas metodologias e ferramentas de processo, fazendo experiências formais e informais constantemente e trazendo conhecimento de especialistas externos para dentro da empresa. Portanto, a sistematização e a organização do processo de desenvolvimento de produtos deve ser feita de maneira a promover este estímulo em toda a empresa.

Wheelwright e Clark (1995) acreditam que a responsabilidade pela melhoria contínua do PDP deve estar centrada no gerente da área de desenvolvimento de produtos. Para os autores, este gerente deve fomentar o estabelecimento de um processo de aprendizagem como uma atividade de alto valor agregado para a organização, através de atividades que fomentem a captura e o compartilhamento de tudo o que foi aprendido. Para que isso aconteça, é preciso que o processo possibilite a identificação das oportunidades de melhoria, o foco na implementação de soluções e a certeza de que tudo o que é aprendido no processo será capturado pela organização. O processo de aprendizagem engloba atividades de aprender, relembrar e aplicar e estas atividades dependem de liderança.

Outras literaturas da indústria automotiva também sugerem atividades de melhoria contínua ao processo de desenvolvimento de produtos. Como exemplo, cita-se a especificação técnica automotiva ISO/TS16949, que agrupa os requisitos de todas as montadoras a partir dos requisitos de certificação de qualidade da QS-9000, e o manual 
APQP (Planejamento Avançado da Qualidade do Produto e Plano de Controle), escritos por representantes das empresas do ramo automotivo, também buscando atender aos requisitos específicos de desenvolvimento de produtos das montadoras.

O manual APQP - que descreve exclusivamente como as montadoras esperam que seus produtos sejam desenvolvidos - tem toda a sua estrutura voltada ao ciclo PDCA, já descrito neste trabalho. Desta forma, este manual tem foco nas atividades do desenvolvimento de produtos e da igual importância às ações de planejar, fazer, verificar e agir corretivamente. Esta última ação faz referência à melhoria contínua do processo de desenvolvimento de produtos que as montadoras esperam de seus sistemistas, como demonstrado na Figura 7.

Com relação à especificação técnica automotiva ISO/TS16949 é possível encontrar um capítulo inteiro tratando das exigências com a melhoria contínua dos processos, qualquer que seja ele. Para o caso desta pesquisa, ele se aplica ao processo de desenvolvimento de produtos.

No elemento quatro da ISO/TS16949 tem-se o capítulo dedicado a Realização dos Produtos, que é o mesmo que desenvolvimento de um novo produto, e neste capítulo existem diversos itens citando a importância da utilização de lições aprendidas de desenvolvimentos anteriores, de atividades de Benchmarking e compartilhamento de informações a outros desenvolvimentos, bem como a utilização de uma equipe multifuncional para o desenvolvimento de qualquer novo produto e o cronograma para que este desenvolvimento atenda aos requisitos acordados com o cliente, seja ele interno ou externo. 


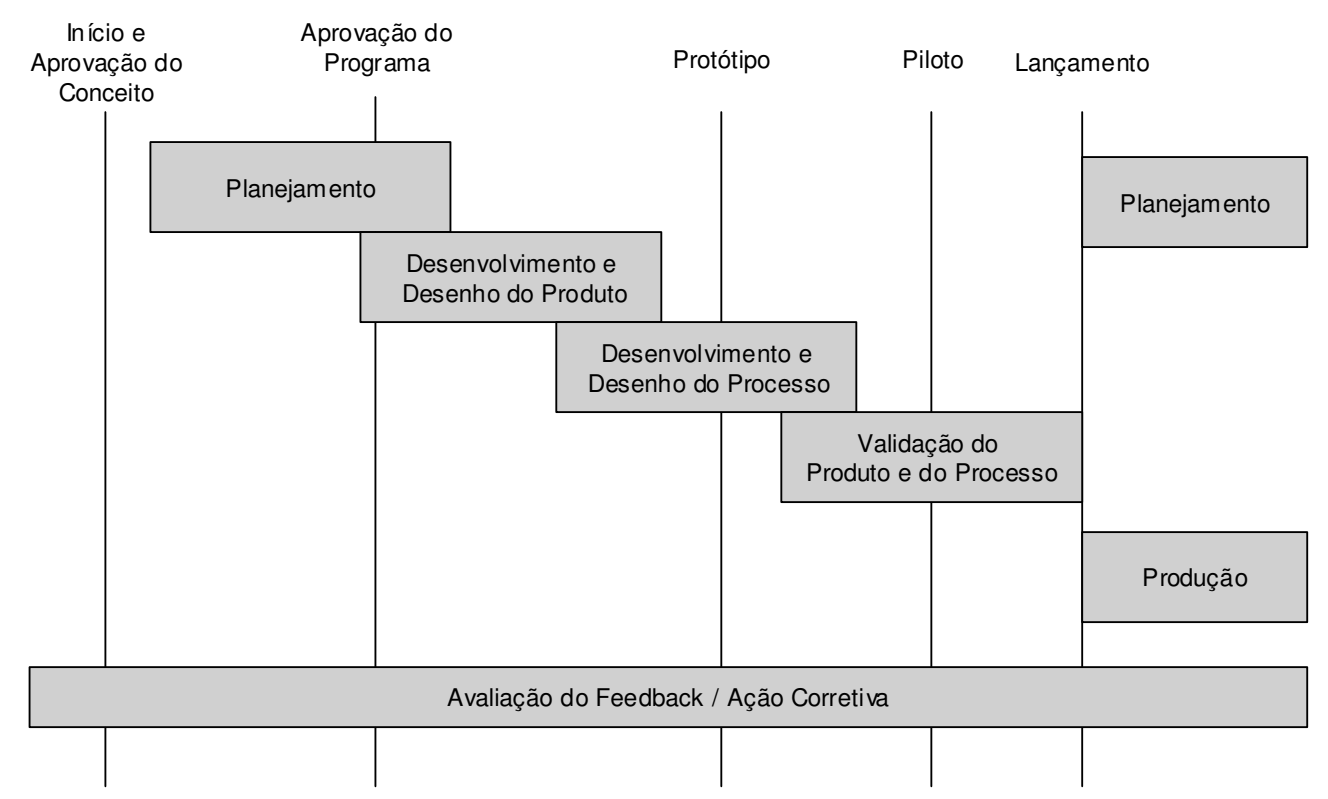

Figura 7 - Fluxo do planejamento da qualidade do produto

Fonte - Traduzido do Manual APQP (1994)

Condotta (2004) desenvolveu uma pesquisa focada na reestruturação de um modelo de gestão do PDP para a indústria automobilística. Segundo o autor, para as empresas de autopeças a reestruturação do PDP deve focar em: fazer da gestão do PDP um argumento de venda como prestação de serviço intrínseca ao desenvolvimento do produto (DP); fazer análise dos produtos da concorrência com a visão do cliente; estruturar um modelo de desenvolvimento avançado de novas tecnologias; prover a interação do DP com os demais departamentos da empresa; utilizar e desenvolver competências internas; estabelecer parcerias estratégicas.

Como exemplificado, neste trabalho foram listadas as atividades que contribuem para a MC do PDP em uma empresa de autopeças; estas atividades estão compiladas juntamente às demais identificadas na literatura - no capítulo de resultados desta pesquisa.

\subsubsection{Mecanismos que podem auxiliar a MC do PDP}

Neste tópico são listados alguns mecanismos que podem auxiliar na melhoria contínua do processo de desenvolvimento de produtos.

Para esta pesquisa, mecanismo é definido como "arranjos ou ações sistematizadas pelas quais algo é produzido ou conseguido" (ALLWORDS english dictionary, 2006), e 
desta forma a escolha dos mecanismos aqui apresentados teve como critérios àqueles que propõem a melhoria contínua ao processo de desenvolvimento destes produtos.

Existem ainda outros mecanismos que não serão aqui discutidos por serem focados exclusivamente em melhorias do produto, estando fora do escopo deste trabalho.

\subsubsection{Benchmarking}

O Benchmarking pode ser entendido como um processo contínuo e sistemático de avaliação de produtos, serviços e processos - foco deste trabalho - e, para este último caso investiga quais empresas são reconhecidas como excelentes no desenvolvimento de produtos (SPENDOLINI, 1993).

Depois de terminada uma atividade de benchmarking ocorre uma chamada para a ação, que envolve diversas atividades, desde recomendações até a implantação real de mudanças. Desta forma, o benchmarking é visto como aprendizado, uma vez que a empresa que busca as melhores técnicas para determinada atividade é uma organização aprendiz.

De acordo com Cheng (1995), o Benchmarking é baseado no princípio Modus Operandi (AAEM) para difusão de conhecimentos na organização, uma vez que se fundamenta no ciclo aprender, aplicar, ensinar e melhorar; observa-se ênfase no processo de aprendizagem da empresa, pois sugere que o processo de melhoria se inicie com a identificação de uma oportunidade de melhoria (aprender), que esta oportunidade seja aplicada ao processo (aplicar), que os conhecimentos adquiridos desta aplicação sejam ensinados aos demais da equipe (ensinar) e finalmente, que aplique a melhoria ao que foi aprendido (melhorar). A Figura 8 representa este princípio.

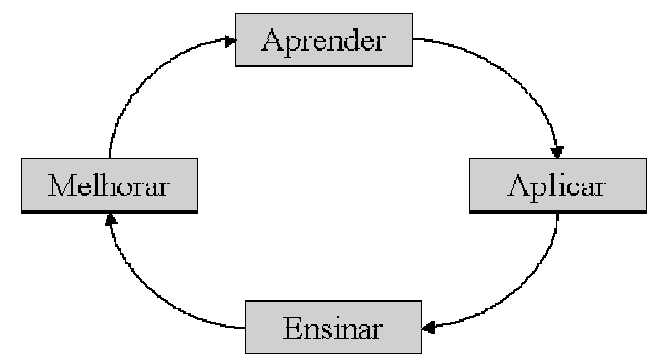

Figura 8 - Ciclo AAEM: Aprender, aplicar, ensinar e melhorar Fonte - Cheng (1995) 


\subsubsection{Programa 5S}

O Programa 5S representa um mecanismo da melhoria contínua focado, dentre outros objetivos, na diminuição de desperdícios, reduzindo os custos e aumentando a produtividade das empresas em qualquer processo de negócios e por esta razão este mecanismo foi incluído no escopo deste trabalho de pesquisa.

O Programa 5S foi concebido por Kaoru Ishikawa em 1950, após o término da Segunda Guerra Mundial, no Japão, pela necessidade que havia então de reorganizar o país após a sua derrota. O programa demonstrou-se extremamente eficaz enquanto reorganizador das empresas e da própria economia japonesa da época que até hoje é considerado o principal instrumento de gestão da qualidade e produtividade utilizadas naquele país. (INSTITUTO DE PESOS E MEDIDAS DO ESTADO DE SÃO PAULO IPEMSP, 2006).

$\mathrm{O}$ nome $5 \mathrm{~S}$ foi atribuído a este mecanismo pelas iniciais das cinco palavras japoneses que sumarizam as etapas do programa, representadas por:

1. Seiri (Descarte): segregar e descartar tudo o que não é essencial para o processo ou a atividade;

2. Seiton (Arrumação): organizar o material de trabalho para serem rapidamente encontrados quando necessário forem;

3. Seisso (Limpeza): limpar e cuidar do ambiente de trabalho;

4. Seiketsu (Saúde): tornar saudável o ambiente;

5. Shiksuke (Disciplina): rotinizar e padronizar as atividades anteriores para que a manutenção das melhorias obtidas seja garantida.

Embora nem todas as etapas estejam diretamente relacionadas à melhoria contínua do PDP podemos encontrar nos itens de Descarte, Arrumação e Disciplina um esforço diretamente voltado à otimização e máximo aproveitamento dos recursos e tempo disponíveis. Este mecanismo está diretamente ligado aos princípios do pensamento enxuto (discutido no item 2.9.3) e aos eventos Kaizen (descrito em 2.9.4).

Como para em qualquer outro processo de negócio da empresa, estas práticas podem fomentam a otimização das atividades do PDP, permitindo que toda a equipe multifuncional, com seus escritórios e material de trabalho organizado e com os 
desperdícios (tangíveis ou intangíveis) descartados - terão mais tempo para realizar atividades que agregam valor para o cliente, que é principal conceito do pensamento enxuto.

\subsubsection{Pensamento Enxuto}

O conceito de manufatura enxuta já consolidado na literatura a partir das boas práticas da Toyota na eliminação de desperdícios também pode ser utilizado no PDP, como rapidamente citado no item sobre o Pograma $5 \mathrm{~S}$, uma vez que também busca maior otimização dos processos, para a máxima utilização dos recursos disponíveis.

Segundo Karlsson e Ahlstrom (1996), para o processo de desenvolvimento de produtos, o principal benefício do pensamento enxuto é melhorar a manufaturabilidade dos produtos e para tanto os autores sugerem práticas para a aplicação dos conceitos do pensamento enxuto para este processo. São elas:

- O envolvimento do fornecedor desde o início do projeto;

- A utilização da engenharia simultânea para ganhos de tempo e custos;

- A formação de uma equipe multidisciplinar comprometida;

- O trabalho conjunto;

- A definiç̧ão do gerente do projeto;

- O próprio projeto visto como um gerenciamento estratégico.

Desta forma, a proposta do desenvolvimento de produtos enxuto mescla diversas técnicas inter-relacionadas, uma vez que o "produto" deste processo - seja ele uma entrada ou uma saída - na maioria das vezes não é algo tangível, como acontece nos processos de fabricação.

A implementação desta proposta de pensamento enxuto ao PDP deve ser vista como o começo de uma jornada para a melhoria contínua, que inclui todos os demais mecanismos e atividades discutidas no decorrer deste trabalho.

Outros autores como McManus (2004), Womack e Jones (1998) e Imai (1997) também discutem o pensamento enxuto nas empresas e iniciam discussões acerca dos demais processos da empresa, incluindo o processo de desenvolvimento de produtos. 


\subsubsection{Kaizen}

Outro mecanismo relacionado ao pensamento enxuto e derivado do Programa 5S é a filosofia Kaizen, que surgiu na indústria japonesa no início dos anos 80 que embora seja uma filosofia e não uma atividade, representa uma mudança de cultura e na maneira de pensar das pessoas que compõem as empresas, e esta mudança faz com que as pessoas apresentem e implementem continuamente idéias para melhorias em todas as áreas de empresa.

O conceito central deste mecanismo está centrado na melhoria das atividades e dos processos, como o próprio nome sugere: Kai (Mudança) e Zen (Melhor), que significa “mudar para melhor”, ou ainda, “melhoria contínua” (IMAI, 1997).

As atividades Kaizen foram difundidas no ocidente no ano de 1986, quando surgiram as primeiras publicações sobre o assunto. Elas são baseadas em um trabalho de equipe formado por todos os níveis da organização e busca melhorar com soluções rápidas e simplificadas. O princípio é o de sugestões, inicialmente de todos os tipos (sobre um problema específico) e posterior seleção neste aglomerado de sugestões.

Nos chamados eventos Kaizen a equipe tem dedicação integral às atividades e também tem poder de decisão. Todas as discussões são baseadas em dados.

Ainda, nos princípios do Kaizen, pequenas melhorias são vistas como uma vantagem competitiva sobre as grandes.

Como característica inerente ao processo, o Kaizen também enfrenta barreiras para implantação de melhorias. Develin (1995) apresenta as principais dificuldades na tentativa de trazer melhorias aos processos, demonstradas na Figura 9.

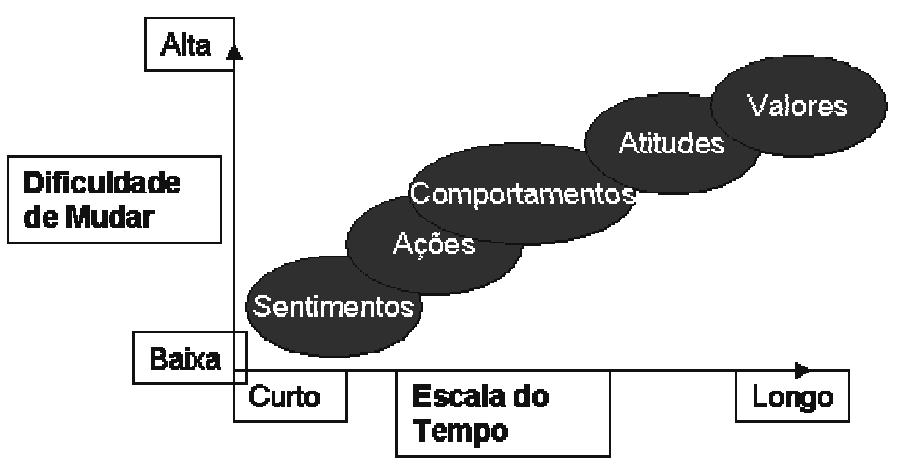

Figura 9 - Dificuldades encontradas nas atividades de Kaizen Fonte - Develin (1995) 
Embora voltada ainda para aos processos de fabricação, os princípios do Kaizen podem ser aplicados buscando a melhoria de qualquer processo, inclusive do PDP. Não foram encontrados estudos científicos que evidenciassem estas atividades no PDP. Nota-se, entretanto, uma tendência das empresas em utilizar estes princípios para os outros processos de negócios, inclusive o PDP.

Para o caso do PDP, a execução de um evento Kaizen pode auxiliar na redução de atividades que não agregam valor aos resultados dos desenvolvimentos, tais como o preenchimento de diversas planilhas com dados semelhantes, o envio de mensagens a pessoas que não estão diretamente envolvidas nas atividades, os tempos das reuniões - bem como o volume e freqüência com que elas acontecem -, a necessidade de se verificar o andamento das atividades fora das revisões do projeto (telefonemas, e-mails, etc), a realização de atividades que já foram feitas no passado pela falta de consulta aos dados históricos dos desenvolvimentos anteriores, o tempo gasto com interpretações de documentos dos desenvolvimentos pela falta de padronização, entre outras tantas atividades sem valor agregado.

Observa-se, portanto, que o mecanismo Kaizen pode auxiliar na identificação dos desperdícios existentes nas atividades do PDP e, por conseqüência, na eliminação dos mesmos, e na implementação das atividades que representam valor ao cliente e desta forma, contribuem para a melhoria contínua do processo de desenvolvimento de produtos da mesma forma que dos processos de fabricação, ainda que considerando as características próprias do PDP, tais como intangilibidade e criatividade.

\subsubsection{Aprovação de Fases}

A sistemática de aprovação de fases (conhecida pelo termo em inglês Stage-Gates) é uma forma de estruturar o processo de desenvolvimento de produtos baseada em estágios de aprovação do desenvolvimento e grupos de atividades que compõem cada um destes estágios (SILVA, 2004).

Pela metodologia, cada um dos estágios que são concluídos - pela conclusão das atividades que ele demanda - passam por um "portão" de aprovação para que as atividades do próximo estágio possam ser iniciadas. 
Neste trabalho, ela é considerada um mecanismo para fomentar a melhoria contínua do PDP, pois nestas fases são capturadas as lições aprendidas do desenvolvimento atual ou de desenvolvimentos passados, além de contribuir para a multiplicação do aprendizado de cada indivíduo pertencente à equipe ou convidado à contribuir para a melhoria do desenvolvimento em questão.

Desta forma, esta sistemática - difundida por Robert Cooper na década de 90 consiste em um modelo para estruturar o PDP em fases e revisões formais das atividades realizadas desde a idéia e conceito até ou além do lançamento (SILVA, 2004).

Por este mecanismo são estabelecidas fases (stages) que englobam um conjunto de atividades que devem ser concluídas com o desenvolvimento de um novo produto. Uma vez concluídas, para cada fase são definidos estágios de decisão (gates) e nestes estágios são verificados requisitos de prazo, custo e qualidade do produto, comparado ao que foi planejado no início do desenvolvimento.

O líder do desenvolvimento - conhecido como gerente do projeto - em conjunto com a equipe multifuncional apresenta os resultados destes estágios a pessoas-chave da organização - representadas por supervisores, gerentes e especialistas no assunto - que vão identificar o direcionamento da seqüência do projeto, frente às estratégias da empresa. Este direcionamento pode ser: parar o projeto, continuar o projeto, revisar e re-apresentar ou parar temporariamente o desenvolvimento.

Para Cooper (2001) e para este trabalho, estas revisões de fases tem especial importância na melhoria do processo de desenvolvimento de produtos, pois:

- Melhora o trabalho em equipe;

- Diminui o retrabalho das atividades de desenvolvimento;

- Melhora as taxas de sucesso no lançamento de produtos;

- Identifica falhas e erros potenciais nas primeiras fases do projeto;

- Diminui em até $30 \%$ o ciclo de desenvolvimento de um produto.

A sistemática de aprovação de fases é importante mecanismo para identificar melhores práticas e fatores críticos de sucesso para o PDP de uma empresa (COOPER, 1993). A Figura 10 representa esta sistemática. 


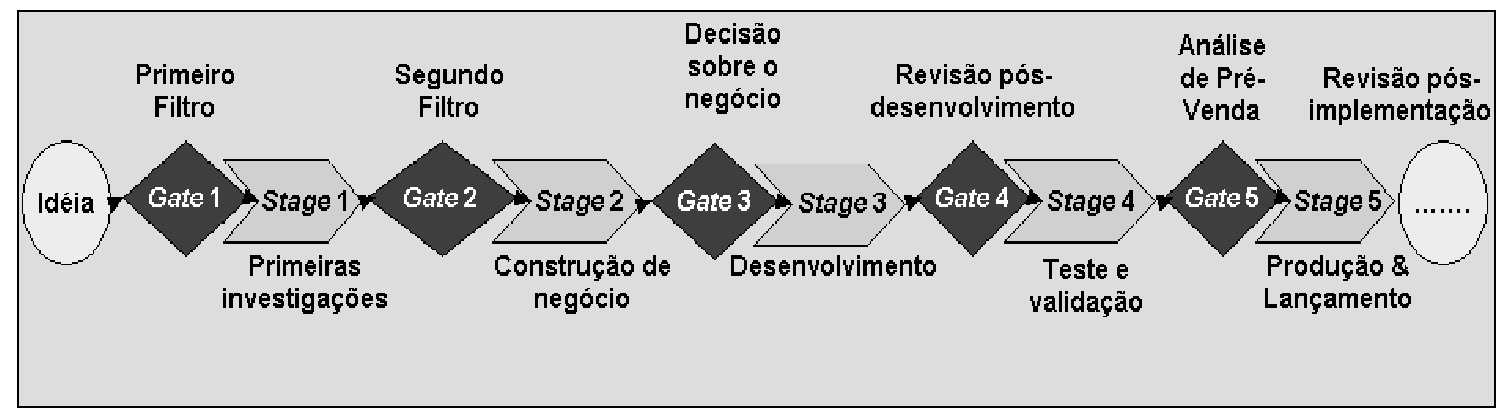

Figura 10 - Sistemática de Aprovação de Fases para o PDP

Fonte - Cooper; Edgett e Kleinschmidt (1999)

\subsubsection{Inibidores e Facilitadores da MC do PDP}

Ainda que faltem estudos mais sistemáticos que considerem os fatores facilitadores e os inibidores para a implantação de atividades de melhoria contínua ao PDP, é possível perceber características comuns no que se refere às dificuldades encontradas para fortalecer e reestruturar o processo de desenvolvimento de produtos de uma organização.

Deschamps e Nayak (1997) discutem estas dificuldades, que para esta pesquisa são definidas por fatores inibidores. Para eles, os inibidores às atividades de MC aplicadas ao PDP estão associados à falta de coesão generalizada da empresa - dificultando a formação de equipes multifuncionais para realização das atividades -, à cultura e valores incompatíveis entre a equipe, à falta de visão estruturada por processos, entre outros fatores.

Os autores sugerem que haja uma infra-estrutura gerencial. Eles acreditam que para trabalhar com eficiência em equipes, as pessoas devem ter claramente definidas suas responsabilidades funcionais e suas responsabilidades de processo.

Há ainda outros autores que discutem estes inibidores, tais como: Amaral (1997), Caffyn (1997), Karlsson e Ahlstrom (1996), Rentes (2000) e Rosenau Jr. (2000); eles afirmam que a intangibilidade e, por conseqüência, a dificuldade de medir os resultados das atividades, são os principais fatores que inibem a melhoria contínua do PDP.

Destacam-se também fatores culturais e valores, além do conflito entre o processo criativo (inerente ao processo de desenvolvimento de produtos) e a necessidade de padronização para efetiva sistematização do processo. Ao término deste trabalho são feitas 
algumas considerações a respeitos destes fatores facilitadores e inibidores encontrados no caso estudado.

Os fatores facilitadores estão representados no item 2.5.1 deste trabalho, pelos mecanismos que podem facilitar a melhoria contínua aplicada ao PDP das empresas. 


\section{Metodologia}

Este capítulo apresenta a metodologia de pesquisa utilizada neste trabalho, a justificativa do delineamento, da abordagem e do método de pesquisa, os critérios utilizados para a seleção do caso estudado e o método de coleta dos dados, com base nos objetivos definidos para a pesquisa.

\subsection{Objetivo e Justificativa}

Demonstrou-se na revisão bibliográfica que a melhoria contínua é fundamental para os processos de negócio de uma empresa, inclusive para o PDP.

De maneira complementar, o processo de melhoria contínua (PMC) pode ser visto como instrumento-chave uma vez que através das atividades que o PMC sugere e que podem ser aplicáveis ao PDP, a efetiva sistematização do PDP pode ser facilitada.

Observou-se na literatura que poucos trabalhos discutem a melhoria contínua aplicada ao PDP.

Na revisão da literatura de gestão do desenvolvimento de produtos, demonstrou-se que a sistematização do processo de desenvolvimento é tida como "melhor prática". Porém, os modelos não citam especificamente o relacionamento entre as atividades do processo de desenvolvimento de produto e a melhoria contínua e como este processo poderia auxiliar na sistematização do PDP. Um dos desafios também é a sistematização e o controle do PDP, por sua vez, é outro grande desafio acadêmico que uma vez investigado poderá ser utilizado pelas empresas nos diferentes segmentos de negócios.

Optou-se por realizar uma pesquisa que pudesse contribuir com esta lacuna nas pesquisas sobre PDP, procurando caracterizar a relação entre PDP e PMC. Para tal, buscouse o caso de uma empresa com experiência recente de sistematização do seu processo de desenvolvimento de produtos.

A opção pela indústria de autopeças, justifica-se por ser reconhecida por seus modelos de PDP completos e ter processos mais estruturados em comparação com outros 
segmentos, contendo as principais atividades do PDP sugeridas pela literatura de melhores práticas.

Uma vez identificada a empresa, realizou-se um estudo de caso visando caracterizar quais atividades de MC foram realizadas durante a etapa de sistematização, incluindo quais fazem parte do PDP e quais fazem parte de um processo de melhoria contínua (MC). Analisou-se em seguida, qual o impacto da sistematização do PDP no desempenho dos projetos de desenvolvimento, procurando-se avaliar a efetividade desta ação.

O objetivo principal deste trabalho é caracterizar a relação entre PDP e PMC, entendendo quais atividades contribuem para a MC do PDP.

Desta forma, esta pesquisa tem como contribuições principais:

a. Levantamento da literatura sobre a relação entre melhoria contínua e o processo de desenvolvimento de produto, por meio da identificação das atividades que contribuem para a MC do PDP;

b. A caracterização das atividades relacionadas à $\mathrm{MC}$ que foram realizadas em um caso específico de sistematização do PDP em uma empresa de autopeças e os resultados obtidos com a sistematização.

\subsection{Questões de Pesquisa}

Esta pesquisa está fundamentada em três questões principais, definidas abaixo. Para que estas perguntas principais fossem respondidas, foram definidas algumas perguntas secundárias, listadas também abaixo como subitens, que serviram como meios para obtenção do resultado principal do trabalho.

O trabalho está, portanto, embasado por:

1. Quais são as atividades que contribuem para a MC do PDP segundo a literatura?

- Quais destas atividades são incluídas como parte do PDP?

- Quais pertencem ao PMC (processo de apoio)?

2. Quais atividades identificadas na questão anterior foram utilizadas no caso da empresa estudada para a sistematização do PDP? 
3. Qual a relação entre sistematização do PDP, a introdução da melhoria contínua e o desempenho deste processo? Como esta relação influenciou a melhoria dos resultados do desenvolvimento de produtos, avaliado segundo os resultados dos projetos da empresa estudada?

- Quais destas atividades foram encontradas em cada projeto?

- Estas atividades trouxeram benefícios aos resultados dos desenvolvimentos estudados?

\subsection{Seleção do Método}

Do ponto de vista abordagem do problema, esta pesquisa pode ser classificada predominantemente como qualitativa, uma vez que "não requer o uso de métodos e técnicas estatísticas, é descritiva e processo e significado são os focos principais de abordagem" (LAVILLE e DIONE, 1999).

A pesquisa tem caráter descritivo-exploratório uma vez que busca responder questões do tipo "quais" fenômenos podem ser identificados na melhoria contínua aplicada ao PDP de acordo com a literatura disponível e com o caso estudado. Ainda, a pesquisa descreve as atividades a partir da compilação da literatura e como é o caso da unidade de negócios em questão e explora aspectos que devem ser analisados no problema.

A decisão por realizar um estudo de caso seguindo um propósito descritivoexploratório é justificada por buscar “propor explanações concorrentes para o mesmo conjunto de eventos e indicar como essas explanações podem ser aplicadas a outras situações” (YIN, 2001). Ainda, como descrito por Gil (1987) "esta pesquisa aprofunda o conhecimento da realidade explicando a razão dos acontecimentos e visa identificar os fatores que determinam ou contribuem para a ocorrência dos fenômenos".

Estabelecidas as questões de interesse da pesquisa, delineou-se uma estratégia de pesquisa dividida em três grandes etapas, a saber:

1) Levantamento bibliográfico específico sobre as atividades que auxiliam a MC do processo de desenvolvimento de produtos;

2) Análise documental sobre o processo de desenvolvimento de produtos padrão utilizado pela empresa e o histórico de sua implantação; 
3) Estudo de caso único e incorporado sobre projetos de desenvolvimento realizados pela empresa.

Para acesso aos documentos e demais informações necessárias para uma sólida interpretação dos dados foram utilizadas as seguintes fontes de dados, como sugerido por Yin, 2001: observação e participação ativa nas atividades; série sistemática de entrevistas semi-estruturadas; consulta a manuais, procedimentos e demais documentos dos projetos ou do próprio portfólio de desenvolvimentos da unidade.

Neste contexto, os instrumentos de coleta de dados utilizados, classificados segundo Bryman (1989), são:

- Entrevistas: podem ser estruturadas, semi-estruturadas ou desestruturadas. Nas duas primeiras, informantes-chave são questionados a respeito de tópicos definidos anteriormente. No último caso, o entrevistado tem liberdade para falar sobre o que considera importante a respeito de um assunto mais amplo;

- Documentos: informações oficiais registradas de forma sistemática pela organização;

- Observação: pode ser direta e passiva do objeto de estudo pelo pesquisador, ou ser participante, na qual o observador é parte dos eventos que estuda. Para este caso, será utilizada a observação participante, visto que o pesquisador participa ativamente dos eventos estudados.

O referencial teórico da pesquisa é positivista, pois de acordo com Martins (1995) "a pesquisa busca a explicação dos fenômenos através das relações dos mesmos... pode ser prevista... e está embasada em fatos que podem ser observados e posteriormente verificados".

O método principal adotado é o estudo de caso. Yin (2001) define o estudo de caso como "uma estratégia de pesquisa que compreende e abrange não só métodos de coleta de dados, mas também a análise dos resultados dos dados coletados”.

Segundo o autor, o processo de investigação de estudo de caso deve: 
- Enfrentar uma situação tecnicamente única em que haverá muito mais variáveis de interesse do que pontos de dados, e, como resultado,

- Basear-se em várias fontes de evidências, com os dados precisando convergir em um formato de triângulo, e, como outro resultado,

- Beneficiar-se do desenvolvimento prévio de proposições teóricas para conduzir a coleta e a análise de dados.

Dentro do método de estudo de caso sugerido por Yin (2001) existem quatro tipos de projetos de pesquisa, que variam de acordo com as questões propostas no trabalho, como representados na Figura 11.

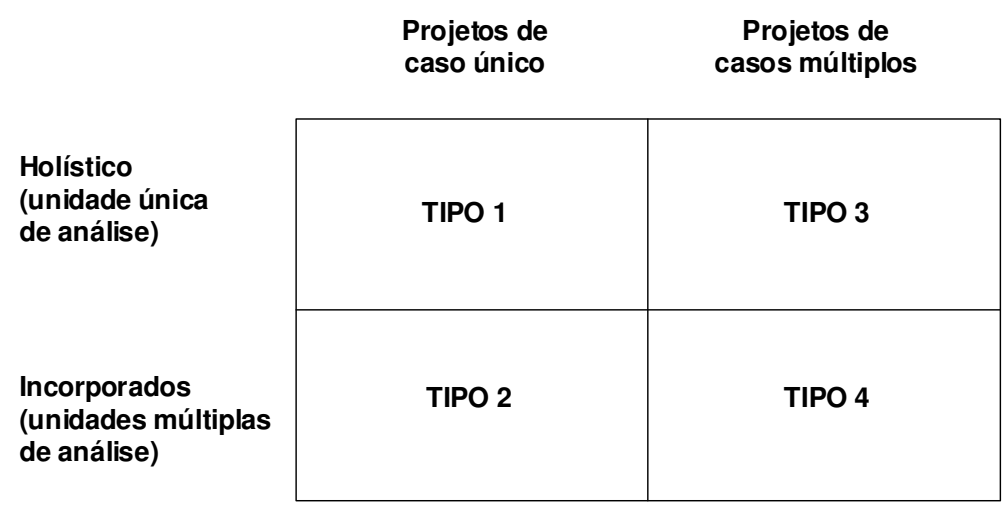

Figura 11 - Tipos de projeto de pesquisa de estudo de caso

Fonte - Yin (2001)

O método de estudo de caso utilizado neste trabalho está representado no Tipo 2 da divisão proposta por Yin (2001), representado por um estudo de caso único e incorporado, pois está baseado em múltiplas unidades de análise.

Esta pesquisa visa, portanto explicar, descrever, ilustrar, explorar e avaliar o fenômeno da melhoria contínua aplicada ao processo de desenvolvimento de produtos.

Inicialmente o estudo de caso teve como proposta fazer observações e consultas a manuais. Com o aprofundamento dos conceitos, melhor entendimento da realidade e necessidades da empresa e objetivando o enriquecimento dos resultados, o caráter da pesquisadora de observador-completo foi alterado para observador-participante, visto que a pesquisadora interferiu nas atividades do processo de desenvolvimento de produtos realizadas na empresa. $\mathrm{O}$ acesso às informações foi facilitado por ter sido a pesquisadora funcionária da empresa durante todo o período em que a pesquisa foi realizada. 
Dane (1990) atribui o nível de participação observador-participante "quando o agente da pesquisa, assumindo o papel de pesquisador, participa das atividades do evento".

\subsection{Seleção e Justificativa da Amostra}

A amostra selecionada para a aplicação do estudo de caso nesta pesquisa considerou primordialmente a necessidade de verificação da eficácia da implantação de atividades que contribuem para a melhoria contínua do processo de desenvolvimento de produtos, a partir de indicadores de desempenho quantitativos individuais dos resultados dos projetos selecionados.

Desta forma, foram analisados os resultados de seis projetos de desenvolvimentos de produtos executados em momentos distintos, com o objetivo de analisar os benefícios das atividades implementadas baseados nos seguintes indicadores de desempenho: orçamento e prazo planejado versus realizado, número de pessoas envolvidas (planejado versus realizado), número de localização de peças em cada desenvolvimento (planejado versus realizado), índice de retorno de peças em campo, número que reclamações formais do cliente.

A justificativa da escolha de seis projetos - ou três pares - se fundamenta pela necessidade de comparação entre os resultados a partir de uma amostragem significativa, observando uma tendência. Analisar um par (dois projetos) não representaria uma tendência, da mesma forma que a análise de dois pares (quatro projetos), que poderia demonstrar dois cenários distintos, não representando uma tendência.

Como citado anteriormente, a facilidade da pesquisadora em obter dados na empresa por ter sido funcionária da área de desenvolvimento de produtos durante a realização da pesquisa contribuiu no acesso e veracidade das informações.

Dados considerados confidenciais à empresa foram discutidos em valores percentuais e não absolutos, preservando as informações estratégicas da empresa. 


\subsection{Objeto Pesquisado}

As unidades de análise do estudo de caso estão representadas pelos projetos de desenvolvimento selecionados, avaliando-se, em cada um deles: quais atividades de melhoria contínua foram realizadas e os resultados em termos de indicadores de desempenho. Os casos foram analisados em pares de igual complexidade, porém executados em diferentes períodos no tempo.

Quando a discussão referir-se aos grupos de projetos, são utilizadas as seguintes nomenclaturas:

- Primeiro grupo de projetos: representa o período 1 , ou seja, os primeiros projetos executados na unidade, sendo um para cada linha de produto selecionada, totalizando três projetos (ocorridos entre 1999 e 2002).

- Segundo grupo de projetos: representa o período 2, ou seja, os projetos seguintes ou posteriores ao primeiro grupo executado na unidade, sendo um para cada linha de produtos selecionada (idênticas ao primeiro grupo), também totalizando três projetos (ocorridos entre 2002 e 2006).

Foram identificadas as mudanças ocorridas no PDP e atividades de melhoria implementadas durante os anos de atividade da unidade de negócios da empresa - que teve suas atividades iniciadas em meados de 1999 - e comparados os resultados para análise dos benefícios trazidos por estas mudanças e melhorias. Neste contexto, as unidades de análise desse trabalho estão representadas na Figura 12.

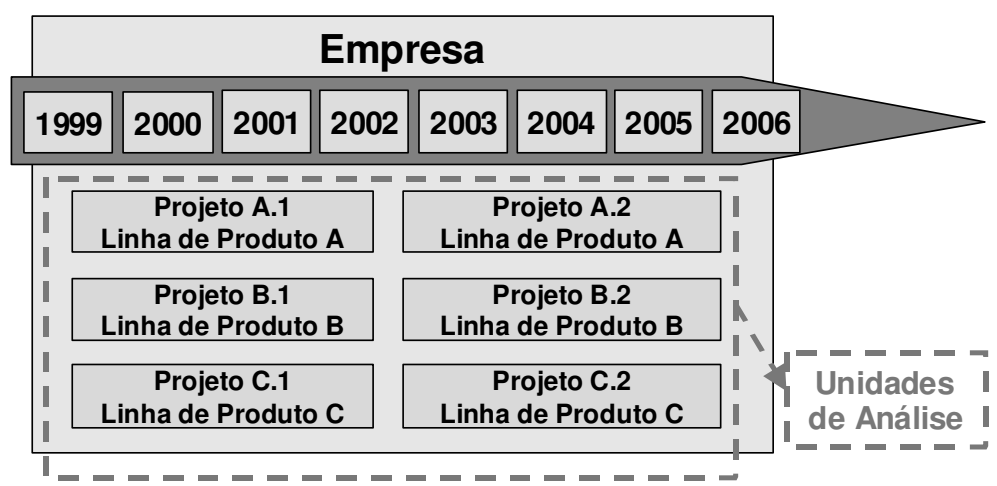

Figura 12 - Unidades de análise da pesquisa 


\subsection{Modelo Teórico da pesquisa}

O modelo teórico desta pesquisa está descrito na Erro! A origem da referência não foi encontrada., representando a estrutura central do trabalho e como os assuntos pesquisados estão relacionados entre si para o alcance dos objetivos propostos.

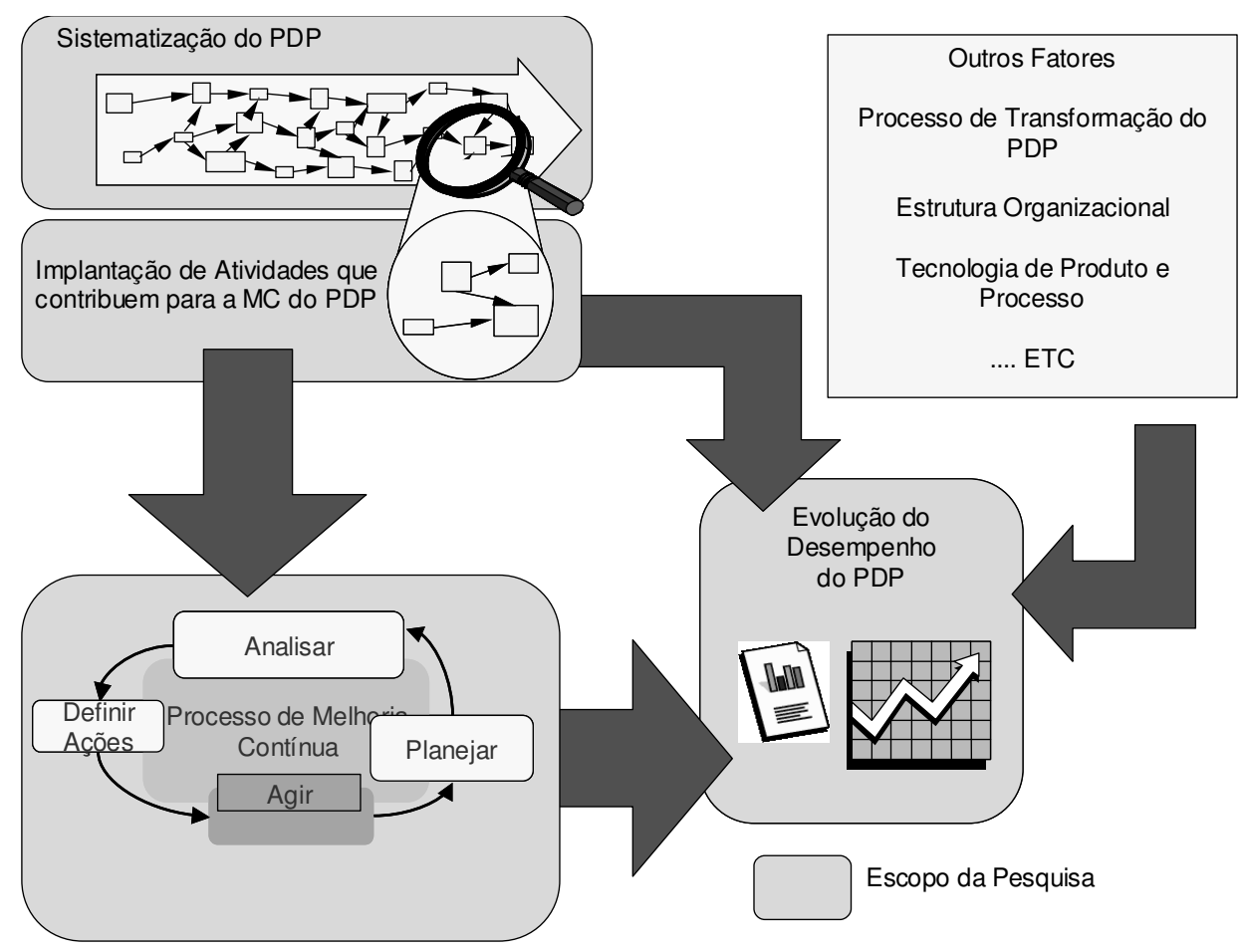

Figura 13 - Modelo teórico da pesquisa

\subsection{Etapas e estrutura da pesquisa}

$\mathrm{O}$ trabalho aqui apresentado foi fundamentado em uma seqüência de atividades, de modo a alcançar os objetivos propostos inicialmente e estão representadas pela estrutura da Figura 14. 


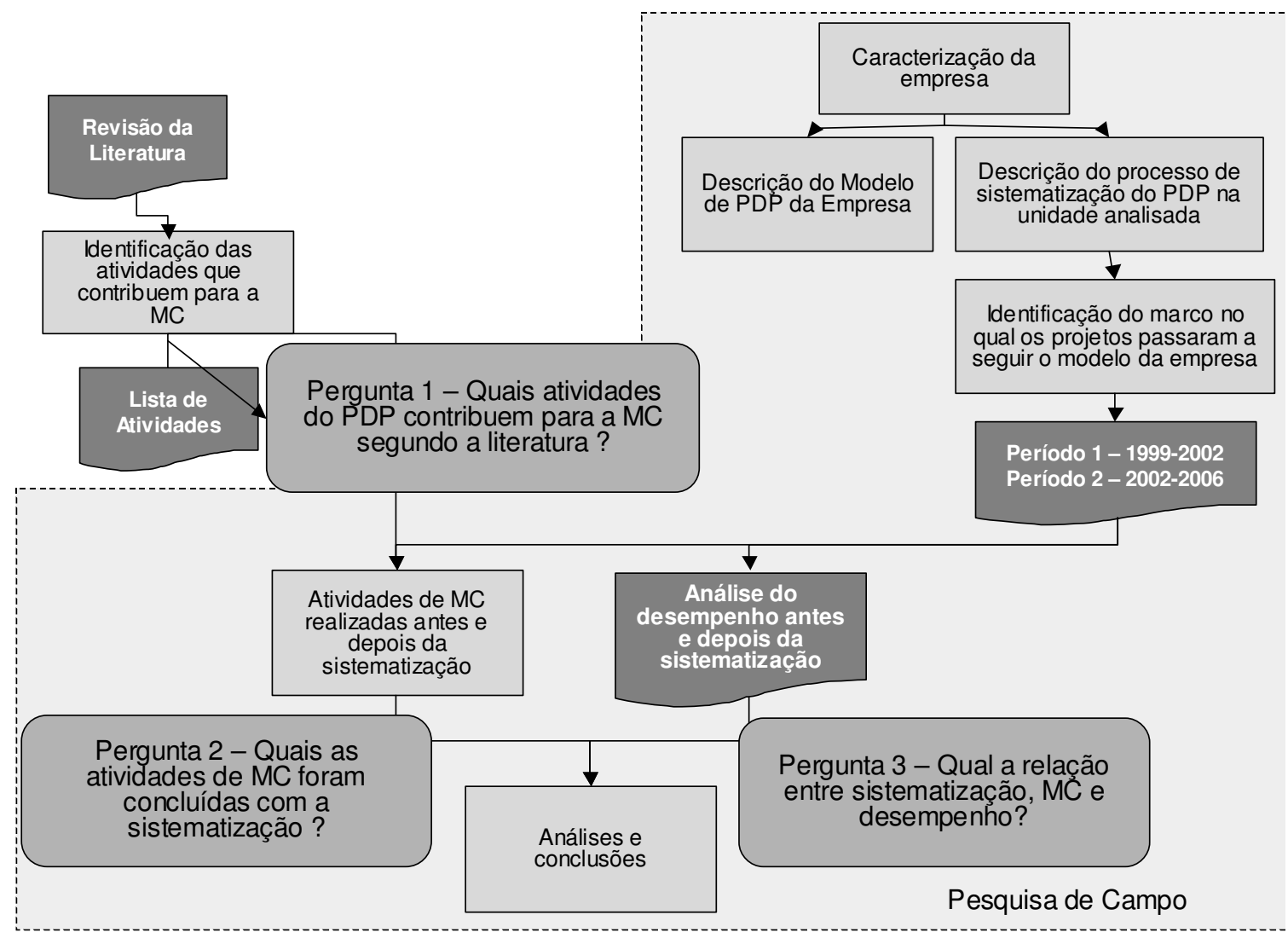

Figura 14 - Estrutura da pesquisa

A representação da Figura 14, portanto, apresenta os objetivos da pesquisa, as principais perguntas que a embasam e, quais atividades foram seguidas - e em qual sequiência - durante a execução deste trabalho para a obtenção dos resultados que estão descritos no próximo capítulo.

É possível dividir a estrutura apresentada em cinco grandes grupos de atividades, como descrito nos itens que seguem.

\subsubsection{Revisão da literatura}

Durante o período de pesquisa observou-se que não havia trabalhos que discutiam a melhoria contínua para o processo de desenvolvimento de produtos, bem como as atividades que esta melhoria demanda de maneira compilada e desta forma, o caráter descritivo-exploratório também foi utilizado. 
Nesta primeira etapa encontra-se a primeira contribuição do trabalho, pois compila as principais discussões acerca da melhoria contínua aplicada ao processo de desenvolvimento de produtos, uma vez que não estavam organizadas na literatura.

\subsubsection{Descrição do modelo de PDP da empresa}

Esta etapa apresenta uma descrição detalhada do modelo de PDP utilizado pela empresa estudada. A justificativa deste detalhamento está embasada na diversidade de modelos já existentes tanto na literatura quanto dentro das empresas de bens de consumo.

\subsubsection{Análise do PDP da empresa quanto à aplicação das atividades de MC}

Após o processo investigativo descrito nas fases anteriores, esta etapa representa a primeira análise realizada nesta pesquisa que se refere ao PDP da empresa e suas vertentes para a sua melhoria contínua.

Foram identificadas atividades que contribuem para a melhoria contínua pertencentes ao próprio modelo (PDP) e também aquelas que são partes do processo de melhoria contínua (PMC) e funcionam como apoio para a melhoria do modelo estudado.

Além do trabalho de observação em campo (Apêndices B, C e D) foram realizadas entrevistas (Apêndice A) com pessoas-chave da organização e estas entrevistas auxiliaram tanto na análise do modelo do processo de desenvolvimento de produtos da empresa como na análise dos resultados dos projetos de desenvolvimento selecionados para esta pesquisa (item 3.7.4).

\subsubsection{Seleção das pessoas-chave para as entrevistas}

Como critérios para a definição de pessoas-chave a serem entrevistadas considerouse que os entrevistados deveriam:

1. Ser de diferentes funções e posições hierárquicas dentro do mesmo projeto, mas de iguais funções entre os projetos;

2. Ter ao menos dois anos de atuação na função em que foram considerados na pesquisa, para que pudessem relatar o histórico das atividades de melhoria do PDP na unidade, caso tivessem ocorrido. 
Desta forma, foram definidas como pessoas-chave

\begin{tabular}{|c|c|c|c|c|c|c|}
\hline \multicolumn{7}{|c|}{ Relação Número de Entrevistados } \\
\hline & \multicolumn{2}{|c|}{ Linha de Produto A } & \multicolumn{2}{|c|}{ Linha de Produto B } & \multicolumn{2}{|c|}{ Linha de Produto $\mathrm{C}$} \\
\hline & Projeto A.1 & Projeto A.2 & Projeto B.1 & Projeto B.2 & Projeto C.1 & \begin{tabular}{|l} 
Projeto C.2 \\
\end{tabular} \\
\hline Gerente da Engenharia & \multicolumn{6}{|c|}{$\frac{1}{1}$} \\
\hline Líder do Projeto & & 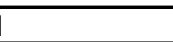 & & 1 & & 1 \\
\hline Membro da Equipe & $=$ & 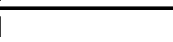 & & 1 & & 1 \\
\hline
\end{tabular}

Quadro 5):

- Gerente da engenharia;

- Líder de cada projeto selecionado ou responsável local, para os projetos mais antigos;

- Representante de um departamento que integra a equipe multifuncional de cada projeto selecionado, preferencialmente o mesmo representante para cada par de projetos.

\begin{tabular}{|c|c|c|c|c|c|c|}
\hline \multicolumn{7}{|c|}{ Relação Número de Entrevistados } \\
\hline & \multicolumn{2}{|c|}{ Linha de Produto A } & \multicolumn{2}{|c|}{ Linha de Produto B } & \multicolumn{2}{|c|}{ Linha de Produto $\mathrm{C}$} \\
\hline & Projeto A.1 & Projeto A.2 & Projeto B.1 & Projeto B.2 & Projeto C.1 & Projeto C.2 \\
\hline Gerente da Engenharia & \multicolumn{6}{|c|}{1} \\
\hline Líder do Projeto & \multicolumn{2}{|c|}{$\overline{1}$} & & 4 & \multicolumn{2}{|c|}{$\overline{1}$} \\
\hline Membro da Equipe & \multirow{2}{*}{\multicolumn{2}{|c|}{1}} & & 1 & \multicolumn{2}{|c|}{1} \\
\hline & & & & & Total: 7 & ntrevistados \\
\hline
\end{tabular}

Quadro 5 - Relação de Entrevistados no Caso

\subsubsection{Estudo comparativo dos seis projetos de desenvolvimento}

Esta etapa da pesquisa representa a segunda atividade de análise dos dados coletados.

A literatura disponível discute a importância da MC para os processos de negócio das empresas - incluindo o PDP -, mas não há registros de estudos que a validem, baseados em indicadores de desempenho, como foi a proposta deste trabalho.

Considerando as características da MC aplicada ao PDP, foram comparados os seis projetos de desenvolvimento de produtos baseado nos indicadores de desempenho prédefinidos, para posteriormente analisar a influência das atividades de melhoria contínua do PDP nos resultados dos projetos e desta forma, aferir a eficiência destas atividades para a efetiva sistematização do processo. 


\subsubsection{Critério para seleção dos projetos}

Os critérios de seleção dos seis projetos de desenvolvimento foram:

- Serem de mesma complexidade entre os pares, considerando as classificações definidas pela empresa;

- Os pares de projetos deveriam pertencer a uma mesma linha de produtos;

- Cada um dos projetos dos pares deveriam ter sido executados em diferentes períodos de tempo;

- Os três projetos pertencentes a cada grupo (Grupo 1 ou Grupo 2) deveriam ter sido executados em períodos de tempo próximos;

- Todos os projetos deveriam estar concluídos até a data em que a coleta de dados foi realizada.

\subsubsection{Critérios para identificação das atividades}

Para identificação das atividades que contribuem para a melhoria contínua do PDP foram utilizados os dados obtidos pelos questionários e pelas observações feitas durante a pesquisa de campo. No entanto, em etapa anterior, uma lista compilada da literatura foi formada, abordando atividades que atendiam aos seguintes critérios:

- Aplicam-se ao PDP como um processo de negócios da empresa, considerando suas entradas e saídas e, por conseqüência, suas inter-relações com os demais processos de negócios da empresa;

- Podem contribuir para a melhoria contínua do PDP.

Como apoio a essa coleta de dados foram utilizados os documentos representados pelos Apêndices B e C, um para cada projeto analisado, no qual:

- Atividade: descrição da atividade sugerida para a melhoria contínua do PDP, seja ela pertencente a este processo ou ao processo de MC que apóia o PDP, subdividida entre os seguintes tipos:

- Formal: representa as atividades constantes, que acontecem com cadência, metodologia e responsáveis pré-estabelecidos, ou seja, existe procedimento formal para execução das mesmas;

- Ad-hoc: representa as atividades que não constantes, ou seja, acontecem de acordo com a necessidade do momento, não 
importando cadência ou responsável. Existe metodologia conhecida, mas a atividade não exige formalidade ou padronização para acontecer.

○ Não-existe: atividades constantes na lista compilada na literatura, mas não identificadas nos projetos analisados.

O Apêndice B refere-se às atividades pertencentes ao processo de desenvolvimento de produtos (PDP) e que podem contribuir para a melhoria do mesmo. O Apêndice C refere-se as atividades pertencentes ao processo de melhoria contínua (PMC), que é um processo de apoio ao PDP e contém atividades de MC que podem ser aplicáveis ao PDP, buscando a sua efetiva sistematização.

Ambas atividades (Apêndices B e C) estão mais detalhadamente descritas no item 4.2.1 deste trabalho. Os conceitos utilizados no Apêndice C são os mesmos que os descritos anteriormente, para o Apêndice B.

\subsubsection{Análise dos resultados e conclusões}

Esta atividade representa a análise final de todas as informações coletadas - tanto da literatura quanto do caso -, as conclusões desta análise e as considerações acerca das conclusões feitas.

Nesta fase são discutidos:

1. A aplicabilidade da MC ao processo de desenvolvimento de produtos;

2. O caso prático;

3. Os resultados obtidos pela observação e coleta de dados, bem como a interpretação e conclusão frente a estes dados;

4. Os reais benefícios que a MC trouxeram para a sistematização do PDP da empresa;

5. Considerações adicionais sobre a importância da melhoria contínua para o PDP como um processo de negócios fundamental e estratégico para as empresas.

Desta forma, ao término do trabalho de observação na empresa, com o auxílio da revisão da literatura, foram compilados os dados que nortearam a análise e a obtenção dos resultados e das conclusões, respondendo as questões propostas por esta pesquisa. 


\section{Resultados}

Nos próximos subitens estão descritos os principais resultados do trabalho, a revisão coletada da literatura - incluindo a lista compilada das atividades que contribuem para a melhoria contínua do PDP -, a caracterização do caso (empresa e unidade de negócios), a descrição do modelo de PDP da empresa, bem como o processo que sua sistematização seguiu, os resultados dos seis projetos de desenvolvimento analisados e, finalmente, as conclusões e principais considerações desta pesquisa, acerca do tema selecionado.

\subsection{Atividades que Contribuem Para a MC do PDP}

Nesta seção são compiladas as atividades que contribuem para a melhoria contínua (MC) do processo de desenvolvimento de produtos (PDP), identificadas na literatura que discute a sistematização deste processo. Esta lista serviu como referência para identificação das atividades existentes na unidade de negócio da empresa estudada.

O conceito de atividade utilizado nesta pesquisa foi extraído de Vernadat (1996), que a define por "um conjunto de ações elementares executadas para realizar uma determinada tarefa na organização. Esta atividade exige tempo e recursos para sua execução e transforma um estado de entrada em um estado de saída".

Utilizando o conceito de melhoria contínua utilizado neste trabalho, descrito no item 2.1, no qual a MC é "um processo, em toda a empresa, focado na inovação incremental e contínua" (CAFFYN e BESSANT,1996) neste trabalho consideramos que a atividade de melhoria contínua é "um conjunto de ações executadas para realizar uma tarefa na organização que foque uma inovação incremental e contínua".

Ainda neste contexto, esta pesquisa considera que atividade que contribui para a melhoria contínua é toda aquela que "fomenta uma inovação incremental ou contínua de um processo de negócio, seja ela pertencente ou não ao processo de melhoria contínua". Neste trabalho elas estão definidas por atividades de PMC e atividades de PDP, respectivamente. 
As listas apresentadas são parte da contribuição da pesquisa, uma vez que compilam estas principais atividades que contribuem para a melhoria contínua do processo de desenvolvimento de produtos disponível na literatura, a partir de referências que discutem este processo. Esta lista foi o principal instrumento para a pesquisa de campo.

Conforme apresentado na introdução deste trabalho, as atividades aqui elencadas foram classificadas em duas categorias, como seguem:

- Atividade de PDP: atividades que contribuem para a MC e pertencentes ao processo de desenvolvimento de produtos; (Quadro 6)

- Atividade de PMC: atividades pertencentes ao processo de melhoria contínua (PMC) que suportam e facilitam a MC do PDP, mas não pertencem a este processo. (Quadro 7)

Elas foram também agrupadas em 2 (duas) colunas que representam respectivamente:

- Atividade: descrição da atividade sugerida para a melhoria contínua do PDP, seja ela pertencente a este processo ou ao processo de MC que apóia o PDP.

- Fonte: apresenta a fonte que contém evidências sobre a prática na literatura. Cada linha compila quais autores sugerem a atividade descrita na segunda coluna.

O Quadro 6 apresenta a lista das atividades de PDP que contribuem para a MC deste processo, segundo a revisão da literatura de desenvolvimento de produtos.

\begin{tabular}{|c|c|}
\hline Atividades do PDP & Fonte \\
\hline \multirow[t]{2}{*}{$\begin{array}{l}\text { Utilizar ferramentas para desenvolvimentos virtuais, tais como: CAD, mockup } \\
\text { digital, etc. }\end{array}$} & $\begin{array}{l}\text { Wheelwright e Clark, } \\
\text { 1992; }\end{array}$ \\
\hline & Anderl, 2000 \\
\hline \multirow[t]{2}{*}{ Definir mapas para auxílio na gestão estratégica de portfólio } & $\begin{array}{l}\text { Wheelwright e Clark, } \\
\text { 1992; }\end{array}$ \\
\hline & Marson, 2003 \\
\hline \multirow[t]{2}{*}{ Aplicar ferramentas que garantam a qualidade como: FMEA, QFD, DFE, etc. } & Clausing, 1992; \\
\hline & Marson, 2003 \\
\hline $\begin{array}{l}\text { Desenvolver e aplicar métodos, ferramentas e padrões para planejamento, } \\
\text { execução e controle dos desenvolvimentos. }\end{array}$ & $\begin{array}{l}\text { Wheelwright e Clark, } \\
\text { 1992; }\end{array}$ \\
\hline
\end{tabular}




\begin{tabular}{|c|c|}
\hline & Marson, 2003; \\
\hline & Marconcin, 2004; \\
\hline & Rosenau Jr.,2000; \\
\hline & Rozenfeld et al., 2006 \\
\hline & Echeveste, 2003 \\
\hline \multirow[t]{3}{*}{$\begin{array}{l}\text { Estabelecer plano agregado de projetos: visão dos desenvolvimentos e } \\
\text { lançamentos nos próximos anos. }\end{array}$} & $\begin{array}{l}\text { Wheelwright e Clark, } \\
\text { 1992; }\end{array}$ \\
\hline & Rozenfeld et al., 2006 \\
\hline & Marson, 2003 \\
\hline \multirow{2}{*}{$\begin{array}{l}\text { Criar estrutura organizacional específica para auxiliar a gestão do } \\
\text { desenvolvimento de produtos (ex. escritório de projetos) }\end{array}$} & Marson, 2003; \\
\hline & Caffyn, 1997 \\
\hline \multirow[t]{3}{*}{$\begin{array}{l}\text { Definir categorias de desenvolvimento para padronizar ações requeridas de } \\
\text { acordo com a complexidade }\end{array}$} & $\begin{array}{l}\text { Wheelwright e Clark, } \\
\text { 1992; }\end{array}$ \\
\hline & Jucá Jr., 2005; \\
\hline & Freitas et al., 2003 \\
\hline \multirow{2}{*}{$\begin{array}{l}\text { Estabelecer critérios de aprovação de mudanças significativas nos } \\
\text { desenvolvimentos }\end{array}$} & Marson, 2003; \\
\hline & Rentes, 2000 \\
\hline \multirow[t]{3}{*}{ Comparar e integrar desenvolvimentos } & Freitas et al., 2003; \\
\hline & Rozenfeld et al., 2006 \\
\hline & Marson, 2003 \\
\hline Envolver os fornecedores desde o início dos desenvolvimentos & $\begin{array}{l}\text { Karlsson e Ahlstrom, } \\
1996 \\
\text { Rozenfeld et al., } 2006\end{array}$ \\
\hline \multirow[t]{3}{*}{ Utilizar conceitos de engenharia simultânea } & $\begin{array}{l}\text { Karlsson e Ahlstrom, } \\
\text { 1996; }\end{array}$ \\
\hline & Rozenfeld et al., 2006 \\
\hline & Anderl, 2000 \\
\hline \multirow{7}{*}{$\begin{array}{l}\text { Implementar / praticar metodologia de "Stage-Gates" para aprovação ou } \\
\text { reprovação de fases do desenvolvimento. }\end{array}$} & Cooper, 1999; \\
\hline & Silva, 2004; \\
\hline & Rozenfeld et al., 2006 \\
\hline & Toledo et al., 2001; \\
\hline & Freitas et al., 2003; \\
\hline & Condotta, 2004; \\
\hline & Rosenau Jr.,2000; \\
\hline
\end{tabular}

Quadro 6 - Atividades do PDP que contribuem para a MC deste processo

O Quadro 7 apresenta a lista das atividades de PMC que contribuem para a melhoria contínua dos processos de negócio das empresas, segundo a revisão da literatura de melhoria contínua. 
Organizar a comunicação entre todos os níveis hierárquicos da empresa: gerência, supervisores, operadores, etc.

Executar workshops para as atividades de MC, incluindo compartilhamento de lições aprendidas e melhores práticas.

\section{Armazenar os conhecimentos do PDP de maneira integrada}

Dar poder de decisão ao líder do desenvolvimento

Ferramenta Denifir medidas para análise de desempenho do PDP
Caffyn, 1997;

Amaral, 2001;

Caffyn, 1998

Caffyn, 1997;

Alliprandini e Ruy, 2002;

Alliprandini e Silva, 2003

Amaral, 2001;

Marson, 2003;

Crossan et al, 1999;

Alliprandini e Silva, 2003

Caffyn, 1997

Wheelwright e Clark, 1992;

Caffyn e Bessant, 1996;

Marson, 2003;

Toledo et al., 2001;

Freitas et al., 2003;

Wheelwright e Clark, 1992;

Alliprandini e Ruy, 2002;

Condotta, 2004;

Toledo et al., 2001;

Caffyn, 1997;

Garvin, 2001;

Crossan et al, 1999;

Alliprandini e Silva, 2003;

Marson, 2003;

Alliprandini e Ruy, 2002

Conscientizar todos os gerentes funcionais para fomentar a MC do PDP

Caffyn, 1997;

Wheelwright e Clark, 1992;

Leonardo-Barton, 1995;

Caffyn e Bessant, 1996;

Alliprandini e Ruy, 2002;

Promover e potencializar a aprendizagem organizacional: estimular o compartilhamento do conhecimento adquirido; tratar o conhecimento como ativo corporativo

Garvin, 2001;

Senge, 1999;

Nonaka e Takeuchi, 1997;

Davenport e Prusak

1998;

Crossan et al, 1999;

Leonardo-Barton, 1995;

Alliprandini e Silva, 2003;

Marson, 2003;

Caffyn e Bessant, 1996;

Karlsson e Ahlstrom, 1996; 


\begin{tabular}{|c|c|}
\hline & $\begin{array}{l}\text { Wheelwright e Clark, } \\
\text { 1992; }\end{array}$ \\
\hline & Caffyn, 1997; \\
\hline & Wheelwright e Clark, 1995 \\
\hline Desenvolver a estrutura organizacional e seus procedimentos & $\begin{array}{l}\text { Wheelwright e Clark, } \\
\text { 1992; }\end{array}$ \\
\hline & Caffyn, 1997 \\
\hline Integrar atividades das equipes multifuncionais & $\begin{array}{l}\text { Wheelwright e Clark, } \\
\text { 1992; }\end{array}$ \\
\hline & $\begin{array}{l}\text { Karlsson e Ahlstrom, } \\
\text { 1996; }\end{array}$ \\
\hline & Freitas et al., 2003; \\
\hline & Condotta, 2004; \\
\hline & Alliprandini e Ruy, 2002; \\
\hline & Echeveste, 2003 \\
\hline Fomentar parcerias estratégicas (clientes, fornecedores, etc). & $\begin{array}{l}\text { Wheelwright e Clark, } \\
\text { 1992; }\end{array}$ \\
\hline & $\begin{array}{l}\text { Karlsson e Ahlstrom, } \\
\text { 1996; }\end{array}$ \\
\hline & Freitas et al., 2003; \\
\hline & Condotta, 2004; \\
\hline & Alliprandini e Ruy, 2002 \\
\hline $\begin{array}{l}\text { Realizar auditoria (aprendizagem) pós-desenvolvimento e utilizar os } \\
\text { resultados como aprendizado em projetos futuros }\end{array}$ & $\begin{array}{l}\text { Wheelwright e Clark, } \\
\text { 1992; }\end{array}$ \\
\hline & $\begin{array}{l}\text { Snyder e Duarte, } 1997 \\
\text { apud Alliprandini e Ruy, } \\
\text { 2002; }\end{array}$ \\
\hline & Marson, 2003 \\
\hline $\begin{array}{l}\text { Definir o líder do desenvolvimento e o próprio desenvolvimento como } \\
\text { fatores estratégicos para a empresa }\end{array}$ & $\begin{array}{l}\text { Wheelwright e Clark, } \\
\text { 1992; }\end{array}$ \\
\hline & Karlsson e Ahlstrom, 1996 \\
\hline Adotar melhores práticas em desenvolvimento de produtos da organização & Freitas et al., 2003; \\
\hline & Marson, 2003; \\
\hline Definir um sistema para registro e recuperação de melhores práticas em & Freitas et al., 2003; \\
\hline & Marson, 2003; \\
\hline & Cheng, 1995; \\
\hline & Spendolini, 1993 \\
\hline Dar ênfase à MC de produtos e processos, incluindo o de aprendizagem & Marson, 2003; \\
\hline & Caffyn, 1997; \\
\hline & Imai, 1997; \\
\hline & Develin, 1995; \\
\hline & Shiba et al., 1997; \\
\hline & Slack et al., 1997; \\
\hline & Garvin, 1993 \\
\hline Organizar a empresa matricialmente (funcional x projetizada) & Toledo et al., 2001 \\
\hline Implantar revisões periódicas com as equipes de desenvolvimento para & Toledo et al., 2001; \\
\hline controlar e nivelar informaçāo sobre a situação do desenvolvimento & Condotta, 2004; \\
\hline & Marson, 2003 \\
\hline
\end{tabular}




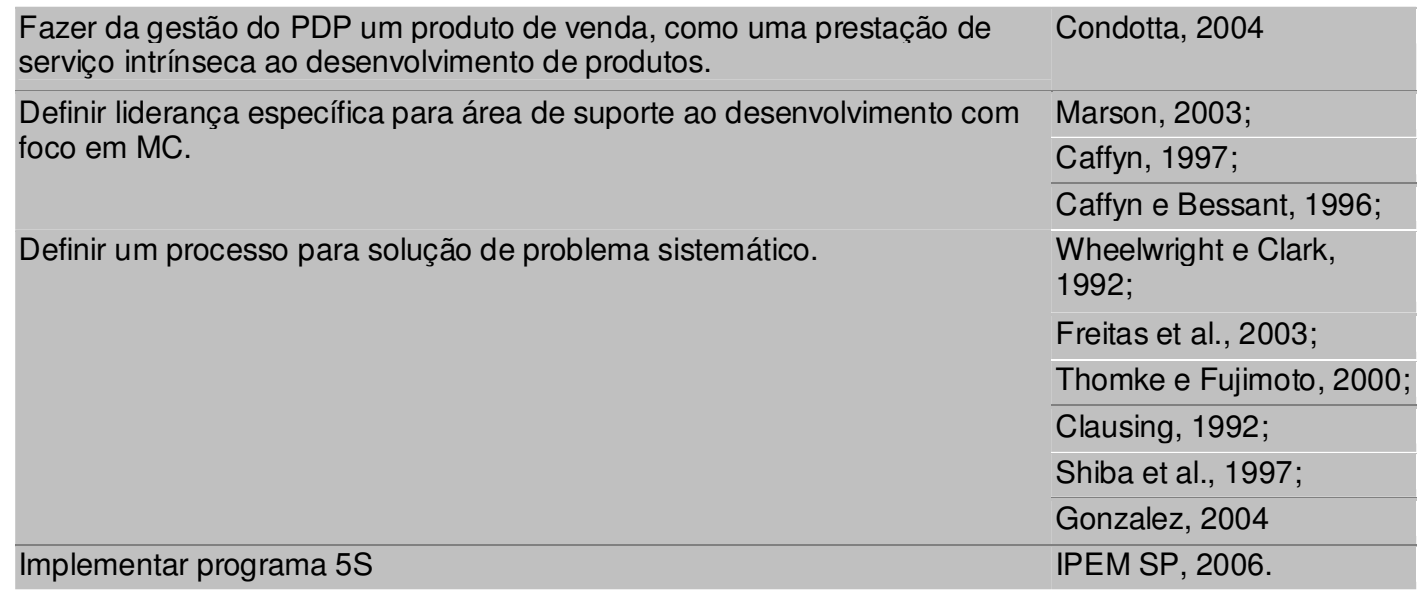

Quadro 7 - Atividades do PMC que contribuem para a melhoria do PDP

Um exemplo de como foram identificadas as atividades de melhoria do PMC é a auditoria pós-projeto. Segundo Clark e Wheelwright (1993), ela representa o momento em que são capturadas as lições aprendidas e as melhores práticas, para posterior compartilhamento dentro da organização, focando a aprendizagem pós-projeto. Mesmo não sendo citada explicitamente como algo para a melhoria, dado que o texto aborda o PDP, ela foi incluída na lista por seu objetivo principal de identificar problemas e iniciar ações de melhoria para o processo, o que inclui as atividades que ele sugere. A Figura 15 representa o momento em que esta atividade deve ser executada, como sugerido pelos autores.

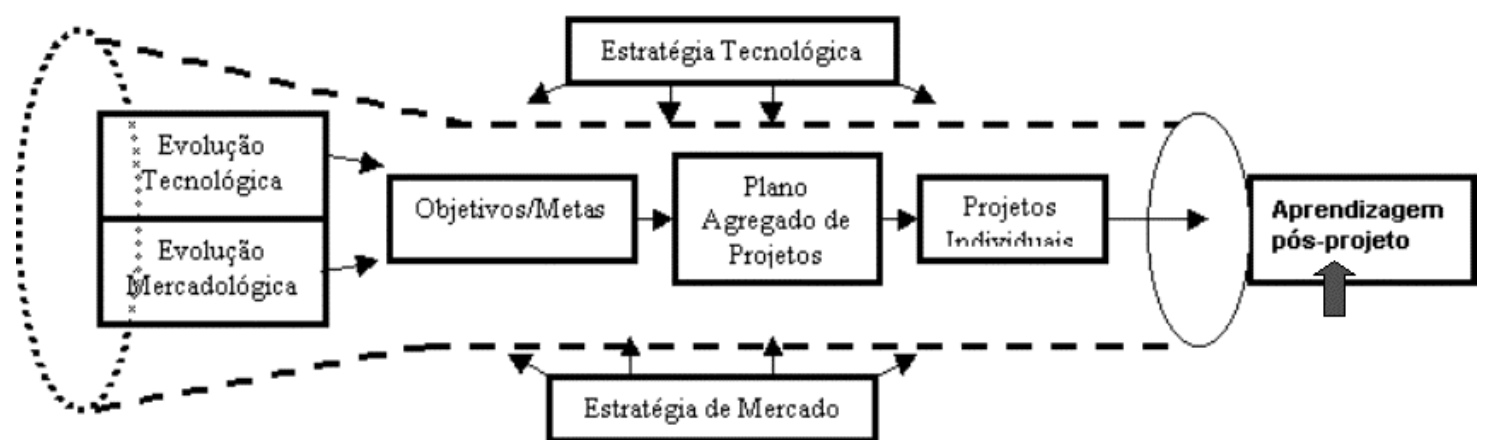

Figura 15 - Auditoria pós-projeto no desenvolvimento de funil Fonte - Clark e Wheelwright (1993) 


\subsection{Caracterização do Caso}

\subsubsection{A Empresa}

A empresa estudada neste trabalho destaca-se no contexto mundial como fornecedora de produtos e serviços especializados para diversas montadoras e fornecedores de autopeças em todo mundo, estando entre as líderes mundiais em tecnologia de eletrônica móvel, componentes e sistemas de transportes.

A Delphi Automotive Systems, ou somente Delphi, possui aproximadamente 180 mil funcionários, que operam 170 fábricas próprias, 42 joint-ventures e 34 centros tecnológicos em 41 países, sendo sua matriz em Troy, Michigan, nos EUA. Na América do Sul conta com 9300 funcionários em 11 fábricas, sendo 10 no Brasil e uma na Argentina.

No Brasil existem ainda dois centros tecnológicos - responsáveis pelo desenvolvimento de novos produtos - e quatro centros de aplicações. Um destes centros tecnológicos está instalado ao lado da fábrica da Delphi em Piracicaba.

Constam no portfólio de produtos: chicotes elétricos, conversores catalíticos, componentes do sistema de gerenciamento de motores, sistemas de injeção de combustível, colunas de direção e semi-eixo, compressores e sistemas de ar-condicionado e sistemas de arrefecimento.

\subsubsection{A unidade de negócios}

Como citado anteriormente, os projetos de desenvolvimento de produtos analisados neste trabalho fazem parte do portfólio de projetos do Centro Tecnológico de Piracicaba.

A unidade iniciou suas atividades no início de 1999. As primeiras atividades de desenvolvimento de produtos independentes da matriz ocorreram em 2001, quando foram nomeados os primeiros engenheiros de produtos. Até esta data as atividades da unidade estavam limitadas a suporte a matriz americana tanto nas responsabilidades de desenvolvimento de novos produtos quanto de novos processos de fabricação. Poucos eram os funcionários que conheciam o modelo de referência para o processo de desenvolvimento de produtos na empresa, ainda que superficialmente, em função do nível de responsabilidade que tinham sobre as atividades. A unidade local trabalhava mais como suporte às atividades que eram lideradas pela matriz. 
Em 2002 foi estabelecido nesta unidade um escritório de projetos, reconhecido por PSO (Project Support Office) para o suporte aos desenvolvimentos, que passaram a ser gerenciados localmente, como parte da estratégia de crescimento da organização no Brasil. Esta necessidade surgiu com o aumento das responsabilidades da equipe local de desenvolvimento, em adição ao novo projeto estratégico que havia sido "ganho"junto à montadora instalada no Brasil, que seria desenvolvido pela equipe brasileira, agora com o suporte da equipe americana (matriz).

Por esta nova realidade fez-se necessária uma melhor estruturação das atividades locais. Até então a documentação local não era padronizada, eram arquivadas fisicamente nos escritórios de cada funcionário e eram feitas a partir de necessidades identificadas pela equipe, sem cadência formal para acontecer.

O PSO a partir deste ano passou a estruturar, padronizar e controlar documentos, ferramentas e procedimentos das principais atividades do processo de desenvolvimento de produtos, especialmente aos componentes do sistema de gerenciamento de motor (EMS), principal produto desenvolvido na unidade. Essa estruturação seguiu obrigatoriamente as práticas da matriz americana, com pequenas adaptações para o cenário brasileiro. O PSO local atua, portanto, como um centro de excelência e suporte ao gerenciamento de projetos, fornecendo a estrutura para facilitar a função.

A estrutura do PSO está ligada ao escritório de projetos estratégico global, que é responsável por desenvolver e manter os processos de desenvolvimento de produtos e de gerenciamento de projetos, prover ou viabilizar treinamentos aos times de projetos, assim como de estruturar ferramentas organizacionais de controle e visibilidade de projetos. Esta ligação facilita a utilização padronizada dos formatos utilizados globalmente.

Enquanto é predominante a estrutura funcional da organização - recentemente com algumas alterações que a tornaram uma estrutura matricial fraca -, a área auxilia as equipes de projeto, através de sua representação junto à administração. Além de liderar a implantação das ferramentas globais, o PSO local tem a atribuição de adaptá-las para satisfazer os requisitos específicos, centralizando e difundindo as melhores práticas coletadas.

O Centro Tecnológico de Piracicaba conta hoje com um efetivo de cerca de 60 engenheiros, 20 técnicos e 14 pessoas da área de suporte, que está distribuído em três 
divisões: Energy \& Chassis, Electronics \& Systems e Thermal \& Interior, sendo a primeira responsável pelo desenvolvimento do sistema de gerenciamento de motores, escopo desta pesquisa.

A unidade tem atualmente cerca de 35 projetos ativos de desenvolvimento de produtos e processos, além de 25 projetos avançados e diversas oportunidades de negócio que vêm sendo desenvolvidas pela mesma equipe que hoje atua nos desenvolvimentos correntes, buscando garantir sua fatia de mercado nos próximos anos.

Todos os projetos e oportunidades citados anteriormente estão distribuídos entre a carteira de produtos desenvolvidos pela unidade, que são: sistema de gerenciamento do motor e componentes de motor ligados a este sistema.

A diferença de conceitos entre as nomenclaturas utilizadas na empresa é representada internamente na empresa como:

- Projetos Ativos: projetos já "vendidos" a alguma montadora e serão entregues dentro de prazo, custo e qualidade previamente definidos;

- Projetos Avançados: projetos ainda não vendidos a alguma montadora, porém aprovado internamente para desenvolvimento avançado - incluindo aprovação de gastos de recursos para o desenvolvimento -, alinhado às estratégias de negócios da empresa para posterior oferecimento ao mercado;

- Oportunidades: oportunidades de negócio identificadas pela equipe de Vendas ou Engenharia da empresa a partir de uma prospecção do mercado, para que sejam feitos estudos de viabilidade antes de se iniciar gastos de recursos para o desenvolvimento. Uma vez aprovada a alocação de recursos, uma oportunidade pode virar um projeto ativo ou um projeto avançado, de acordo com os critérios citados nos itens anteriores.

Estes conceitos estão muito bem difundidos hoje dentro da unidade, depois de um intenso trabalho de treinamento e envolvimento dos funcionários das atividades, na gestão do portfólio da empresa e até na tomada de decisões. Os esforços trouxeram grande comprometimento dos funcionários na obtenção das metas e objetivos da unidade, de uma maneira geral. 


\subsection{A sistematização do PDP na empresa}

\subsubsection{O Modelo de PDP da empresa}

A Erro! A origem da referência não foi encontrada. traz uma visão geral do modelo do processo de desenvolvimento de produtos adotado pela empresa. Ela padronizou "portões" (Gates) para as fases do desenvolvimento do produto, de modo que avaliações fossem feitas durante o desenvolvimento, para dar direcionamento estratégico aos projetos, a partir da situação apresentada naquele momento. Estes direcionamentos podem ser: parar, continuar ou refazer e reapresentar, de acordo com os resultados parciais apresentados.

Existem dois tipos de portões: os técnicos, denominados "revisões de desenho" (design reviews) representados pelos losangos na Figura 16, e portões gerenciais, chamados "revisões de projetos" (project reviews) e representados na mesma figura pelos círculos, que têm a função de verificar a situação atual de determinado desenvolvimento contra o plano definido no início do mesmo, incluindo escopo, prazos, requisitos de qualidade, custos, time de projeto, etc.

Observa-se que o início do desenvolvimento se dá a partir da escolha de um projeto frente ao portfólio de produtos disponíveis. Ainda, a comunicação com o cliente acontece durante todas as fases do PDP, garantindo a participação e o acompanhamento constantes do mesmo quanto à situação do projeto.

O modelo enfatiza a fase de planejamento e início do desenho. Pela representação no modelo, a empresa propõe que esta fase de planejamento e definição do conceito sejam as fases mais longas do desenvolvimento, sugerindo que desta forma as fases seguintes tenham duração mais curta, uma vez que o planejamento considerou as variáveis necessárias e os riscos potenciais para evitar atrasos no decorrer do desenvolvimento.

Como sugerido pelas boas práticas das montadoras orientais, é preciso desprender mais tempo e recurso durante as fases de planejamento e definição do desenvolvimento para que não seja necessário desprender maior número de recursos e desperdiçar dinheiro com retrabalho em problemas identificados tardiamente pela equipe de desenvolvimento. Quanto mais tarde o problema é identificado, mais cara é a sua solução. Essa máxima já está comprovada em diversas teorias disponíveis na literatura, como citado em Wheelwright e Clark (1992), Rosenau Jr. (2000) e Rozenfeld et al. (2006). 
O documento PDP01 Source Document facilita a compreensão das atividades sugeridas pelo modelo, uma vez que as descreve detalhadamente e faz referência ao capítulo do APQP no qual o cliente exige estas atividades e ao procedimento que descreve como a empresa deve atender a este requisito, para referência interna na empresa. Este documento passou a ser muito utilizado pela equipe local de desenvolvimento - em especial pelos gerentes de projetos - pois referencia todas as correlações e exigências para cada atividade dentro do modelo de PDP da empresa.

Exemplo de descritivo deste documento está representado na Tabela 1. Nele pode ser observado o nível de detalhamento da respectiva atividade, sempre buscando facilitar o entendimento - e por conseqüência, a sua utilização - e a padronização mundial do modelo e das suas atividades. A primeira coluna, intitulada WBS, representa a hierarquia das atividades dentro do modelo. Como exemplo, PL-PM-020-010-E significa:

- PL: fase de lançamento do projeto (Project Launch);

- PM: responsabilidade do gerente de projetos (Project Manager);

- 020: segunda atividade da etapa de PL;

- 010: primeira sub-atividade da atividade 020;

- E: atividade executada somente para divisão Energy da empresa.

Tabela 1 - Exemplo de detalhamento de atividade do modelo de PDP da empresa PL-PM-020 PLANO DE PROJETO INICIAL

Isto é um resumo do documento formal que será utilizado para guir o projeto. Os usos primários do Plano de Projeto são para documentar as suposições e decisões do planejamento e facilitar a comunicação entre os envolvidos no projeto.

\begin{tabular}{|c|c|c|c|c|c|c|}
\hline \multicolumn{7}{|c|}{ Tabela de Entregas da Atividade } \\
\hline WBS & Entregas da Atividade & APQP & $\begin{array}{c}\text { Processo / Procedimento } \\
\text { Corporativo }\end{array}$ & $\begin{array}{l}\text { Procedimento } \\
\text { Divisional }\end{array}$ & $\begin{array}{l}\text { Procedimento } \\
\text { do Site }\end{array}$ & $\begin{array}{l}\text { Dono do } \\
\text { Item }\end{array}$ \\
\hline PL-PM-020-010 & $\begin{array}{l}\text { Cronograma inicial do } \\
\text { projeto, incluindo os } \\
\text { marcos-chave }\end{array}$ & $\begin{array}{c}\text { Pág. 5- } \\
\text { Plano de } \\
\text { Cronogra } \\
\text { ma da } \\
\text { Qualidade } \\
\text { do } \\
\text { Produto }\end{array}$ & $\mathbf{n} / \mathbf{a}$ & $\underline{818}$ & $\mathbf{n} / \mathbf{a}$ & $\mathrm{n} / \mathbf{a}$ \\
\hline PL-PM-020-020 & $\begin{array}{c}\text { Registros iniciais do } \\
\text { projeto }\end{array}$ & & $\mathbf{n} / \mathbf{a}$ & E236, $271 \underline{277}$ & $\mathbf{n} / \mathbf{a}$ & $\mathbf{n} / \mathbf{a}$ \\
\hline PL-PM-020-025-E & $\begin{array}{l}\text { Plano de recursos } \\
\text { inicial }\end{array}$ & & $\mathbf{n} / \mathbf{a}$ & $\underline{271}$ & $\mathbf{n} / \mathbf{a}$ & $\mathbf{n} / \mathbf{a}$ \\
\hline PL-PM-020-030 & Riscos iniciais do prjeto & & $n / a$ & 271259 & $n / a$ & $n / \mathbf{a}$ \\
\hline PL-PM-020-040 & $\begin{array}{c}\text { Ditribuição inicial da } \\
\text { informação aos } \\
\text { envolvidos }\end{array}$ & & $\mathbf{n} / \mathbf{a}$ & & $n / a$ & $n / a$ \\
\hline
\end{tabular}

Fonte - DELPHI (2001) 
O modelo também sugere que os desenvolvimentos sejam classificados de acordo com o nível de complexidade de produto ou processo de fabricação. As categorias são mundialmente definidas por $\mathrm{A}, \mathrm{B}, \mathrm{C}$ e $\mathrm{D}$, na qual A representa um projeto extremamente estratégico e de grande complexidade para a organização, como detalhado no Quadro 8. Desta forma, todos os projetos de uma determinada categoria têm as mesmas exigências, atividades e os mesmos passos a serem seguidos, em esfera mundial na organização.

\begin{tabular}{|c|c|l|}
\hline Categoria & Nomenclatura & \multicolumn{1}{|c|}{ Detalhamento } \\
\hline A & Projetos Estratégicos & $\begin{array}{l}\text { Iniciativa com grande modificação de produto e/ou processo de manufatura } \\
\text { que impacta diretamente a entrega de novos produtos em programas de alta } \\
\text { visibilidade (estratégicos) de clientes estratégicos. Ex. Introdução de nova } \\
\text { tecnologia estratégica; novo cliente; mudança para aumento de capacidade } \\
\text { ou de volume. Tradicionalmente representa uma pequena porcentagem } \\
\text { entre os projetos da Delphi E\&C. }\end{array}$ \\
\hline B & $\begin{array}{l}\text { Projetos de implementação de novos produos ou mudança nos processos } \\
\text { de fabricação para aplicações conhecidas de clientes conhecidos. Ex. } \\
\text { aplicação de tecnologia conhecida (nova tecnologia não estratégica); } \\
\text { atualização de um sistema ou componente; aumento de volume ou novo } \\
\text { volume. Tradicionalmente representam a maior parte dos projetos da Delphi } \\
\text { E\&C. }\end{array}$ \\
\hline C & $\begin{array}{c}\text { Projetos de Melhoria } \\
\text { Contínua }\end{array}$ & $\begin{array}{l}\text { Projetos que requerem apenas pequenas modificações em produtos ou } \\
\text { processos de fabricação existentes para clientes novos ou para aplicações } \\
\text { similares a clientes já existentes. Tradicionalmente requerem um pequeno } \\
\text { número de recursos e um pequeno tempo para implementação. Ex. } \\
\text { mudança de um conector ou etiqueta; localização de componentes. }\end{array}$ \\
\hline D & Projetos Internos & Sem impacto no cliente externo. \\
\hline
\end{tabular}

Quadro 8 - Classificação dos Projetos da Empresa de acordo com a Complexidade Fonte - DELPHI (2001)

Algumas críticas podem ser feitas a estas classificações, que não foram adaptadas à realidade brasileira. Pode-se notar pelos resultados coletados dos projetos que existe uma dificuldade da equipe local em definir qual classificação pode ser utilizada para os projetos brasileiros. Em dois dos casos, a classificação foi alterada durante o desenvolvimento dos projetos.

Ainda, a nomenclatura C - Projetos de Melhoria Contínua - poderia ser mais apropriadamente chamada de Projetos de Melhoria Incremental, seguindo as definições pesquisadas durante a elaboração deste trabalho.

Finalmente, observa-se que o modelo sugere que atividades de melhoria contínua aconteçam formalmente a partir do lançamento do novo produto ou processo. Para o foco desta pesquisa, as atividades identificadas nos projetos não representam apenas atividades do processo de melhoria contínua, mas também aquelas que pertencem ao PDP da empresa 
e podem contribuir para que a melhoria contínua deste processo aconteça, e estão descritas no decorrer deste trabalho.

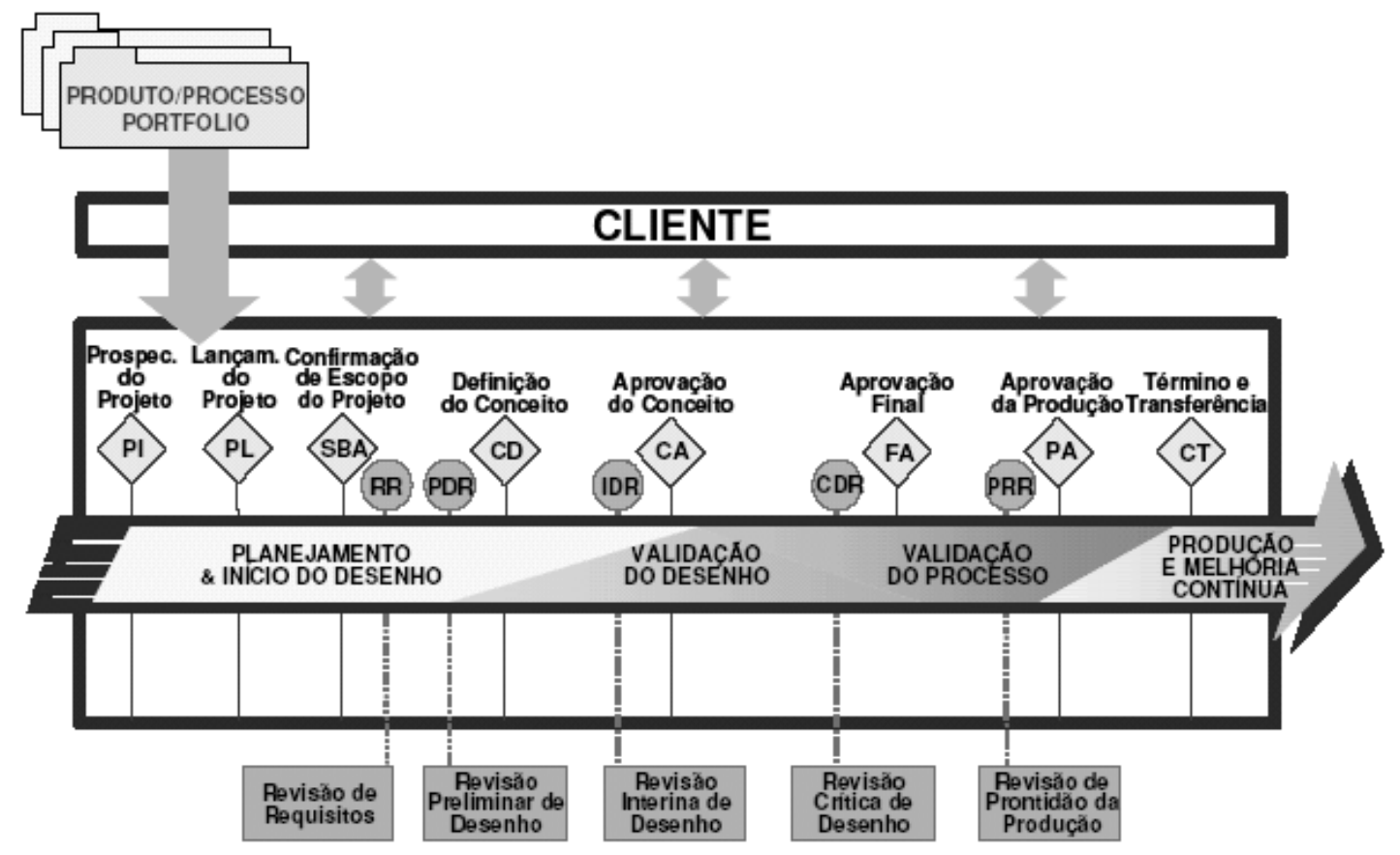

Figura 16 - Modelo de referência para o PDP na Delphi

Fonte - DELPHI (2001)

\subsubsection{Os Projetos de Desenvolvimentos de Produtos}

Os projetos analisados nesta pesquisa são parte do portfólio de projetos do Centro Tecnológico da Delphi de Piracicaba, sendo projetos concluídos pertencente às famílias de componentes do sistema de gerenciamento de motores, principal produto desenvolvido nesta unidade e estão internamente representados e monitorados na empresa pelo gráfico da Figura 17. O gráfico foi uma sugestão de melhoria feita a partir da literatura de desenvolvimento de produtos por um funcionário desta área da empresa, pois não havia uma gestão visual do portfólio de projetos da unidade. Posteriormente a ferramenta também foi utilizada para visualizar os projetos avançados e as demais oportunidades de negócios para a unidade. 


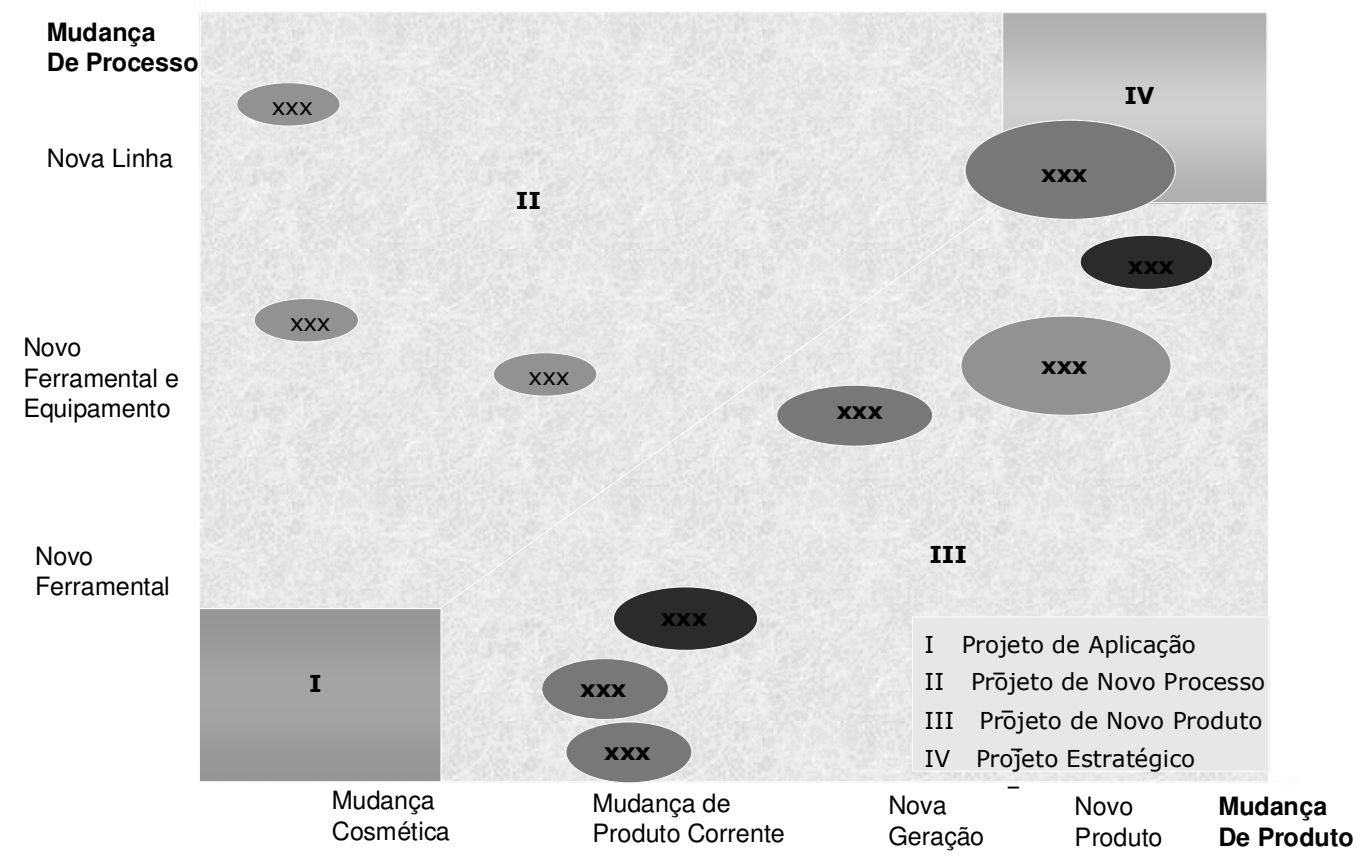

Figura 17 - Gráfico de controle do portfólio de projetos ativos da unidade

Por questões de confidencialidade das informações sobre as linhas de produto e dos componentes selecionados não serão citados, sendo definidos como linhas de produtos A, B e C.

Ainda, os projetos serão chamados de projeto 1 e 2 para cada linha de produto, representando respectivamente pares de projetos para cada linha de produto como representado na Figura 12, onde o projeto 1 de cada linha representa os projetos pertencentes ao primeiro grupo e o projeto 2 pertencentes ao segundo, de modo que os projetos 1 sempre serão os executados entre 1999 e 2002 e os projetos 2 os executados entre 2002 e 2006, como já descrito no capítulo anterior deste trabalho.

Os projetos selecionados têm semelhante complexidade entre os pares. A principal diferença encontrada em cada par refere-se ao nível de responsabilidade nas atividades que a unidade local possuiu em cada um deles e o tempo em que eles foram executados.

Para os três pares de projetos, em cada linha de produto têm-se nos primeiros projetos (projetos 1) as responsabilidades maiores pelo desenvolvimento (gerenciamento do projeto, desenvolvimento do produto e do processo novo) centrada na matriz (EUA) tendo o Brasil como suporte. Da mesma forma, para os últimos projetos analisados (projetos 2) 
para cada linha de produto têm-se as mesmas principais responsabilidades centradas na filial (Brasil), tendo a matriz (EUA) como suporte aos desenvolvimentos gerenciados pela equipe brasileira.

\subsubsection{Histórico da Implementação do Modelo de PDP na Empresa}

O modelo de processo de desenvolvimento de produtos adotado pela empresa foi inicialmente publicado na matriz da empresa (EUA) em 1995, pouco depois da publicação do manual APQP, pelas montadoras. A proposta do modelo era definir um padrão para que todo e qualquer desenvolvimento de novo produto na empresa estivesse em conformidade com os requisitos das montadoras. Em 1997 o modelo sofre sua primeira revisão, ainda centrado na matriz, e em 1998 a segunda.

Mesmo após ter sofrido duas revisões, o modelo de PDP adotado era complexo. Havia uma lista com mais de 700 atividades a serem cumpridas - ou ao menos analisadas para qualquer desenvolvimento, independente de sua complexidade.

A mais recente revisão do modelo ocorreu em 2001, quando foram "enxugadas" todas as micro-atividades e também aquelas consideradas de baixo valor agregado nos desenvolvimentos, uma vez que a revisão de 2001 apresentava 105 atividades obrigatórias, menos que $15 \%$ do número de atividades encontradas na versão anterior. Esta ação foi executada pela matriz e nesta época a nova revisão do modelo - reconhecida internamente por PDP01 - já estava difundida a diversas filiais da empresa, inclusive ao Brasil, uma vez que as equipes multifuncionais das filiais já participavam dos desenvolvimentos de produtos, ainda que com a responsabilidade de suporte a matriz.

Mais recentemente, em 2006, ainda que sem a revisão formal do modelo, 13 subtarefas foram adicionadas ao documento chamado PDP01 Source Document para atender necessidades identificadas durante a utilização da última revisão do modelo. Alguns exemplos são:

- Análise dos requisitos de qualidade do cliente;

- Preenchimento da matriz de verificação de características especiais;

- Análise de características especiais na manufatura e;

- Plano de controle de produção. 
Com base nos documentos observados - neste caso, um boletim emitido pela empresa do início de 2006 -, sabe-se que a empresa planeja nova revisão do modelo de PDP para o ano de 2007. As alterações previstas não foram divulgadas, mas esta iniciativa demonstra preocupação com a melhoria contínua do modelo, de maneira que acompanhe o dinamismo das atividades e práticas da empresa, no que se refere ao desenvolvimento de novos produtos, respondendo às necessidades do mercado.

A difusão do modelo de PDP da empresa foi fomentada pelo PSO (Project Support Office ) - descrito anteriormente - grupo de suporte à engenharia de desenvolvimento de produtos instituído mundialmente com o objetivo de garantir que as melhores práticas nos desenvolvimentos estariam sendo absorvidas por todas as unidades da empresa, além de garantir também que as atividades seriam padronizadas e documentadas como representadas no modelo.

Este grupo se expandiu rapidamente por toda a organização e hoje existem os chamados gerentes de programas dedicados exclusivamente para garantia da conformidade das atividades dos desenvolvimentos, no que se refere a prazo, custo e qualidade esperadas pelo cliente, em conformidade com o manual APQP.

As alterações do modelo de PDP da empresa são coordenadas e implementadas pelo PSO local, bem como os treinamentos necessários a toda a equipe de desenvolvimento, para que haja compreensão e aderência às alterações por parte de toda a equipe, facilitando o trabalho de todos.

O PSO local possui hoje supervisão independente reportando-se diretamente ao diretor de engenharia da unidade. Vale destacar que esta nova estrutura, embora tenha ganhado notoriedade e responsabilidade nos últimos anos continua com força apenas dentro do departamento de engenharia, local onde está localizado na hierarquia da empresa.

A literatura sugere que o escritório de projetos (representado neste caso pelo PSO local) deve reportar-se diretamente ao diretor da empresa, tendo autonomia frente aos demais departamentos envolvidos durante os desenvolvimentos.

A empresa, e por conseqüência a unidade estudada, conta hoje com uma tendência à estrutura matricial fraca, pois embora existam gerentes de projetos e programas dedicados, a estrutura departamental ainda define a hierarquia formal na empresa. As modificações na estrutura hierárquica da unidade, que trouxeram maior autonomia e responsabilidade para o 
PSO local, sinalizam uma possibilidade de adoção de uma estrutura matricial forte na unidade para os próximos anos. Esta tendência foi confirmada pelo diretor da engenharia, durante a realização das entrevistas.

\subsubsection{Histórico da Implementação do Modelo de PDP na Unidade}

\subsubsection{Implementação do PDP}

Como citado anteriormente, o modelo de PDP na empresa foi inicialmente utilizado pela matriz americana, quando as atividades de desenvolvimento de produtos começaram a ser realizadas no Brasil. Até então, os times localizados na unidade brasileira conheciam o modelo de referência, porém os conhecimentos estavam restritos às atividades de aplicação de determinado produto no mercado local, atividade de engenharia de aplicações, como denominado pela empresa. Nesta função a equipe local era responsável por acompanhar as atividades de desenvolvimento de produtos que aconteciam na matriz americana (muitas vezes viajando até a matriz) e posteriormente aplicavam estes novos produtos à realidade do mercado automotivo brasileiro.

Não havia liderança formal local nas atividades de desenvolvimento, pois o grupo era conduzido por líderes da matriz americana. Esta informação prévia de caracterização da unidade foi posteriormente aferida pela aplicação das entrevistas e notou-se que unanimamente os respondentes afirmaram que as responsabilidades e o conhecimento do modelo e das atividades de PDP da unidade aumentaram significativamente nos últimos anos, fazendo com que esta unidade ganhasse muito mais autonomia e, por consequiência, responsabilidade sobre todas as atividades do PDP, embora ainda tendo que obter aprovações finais da matriz para atividades ou decisões-chave do PDP, como é o caso, por exemplo, da atividade de congelamento do projeto.

A primeira reestruturação da área de desenvolvimento de produtos da unidade aconteceu em 2001, quando - por esforços contínuos da alta gerência para com a matriz americana - foram nomeados os primeiros engenheiros de produtos e gerentes de projetos locais. Esta nova responsabilidade local demandou novos treinamentos, nova reestruturação de pessoal, de equipamentos, ferramentas para armazenamento e controle das informações, novos laboratórios, novos técnicos para suporte às atividades locais, etc. 
A partir de 2002 a unidade formalizou a estrutura de gerenciamento de projetos através da nomeação de um supervisor. Este foi um grande passo para a unidade na busca por uma estrutura matricial forte. A nova estruturação contribuiu para o fortalecimento das atividades de desenvolvimento de produtos na unidade, de modo que engenheiros de produtos e gerentes de projetos e programas locais - nomeados em 2001 - passaram a ter uma referência local para obterem treinamentos, orientações, ferramentas, além de fonte para capturarem melhores práticas e lições aprendidas pelos desenvolvimentos anteriores.

Este novo grupo, agora com supervisão independente da estrutura departamentalizada, passou a criar sistemáticas padronizadas e práticas para garantir a conformidade das atividades com os padrões mundiais, tendo como objetivo principal garantir a qualidade, o prazo e o preço esperado pelo cliente.

É importante destacar que também nesta época iniciaram-se os treinamentos a todos os engenheiros de produto da unidade nos centros de excelência da empresa (EUA ou México) para que pudessem executar suas funções com maior autonomia e garantir que as atividades realizadas na unidade estivessem dentro dos padrões sugeridos mundialmente.

A reestruturação do grupo de engenharia de manufatura - ou processos de fabricação - da unidade também contribuiu para a formalização e sistematização das atividades do PDP localmente. Até 2003 os engenheiros de manufatura eram responsáveis pelas fases de desenvolvimento do processo de fabricação do novo produto e do controle e manutenção do funcionamento deste processo (máquinas, ferramentas e demais componentes da linha) após o início de produção deste novo produto.

A mudança representou uma ruptura deste grande grupo em dois grupos menores: um grupo ficou dedicado às fases de desenvolvimento do novo processo de fabricação e o outro grupo ficou dedicado ao controle e manutenção deste processo após o início de produção do novo produto, ambos com supervisão independente. Esta modificação permitiu que os engenheiros de desenvolvimento do novo processo de fabricação tivessem dedicação total às atividades do PDP. A iniciativa deveu-se a necessidade de se ter o desenvolvimento das máquinas e equipamentos do processo de fabricação juntamente com o produto que posteriormente seria produzido. Até então, o produto chegava à fábrica e somente mais tarde seria verificado se o processo de fabricação estava apto a produzi-lo, uma vez que a interface entre as áreas era muito pequena, devido às priorizações das atividades. As 
correções demandadas pela identificação tardia de divergências do produto com o processo para sua fabricação traziam altos custos adicionais à empresa, visto que mais fatores estavam envolvidos nas correções, muitas vezes até clientes e fornecedores.

Existem hoje pessoas-chave das diversas áreas da equipe multifuncional de desenvolvimento com responsabilidades exclusivas aos novos desenvolvimentos, estando desvinculados das atividades fabris, como o exemplo dado nos parágrafos anteriores.

Ainda, o PSO local promoveu o boletim informativo mensal enviado à todas as pessoas da equipe multifuncional dos desenvolvimentos - estando ou não localizadas em Piracicaba -, além de uma Intranet que centraliza todas as documentações dos projetos ativos ou concluídos, de maneira padronizada. O acesso é controlado por usuário, considerando nível de responsabilidade individual dentro de cada projeto.

Até a conclusão desta pesquisa, uma base de conhecimento estava sendo formulada para que as equipes possam depositar e compartilhar o conhecimento adquirido com as demais pessoas da equipe, de outras equipes e até de outras unidades da empresa.

O PSO local também é responsável agora pelos eventos de abertura (kick-off meeting) e fechamento (celebram juntos e neste mesmo evento também capturam mais lições aprendidas).

\subsubsection{A difusão da visão por processo}

A partir das primeiras observações feitas pela pesquisadora foi possível depreender que o processo de sistematização do PDP na unidade está baseado na introdução de um modelo de estruturação das atividades, no qual as diversas áreas da empresa estão integradas, desempenhando suas tarefas, buscando um objetivo comum, ou seja, os produtos a serem ofertados ao mercado com qualidade, custo e prazo pré-definidos. Este modelo é conhecido e adotado pelas equipes dos desenvolvimentos existentes na unidade estudada, mas observou-se que alguns membros da equipe ainda têm dúvidas sobre as entradas e saídas de cada atividade deste processo.

A aplicação das entrevistas comprovou a primeira impressão de que nem toda a equipe está totalmente familiarizada com as atividades do PDP e como elas se relacionam, apesar de terem grande conhecimento das suas responsabilidades individualmente. Notouse que os funcionários estabelecidos na unidade estudada conheciam profundamente o modelo de PDP da empresa e suas atividades requeridas, enquanto que os demais 
funcionários da equipe multifuncional, não necessariamente estabelecidos nesta unidade, não possuíam uma visão clara do todo, ou seja, das entradas e saídas de cada processo de negócio dentro do modelo.

Contudo, existem evidências de esforços da unidade no sentido de esclarecer como são as interações entre os departamentos envolvidos no desenvolvimento de um novo produto. Exemplos desta tendência são:

- Difusão dos chamados Diagramas de Tartaruga, que são mapas representando cada processo, considerando suas entradas, as transformações existentes em cada processo e suas saídas; ainda, para cada entrada e cada saída existe uma referência ao departamento que envia ou recebe a informação, como representado no Anexo 1;

- Programa de treinamentos para toda a equipe multifuncional tanto sobre o modelo de PDP da empresa quanto nas atividades que este modelo requer;

- Auditoria pós-projeto, na qual toda a equipe multifuncional é convidada a contribuir com sugestões e lições aprendidas durante os desenvolvimentos.

Estes e outros esforços não citados aqui - vindos tanto da área de Qualidade quanto da Engenharia de Produtos e do $P S O$ - já vêm ocorrendo mais intensamente nos últimos três anos. A Figura 18 representa através de exemplos de atividades, o histórico da sistematização do PDP na unidade local. Embora sejam apenas exemplos, por ela é possível notar que o período que separa o primeiro do segundo grupo de projetos (2002 - 2003) representou um período em que mudanças significativas aconteceram. 


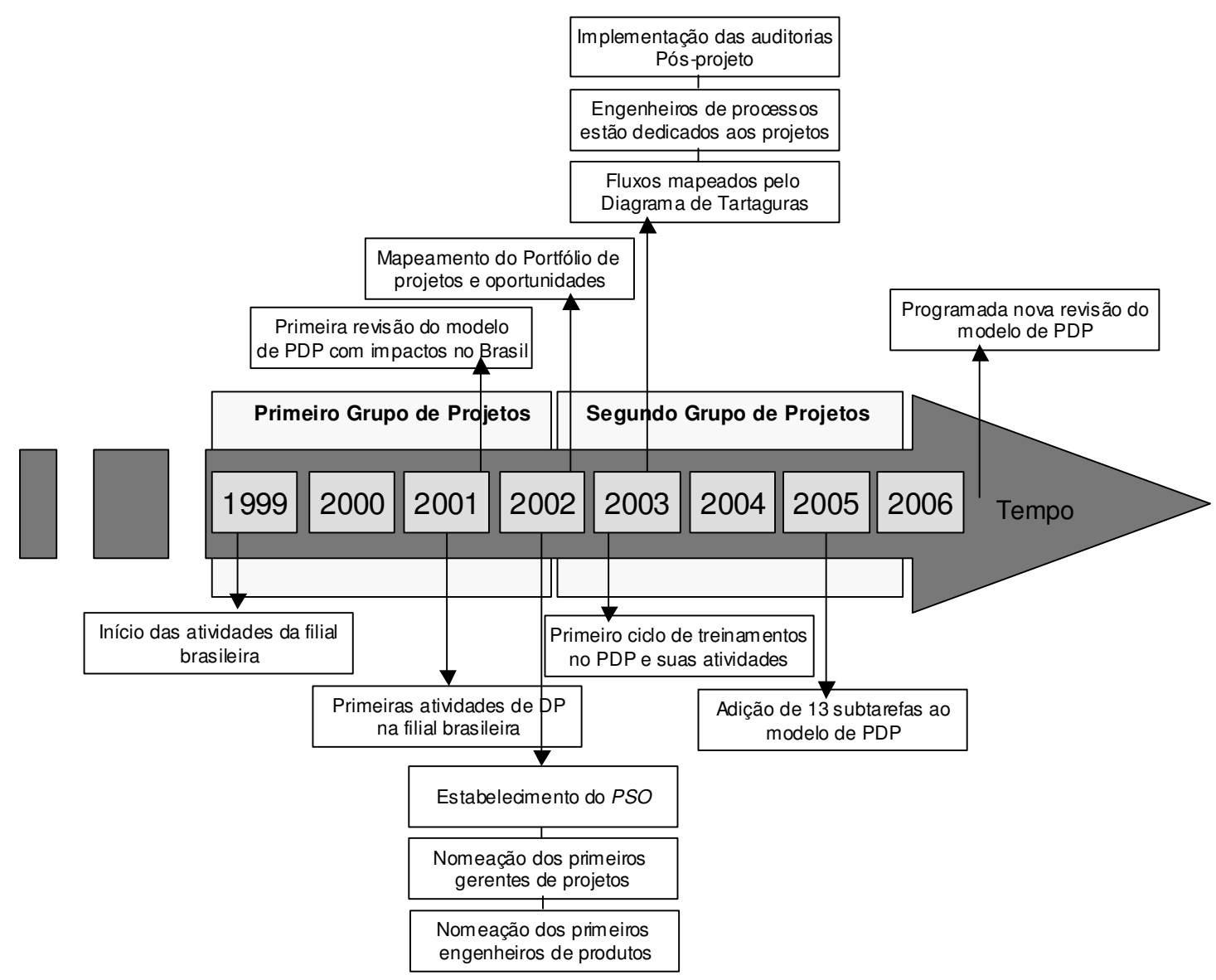

Figura 18 - Exemplos de mudanças para a sistematização do PDP na unidade

Para análise do caso as atividades identificadas estão divididas em duas categorias atividade de PDP e atividade de PMC -, como explanado anteriormente. Foram consideradas como "não existem" as atividades que constam na revisão da literatura como atividades que contribuem para a melhoria contínua do PDP, mas que não foram identificadas no caso.

Observou-se também que as atividades propostas no modelo de PDP da empresa são seguidas em todos os projetos de desenvolvimento de produtos, validando a primeira premissa desta pesquisa de que o modelo de referência é sistematizado. Nos primeiros projetos, embora as atividades já fossem executadas, a liderança estava centralizada na matriz americana. 
Nos projetos mais recentes, a responsabilidade pela execução, controle e prestação de contas dos resultados destas atividades estava centralizada em pessoas da unidade local, foco deste trabalho.

\subsubsection{Treinamentos}

Com a estruturação do $P S O$ na unidade, foi definida uma cadência de treinamentos nas atividades do modelo de PDP adotado pela empresa. Inicialmente com foco nos gerentes de projetos e engenheiros de produto, a matriz de treinamentos da unidade ganhou prestígio nos últimos anos e hoje inclui funcionários todas as áreas funcionais envolvidas no processo de desenvolvimento de produtos.

A matriz de treinamentos apresenta a lista de competências esperadas para cada função de uma equipe multifuncional, o histórico de treinamentos de cada pessoa, e quais são os treinamentos que ainda faltam para serem oferecidos, bem como a cadência de reciclagem dos mesmos, como representada no Quadro 9. As siglas representam:

A - Presença do funcionário era requerida, porém ele não compareceu ao treinamento;

$\mathrm{R}$ - Presença do funcionário é requerida, porém ainda não foram oferecidas turmas para este treinamento desde que este funcionário assumiu a função;

3 - 2003, ou seja, ano em que o funcionário recebeu o treinamento, representando sempre o treinamento mais recente;

Alguns treinamentos são oferecidos internamente, por multiplicadores treinados, e outros são contratados serviços de terceiros, de acordo com a complexidade da competência a ser desenvolvida.

A matriz de treinamentos está passando por uma revisão desde o início de 2006 para que a visão de portfólio para as competências desenvolvidas seja melhorada.

Uma visão mais detalhada do mapeamento de treinamentos da Delphi pode ser encontrada em Palma, 2005. 


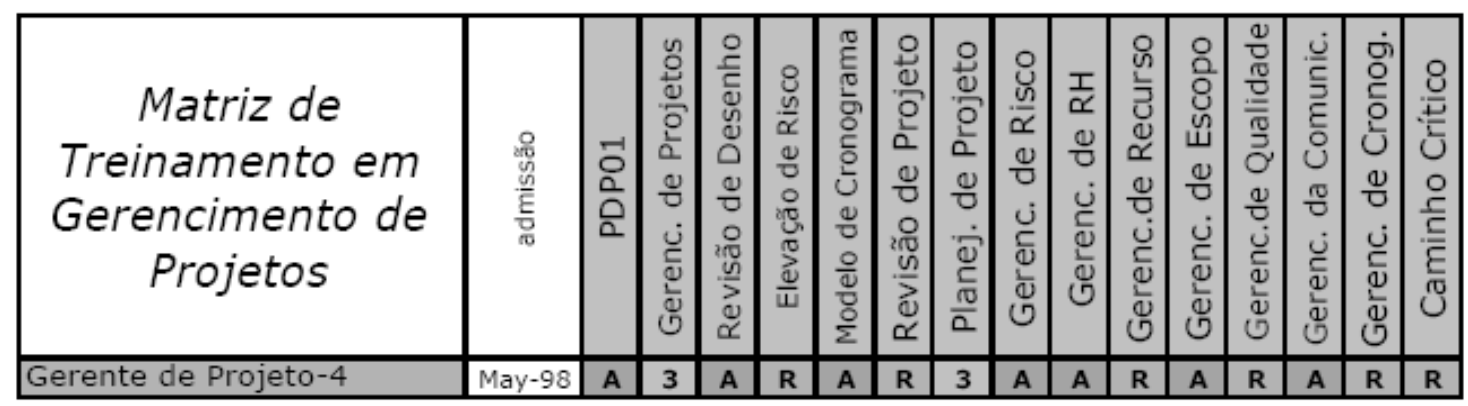

Quadro 9 - Matriz de treinamentos da unidade

Durante a implementação do modelo PDP da empresa na unidade estudada detalhou-se uma série de atividades de melhoria contínua, aplicadas para difusão de conhecimentos sobre o modelo, dentre elas: reestruturação para um formato projetizado de hierarquia, desenvolvimento da visão por processos, sistematização das competências requeridas $\mathrm{x}$ treinamentos oferecidos na unidade, e posteriormente, a divisão dos projetos de desenvolvimento de produtos de acordo com seu grau de complexidade e o manual para detalhamento de cada atividade requerida pelo modelo.

\subsection{Identificação das atividades que contribuem para a MC do PDP nos projetos}

A análise comparativa dos resultados dos projetos utilizados neste trabalho foi baseada nas observações feitas em campo, na análise documental de cada projeto (quando existente) e nas entrevistas aplicadas a pessoas-chave da empresa para cada projeto, como detalhado anteriormente.

Os resultados foram agrupados seguindo os grupos de projetos apresentados no item 3.5 do trabalho. O primeiro grupo compreende projetos realizados entre 1999 e 2002 e o segundo grupo aqueles realizados entre 2002 e 2006.

A escolha destes períodos é resultado do estudo da sistematização do modelo de PDP da empresa, isto é, considerando o contexto histórico da aplicação do PDP. São dois períodos bem distintos, tendo acontecido a partir de 2002 uma evolução da aplicação do modelo de PDP da empresa. 
Por conseguinte, espera-se um crescimento do nível de melhoria contínua do processo de desenvolvimento de produtos (PDP) - seja ela por atividades inerentes ao próprio PDP ou ao processo de melhoria contínua (PMC) que apóia os demais processos dentro de uma empresa.

Os dados de cada projeto estão resumidamente representados nos itens abaixo e a composição de cada gráfico pode ser encontrada nos apêndices, ao final deste trabalho.

\subsubsection{Atividades encontradas na Linha de Produto A}

Os desenvolvimentos da linha de produtos A representaram uma nova aplicação de uma tecnologia conhecida, ambos para a mesma montadora de veículos. Ambos representaram desenvolvimentos de um componente do sistema de gerenciamento do motor dos automóveis.

Projetos A.1 e A.2

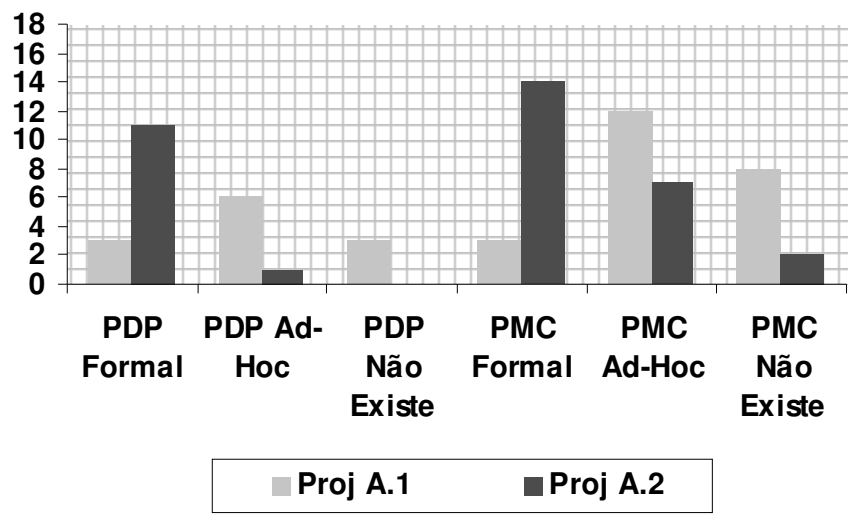

Quadro 10 - Atividades encontradas nos projetos da linha de produto A

Pelo Quadro 10 observa-se uma maior concentração de atividades formais no projeto A.2 da linha de produto A, tanto para as atividades de PDP quanto para as atividades de PMC. Ainda, para o projeto A.2 não foram encontradas atividades sugeridas pela literatura que não aconteceram durante o projeto, para o caso das atividades de PDP. Para o PMC ficou demonstrada uma significativa diminuição no número de atividades que não foram executadas durante o projeto, quanto comparado com o projeto A.1. 
Em percentuais, estes dados estão representados por:
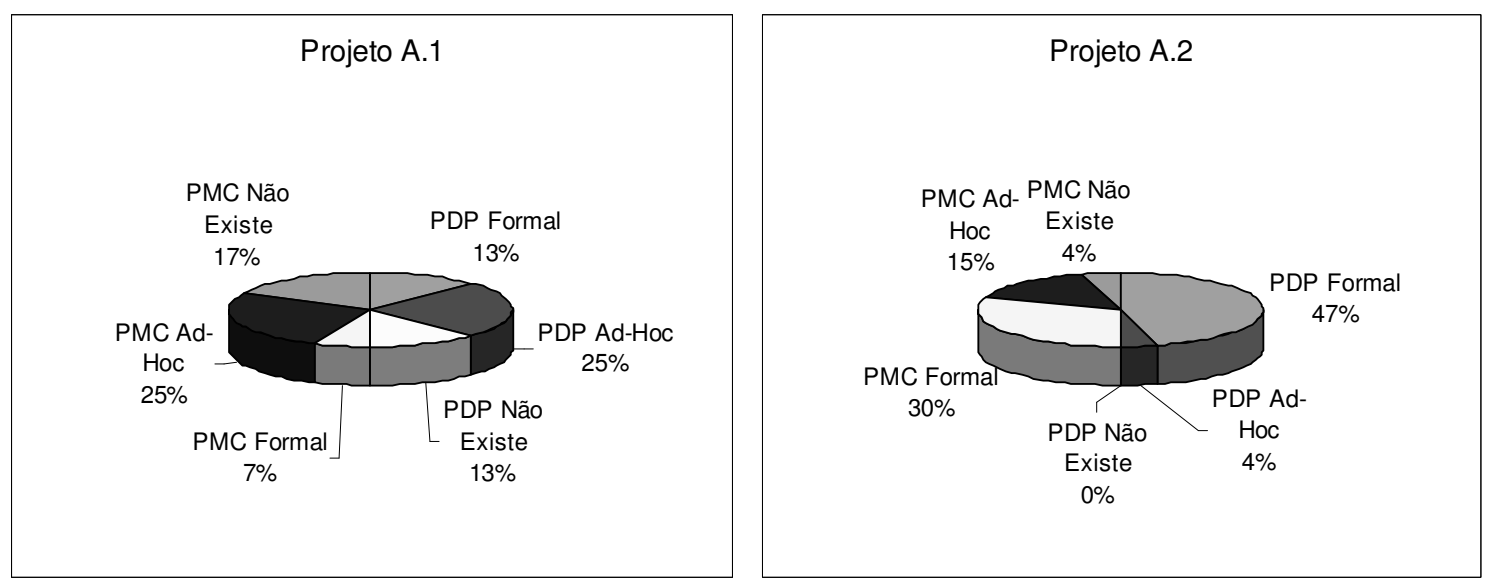

Quadro 11 - Percentual de atividades encontradas nos projetos da linha de produto A

\subsubsection{Atividades encontradas na Linha de Produto B}

Para o caso dos desenvolvimentos da linha de produtos B foi observado que a complexidade dos projetos foi relativamente maior que a da linha de produtos $\mathrm{A}$, embora também representada como uma nova aplicação de uma tecnologia existente. Isso demonstrou que a classificação da complexidade dos projetos sugerida pelo modelo da empresa pode não ser suficiente para representar todas as classificações que os desenvolvimentos demandam.

Da mesma forma que nos anteriores, os dois projetos representaram desenvolvimentos de um componente do sistema de gerenciamento do motor dos automóveis para uma mesma montadora.

Os dados estão representados no Quadro 12: 
Projetos B.1 e B.2

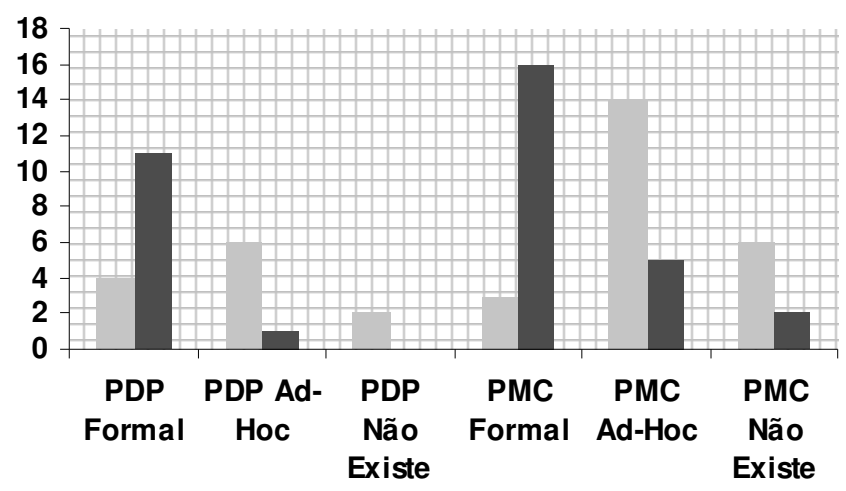

Proj B.1 $\quad$ Proj B.2

Quadro 12 - Atividades encontradas nos projetos da linha de produto B

As mesmas considerações da linha de produto A podem ser aplicadas a esta linha de produtos. Houve significativa diminuição das atividades de PMC que não foram executadas no projeto B.2, quando comparadas ao projeto B.1. Da mesma forma, todas as atividades que podem contribuir para a melhoria contínua do PDP da empresa sugeridas pela literatura (constantes no PDP) foram realizadas no projeto B.2, enquanto que no projeto B.1 verificou-se a ausência de algumas atividades sugeridas pela literatura. Com relação às atividades denominadas ad-hoc, observou-se significativa diminuição tanto para o caso das atividades de PDP quanto para as atividades de PMC.

Os dados estão percentualmente representados na seqüência:
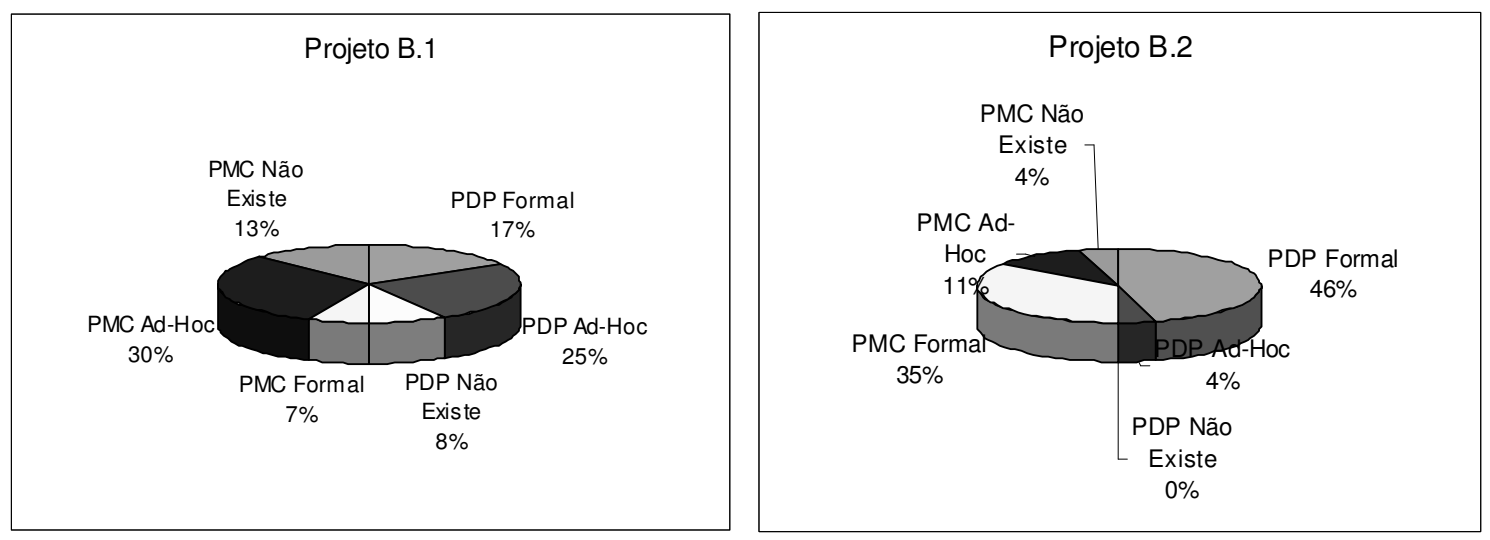

Quadro 13 - Percentual de atividades encontradas nos projetos da linha de produto B 


\subsubsection{Atividades encontradas na Linha de Produto C}

A terceira linha de produto analisada foi denominada linha de produto $\mathrm{C}$ e também representa um componente do sistema gerenciamento do motor do veículo. Para este caso, os projetos foram categorizados como $\mathrm{C}$ uma vez que representavam um aumento de volume de um produto já existente com pequenas modificações para aplicação em um novo veículo de uma mesma montadora. A distribuição das atividades destes projetos estão representadas no Quadro 14:

Projetos C.1 e C.2

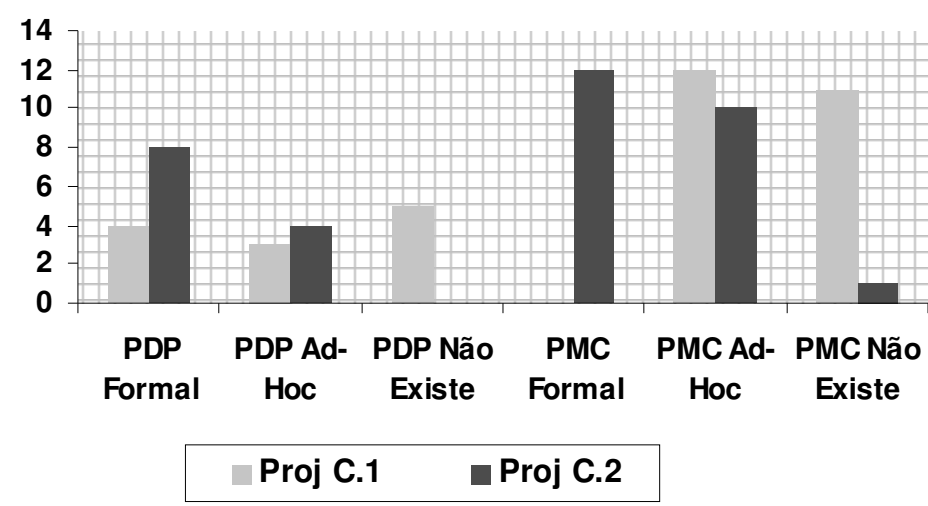

Quadro 14 - Atividades encontradas nos projetos da linha de produto C

As mesmas considerações feitas para as linhas de produto A e B são aplicáveis a esta linha de produto, o que demonstra uma tendência para todos os projetos, que será discutida posteriormente. Os percentuais são representados como seguem:
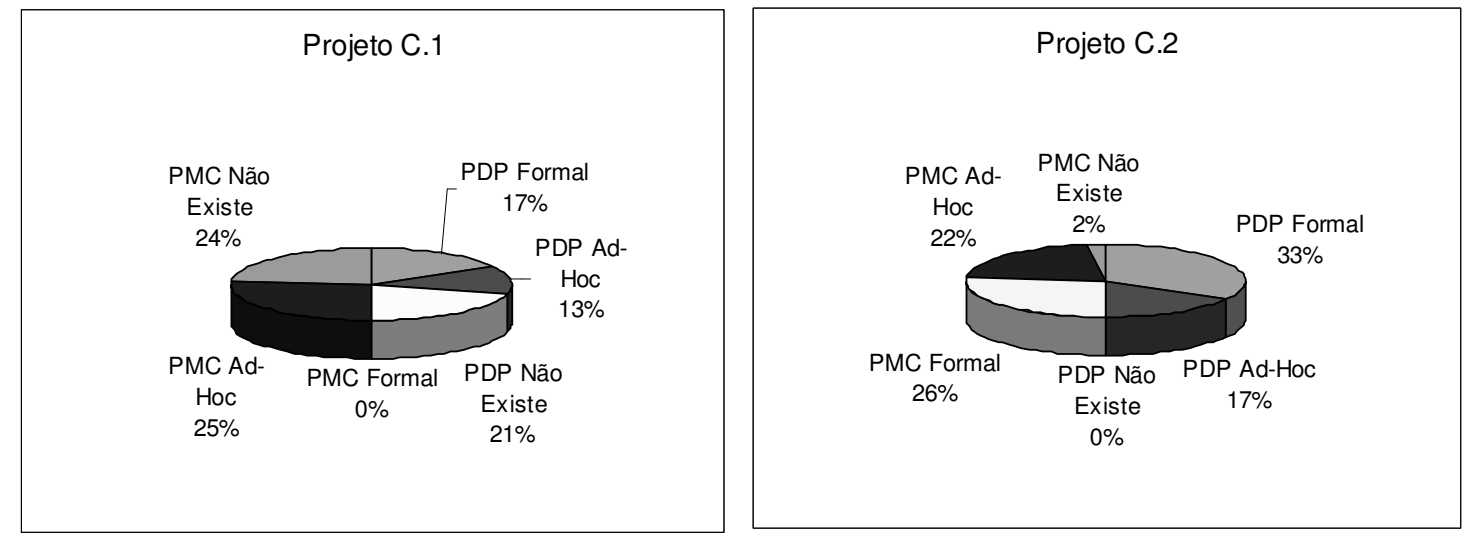

Quadro 15 - Percentual de atividades encontradas nos projetos da linha de produto C 
Desde a observação destes primeiros dados é possível visualizar um aumento na quantidade de atividades formais em todos os projetos e uma diminuição do número de atividades que não são executadas durante o andamento dos projetos - seguindo a lista compilada da literatura -, quando comparados o primeiro e o segundo grupo de projetos analisados.

A partir da coleta destes dados foi possível obter o percentual de atividades formais, $a d-h o c$ ou que não existem identificados em cada grupo de projetos separadamente, tendo como referência a lista das atividades que contribuem para a melhoria contínua do PDP nas empresas de autopeças sugeridas pela literatura disponível, já mencionada no início deste capítulo. Desta forma temos:

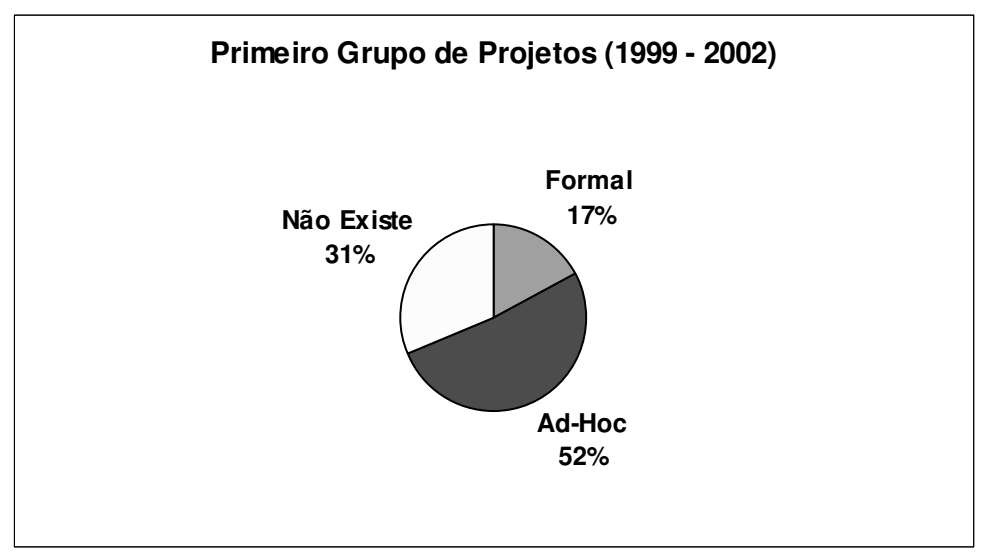

Quadro 16 - Cenário das atividades que contribuem para a MC do PDP do primeiro grupo de projetos

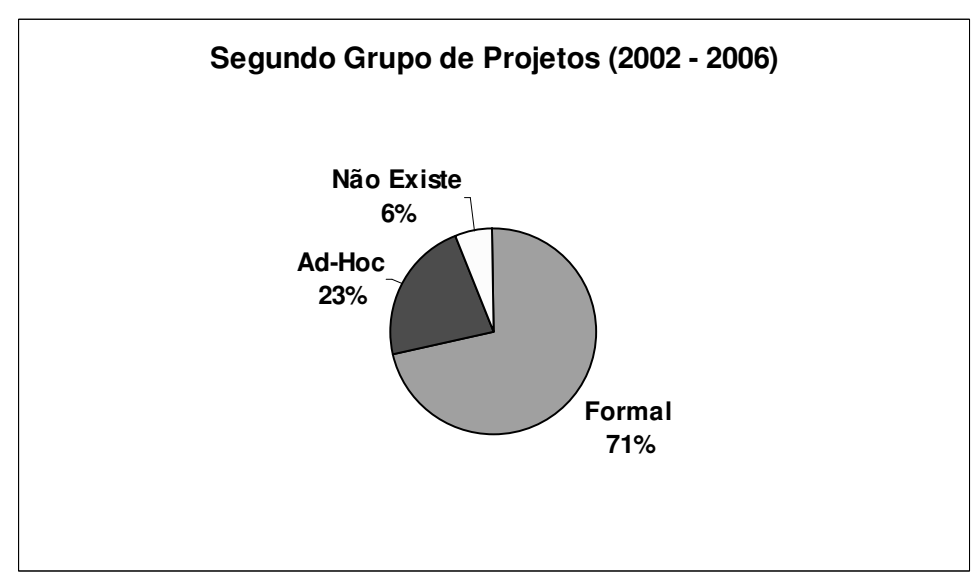

Quadro 17 - Cenário das atividades que contribuem para a MC do PDP do segundo grupo de projetos 
Para o primeiro grupo de projetos analisados nesta pesquisa (Quadro 16) observouse que um pequeno número de atividades que podem ser aplicadas para a melhoria contínua (MC) do PDP foi utilizado, uma vez que apenas $17 \%$ das atividades sugeridas pela literatura foi formalmente utilizado nos primeiros projetos executados pela unidade de negócios. Da mesma forma, $31 \%$ destas atividades não foram utilizadas na época e $52 \%$ aconteciam de maneira ad-hoc.

Em contrapartida, para o segundo grupo de projetos (Quadro 17) observa-se significativa mudança na aplicação das atividades que podem contribuir para a MC do PDP uma vez que para este grupo de projetos apenas $6 \%$ das atividades sugeridas pela literatura não tenham sido executadas durante a evolução dos projetos. Tem-se um aumento significativo no percentual de atividades realizadas formalmente, que de $17 \%$ do primeiro grupo de projetos passou a $75 \%$ no segundo. Houve também uma diminuição do percentual de atividades ad-hoc, de maneira que os $52 \%$ representados no primeiro grupo foram reduzidos a $19 \%$, no segundo grupo.

Comparando os resultados apresentados pelo número de atividades encontradas nos projetos temos um grande aumento nas atividades que acontecem de maneira formal, ao mesmo tempo em que houve também uma redução significativa nas atividades que aconteciam de maneira $a d-h o c$ ou ainda que não aconteciam nos primeiros projetos, como demonstrado no Quadro 18.

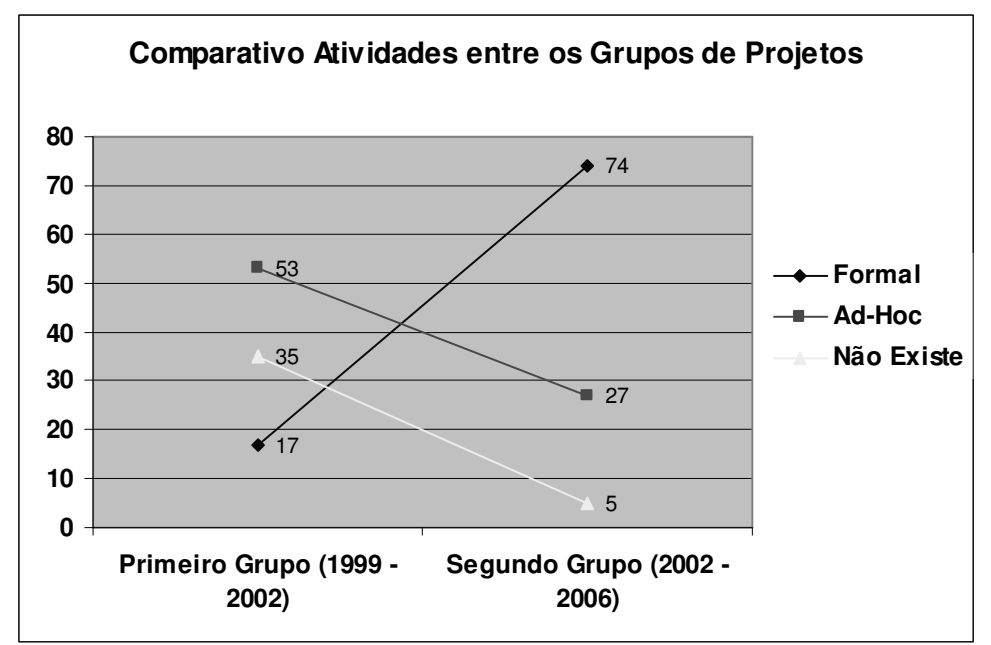

Quadro 18 - Número de atividades por tipo em cada grupo de projetos 
Os Quadro 19 e Quadro 20 representam mais detalhadamente este comparativo entre os dois grupos de projetos, separados por atividades de PDP e atividades de PMC:

Atividades do PDP: Comparativo entre projetos dos grupos 1 e 2.

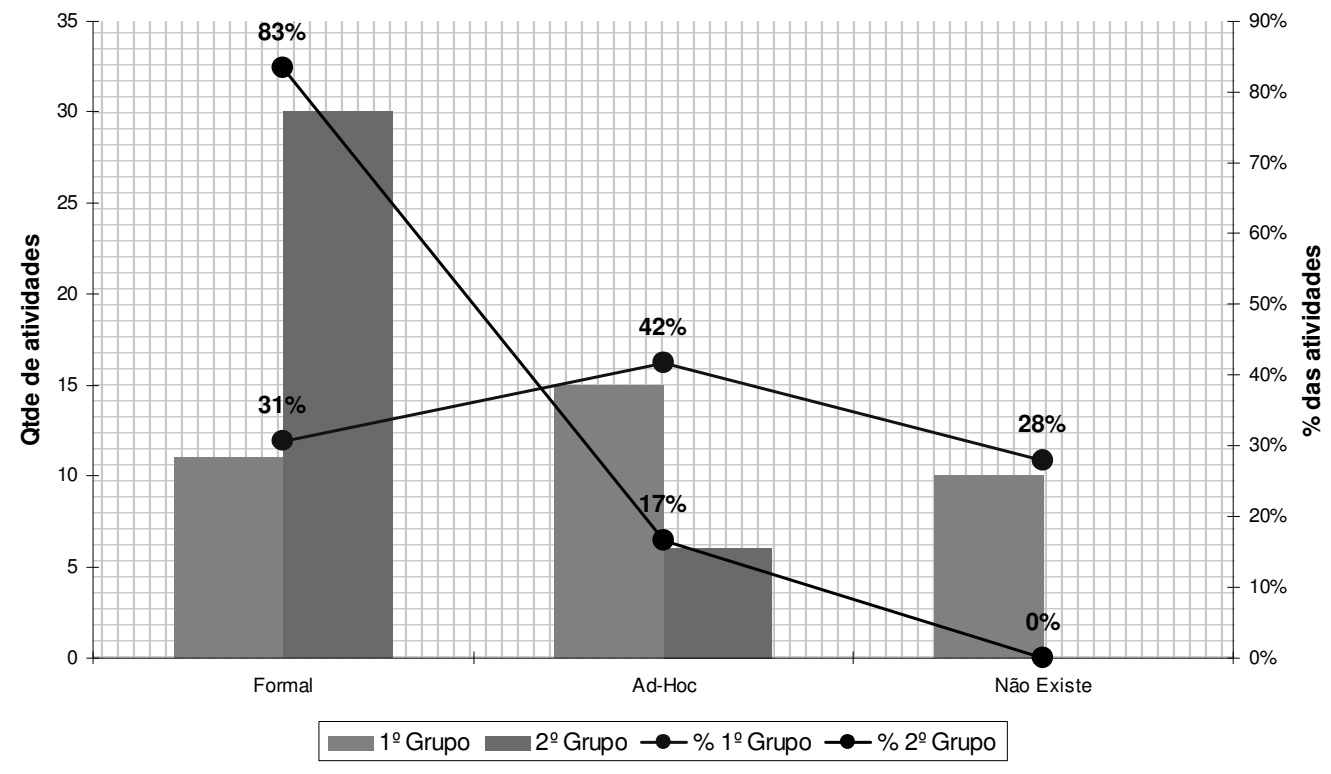

Quadro 19 - Atividades do PDP: Comparativo entre grupos 1 e 2

Atividades do PMC: Comparativo entre projetos dos grupos 1 e 2.

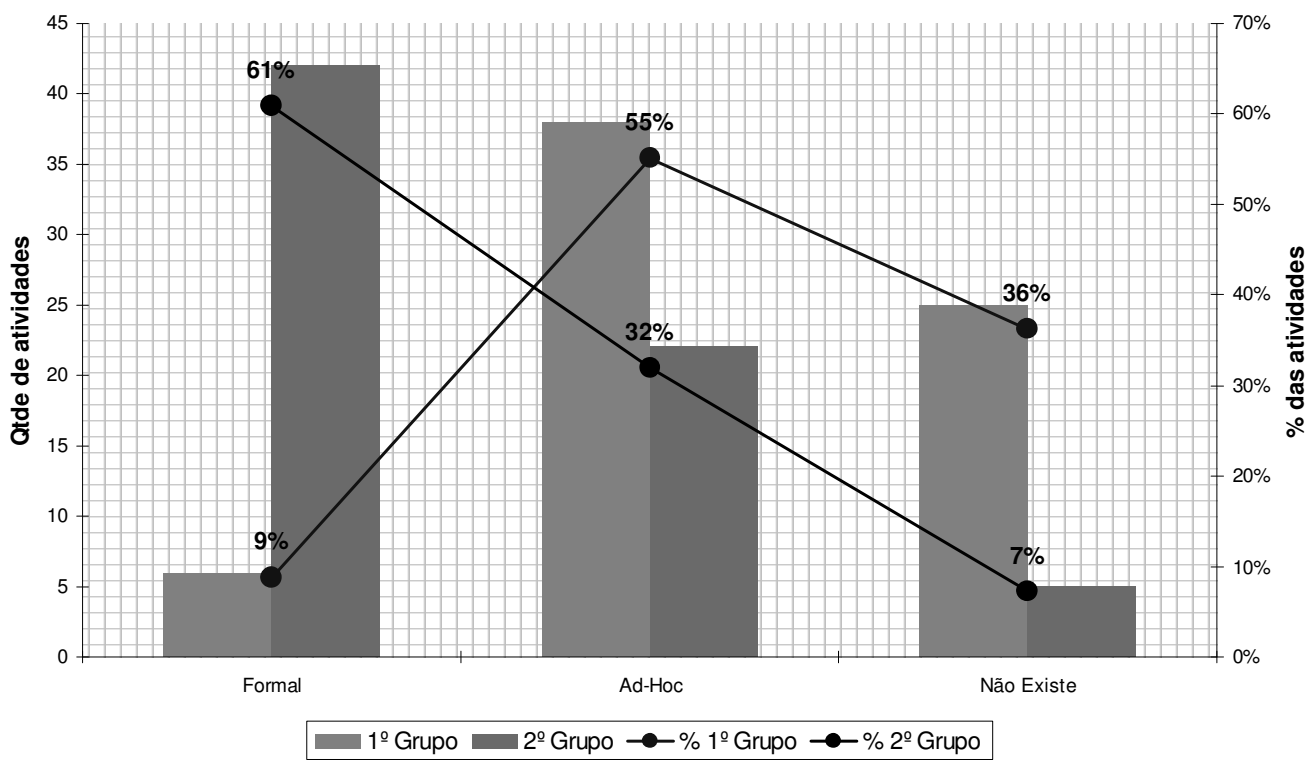

Quadro 20 - Atividades do PMC: Comparativo entre grupos 1 e 2 
Os dados apresentados sinalizam um significativo aumento no número de práticas de melhoria contínua aplicada ao PDP quando comparamos os primeiros desenvolvimentos da unidade (primeiro grupo) com os desenvolvimentos posteriores (segundo grupo), o que infere que esta unidade da empresa desenvolveu e aprimorou suas práticas buscando a sistematização do PDP.

Os Quadro 19 e Quadro 20 também apresentam dados ainda mais interessantes a respeito da evolução das atividades que contribuem para a melhoria contínua do PDP nos seis projetos estudados. Dentre eles, destacam-se:

1. O número de atividades do processo de melhoria contínua (PMC) que apóia o PDP não existentes no primeiro grupo de projetos é consideravelmente maior que o número das atividades do PDP que contribuem para a sua melhoria contínua, o que sinaliza que uma maior atenção às atividades do PDP já era dada desde os primeiros projetos;

2. O número de atividades formais do PMC aumentou do primeiro para o segundo grupo de projetos, porém ainda existe um grande número que acontece ad-hoc ou não acontece; em uma análise mais aprofundada, esse dado não demonstra um cenário necessariamente ruim pois é possível que não haja a necessidade de se realizar na unidade todas as atividades que a literatura sugere;

3. O fato de que o número de atividades que acontecem de maneira ad-hoc aumentou significativamente pode representar que a unidade evoluiu para um nível de maturidade e está se preparando para que nos próximos anos mais um passo seja dado, crescendo para um nível maior com a formalização destas atividades; no entanto este cenário não deverá obrigatoriamente acontecer para que a unidade melhore, pois cabe a unidade decidir se o nível de maturidade que chegaram lhes é suficiente para garantir processos eficazes ou não;

4. As atividades constantes no PDP e que contribuem para a sua melhoria contínua sugeridas pela literatura foram todas utilizadas nos projetos do segundo grupo, ainda que algumas continuem sendo feitas de maneira adhoc. 
5. Embora o número de atividades de PMC não existentes na unidade tenha diminuído do primeiro para o segundo grupo, elas ainda acontecem de forma Ad-hoc, o que demonstra que a necessidade de formalizar as atividades de PMC no PDP ainda é grande.

\subsection{Sistematização do PDP e o desempenho dos projetos}

Uma vez identificadas às atividades que contribuem para a melhoria contínua do processo de desenvolvimento de produtos, a pesquisa de campo buscou evidências da utilização destas em seis casos práticos em uma empresa de autopeças. Observou-se que a maturidade na utilização destas atividades aumentou.

No entanto, a constatação de que havia uma maior utilização e sistematização das atividades que contribuem para melhoria contínua do PDP por si só não é suficiente para garantir que os resultados dos projetos sejam aprimorados.

Foram pesquisados dados que indicassem o desempenho dos projetos nos dois períodos que marcam mudanças significativas do nível de sistematização do PDP da empresa, denominados de 1 e 2, no qual período 1 representa os projetos de 1999 a 2002 e período representa projetos executados entre 2002 e 2006, conforme apresentado. Os resultados de cada um dos projetos analisados são apresentados nas Tabela 2 e Tabela 3.

Tabela 2 - Indicadores de desempenho do primeiro grupo de projetos

\begin{tabular}{|c|c|c|c|c|c|c|}
\hline \multicolumn{7}{|c|}{$1^{\circ} \stackrel{0}{\text { grupo de projetos }(1999-2002)}$} \\
\hline & \multicolumn{2}{|c|}{ Projeto A.1 } & \multicolumn{2}{|c|}{ Projeto B.1 } & \multicolumn{2}{|c|}{ Projeto C.1 } \\
\hline & Planejado & Executado & Planejado & Executado & Planejado & Executado \\
\hline Complexidade & $\mathrm{B}$ & $\mathrm{B}$ & $\mathrm{B}$ & $\mathrm{B}$ & $\mathrm{C}$ & $\mathrm{C}$ \\
\hline $\begin{array}{l}\text { Número Pessoas } \\
\text { Envolvidas }\end{array}$ & 15 & 12 & 30 & 30 & 9 & 9 \\
\hline Prazo & 2 anos & 2 anos & 3 anos & 3 anos & $\begin{array}{c}1 \text { ano }+2 \\
\text { meses }\end{array}$ & $\begin{array}{c}1 \text { ano }+2 \\
\text { meses }\end{array}$ \\
\hline Orçamento & 100 & 90 & 100 & 100 & $\begin{array}{c}\text { Não } \\
\text { definido }\end{array}$ & $\begin{array}{c}\text { Não } \\
\text { definido }\end{array}$ \\
\hline \begin{tabular}{|l|} 
Percentual de \\
Nacionalizações
\end{tabular} & $0 \%$ & $0 \%$ & $\begin{array}{c}\text { Não } \\
\text { definido }\end{array}$ & $3 \%$ & $10 \%$ & $10 \%$ \\
\hline $\begin{array}{l}\text { Retorno de Peças } \\
\text { de Campo }\end{array}$ & $\begin{array}{c}\text { Não } \\
\text { definido }\end{array}$ & $1000 \mathrm{ppm}$ & $\begin{array}{c}\text { Redução } \\
\text { de } 70 \% \\
\text { ppm do } \\
\text { atual } \\
\end{array}$ & $\begin{array}{c}\text { Redução } \\
\text { de } 70 \% \text { do } \\
\text { ppm atual }\end{array}$ & 0 & 0 \\
\hline $\begin{array}{l}\text { Reclamações } \\
\text { Formais do Cliente }\end{array}$ & 0 & 0 & 0 & 0 & 0 & 0 \\
\hline
\end{tabular}


Tabela 3 - Indicadores de desempenho do segundo grupo de projetos

\begin{tabular}{|c|c|c|c|c|c|c|}
\hline & & rupo de pr & jetos (2002 & - 2006) & & \\
\hline & Proje & to A.2 & Proje & to B.2 & Proje & to C.2 \\
\hline & Planejado & Executado & Planejado & Executado & Planejado & Executado \\
\hline Complexidade & $\mathrm{B}$ & C-B & $\mathrm{B}$ & $B-A$ & $\mathrm{C}$ & $C-B$ \\
\hline $\begin{array}{l}\text { Número Pessoas } \\
\text { Envolvidas }\end{array}$ & 10 & 10 & 20 & 20 & 9 & 9 \\
\hline Prazo & 2 anos & 2 anos & $\begin{array}{c}2 \text { anos e } \\
\text { meio }\end{array}$ & $\begin{array}{c}2 \text { anos e } \\
\text { meio }\end{array}$ & 2 anos & 2 anos \\
\hline Orçamento & 100 & 90 & 100 & 80 & 100 & 95 \\
\hline $\begin{array}{l}\text { Percentual de } \\
\text { Nacionalizações }\end{array}$ & $10 \%$ & $10 \%$ & $\begin{array}{c}\text { Superior } \\
\text { ao obtido } \\
\text { no projeto } \\
1\end{array}$ & $35,30 \%$ & $\begin{array}{c}\text { Não } \\
\text { aplicável }\end{array}$ & $\begin{array}{l}\text { Não } \\
\text { aplicável }\end{array}$ \\
\hline $\begin{array}{l}\text { Retorno de Peças } \\
\text { de Campo }\end{array}$ & 500 ppm & 500 ppm & 1000 ppm & 445 ppm & 1000 ppm & $445 \mathrm{ppm}$ \\
\hline $\begin{array}{l}\text { Reclamações } \\
\text { Formais do Cliente }\end{array}$ & 0 & 0 & 0 & 0 & 0 & 0 \\
\hline
\end{tabular}

Os resultados estão representados apenas demonstrando os percentuais e não os números absolutos reais, uma vez que faz parte das estratégias de negócios da empresa a não divulgação dos números exatos.

Os indicadores apresentados demonstram que os primeiros projetos (pertencentes ao primeiro grupo) atingiram as expectativas da empresa e do cliente, uma vez que os prazos, os custos e a qualidade planejados para cada projeto foram respeitados.

No entanto, através da aplicação das entrevistas e posterior verificação da documentação notou-se que o planejamento dos primeiros projetos tinha objetivos de custo e prazo menos "rigorosos" que os posteriores, de modo que foi, segundo os depoentes, significativamente mais "fácil" atingi-los.

Para o projeto A.1, o indicador de desempenho denominado "Retorno de Peças em Campo" não havia metas definidas, o que dificultou a análise precisa do desempenho. O nível de responsabilidade da equipe local era baixo, uma vez que esta apenas dava suporte a equipe da matriz americana, que liderava praticamente todas as atividades do desenvolvimento. A tomada de decisão obrigatoriamente vinha desta equipe localizada na matriz. Os custos dos desenvolvimentos também foram projetados maiores que os custos dos projetos do segundo grupo, pois a quantidade de viagens da equipe americana para o Brasil era grande. 
Para os casos dos projetos pertencentes ao segundo grupo o cenário apresentou-se bastante diferenciado. Os orçamentos destinados ao desenvolvimento foram mais rigorosos e a complexidade dos projetos era tão grande quanto era a complexidade dos projetos do primeiro grupo.

Analisando os dados quantitativos das Tabela $2 \mathrm{e}$

Tabela 3 pode-se notar que os projetos mais recentes tiveram desempenhos superiores uma vez que além de atingirem os prazos mais rigorosos ainda conseguiram ficar abaixo do estimado durante a fase de planejamento de muitos deles, como é o caso do item orçamento para os três projetos do segundo grupo. Estes indicadores validam a premissa encontrada na literatura de que a implementação de atividades que contribuem a melhoria contínua do processo de desenvolvimento de produtos traz ganhos em custos e prazos, o que torna a empresa mais competitiva.

Com relação ao requisito de qualidade, não foram encontradas evidências de que estas atividades que trouxeram melhorias no processo de desenvolvimento de produtos da empresa influenciaram positivamente nos resultados. Há várias razões possíveis: uma é o fato da empresa possuir critérios rigorosos para iniciar a manufatura dos produtos, tornando-se um filtro final igualando o resultado dos projetos. Com relação ao requisito de qualidade, ma deficiência dos dados analisados foi a definição de apenas um indicador de desempenho relacionado à qualidade, que é o PPM. Para o primeiro grupo de projetos alguns objetivos de PPM não estavam definidos e, para o segundo grupo, dois dos projetos analisados eram interdependentes para os números de reclamação em campo. Por estas razões não é possível afirmar com certeza se houve impacto da qualidade dos produtos desenvolvidos ou não.

Dados sobre alterações de engenharia poderiam ajudar neste aspecto, mas não havia registros suficientemente rigorosos que permitissem esta análise.

Contudo, grande diferença entre os primeiros projetos e os projetos posteriores estava no nível de responsabilidade da equipe local. Nos mais recentes, a equipe local foi responsável pela maior parte das atividades e por grande parte da tomada de decisão, ainda que não em sua totalidade. Os engenheiros de desenvolvimento dos produtos e dos novos processos eram agora locais e apenas recebiam orientações e suporte da equipe da matriz americana, quando necessário. 
Da mesma forma os líderes dos desenvolvimentos - ou gerentes de projetos, como eram chamados - eram funcionários da filial brasileira. Eram eles que tinham total responsabilidade pelo bom gerenciamento de todas as atividades dos desenvolvimentos e, por conseqüência, da satisfação do cliente frente ao que estava sendo desenvolvido, considerando critérios de custo, prazo e qualidade.

Houve preocupação em entrevistar funcionários que participaram dos dois desenvolvimentos nos diferentes períodos, para melhor comparação dos períodos também por parte dos entrevistados.

Um dos questionamentos feitos foi relacionado à questão da mudança do nível de responsabilidades. Em função dos primeiros projetos terem sido executados com responsabilidade na matriz os entrevistados foram questionados sobre o baixo número de atividades encontradas não se deveu ao fato de ter sido executadas na matriz. Para todos os entrevistados - incluindo o representante da alta gerência da empresa - isso não aconteceu, uma vez que todas as atividades foram acompanhadas pelos funcionários da filial brasileira.

Evidência disto é que nos três projetos do primeiro grupo a documentação existente do projeto estava armazenada em arquivo local, usualmente em pastas físicas e fora de um formato padrão.

Estas oportunidades de melhoria foram também identificadas durante os desenvolvimentos dos projetos do grupo $1 \mathrm{e}$, para o segundo grupo de projetos, os arquivos já foram todos armazenados em formato digital padronizado.

Outras observações feitas foram:

- No segundo grupo de projetos havia uma Intranet na qual todos os dados dos projetos estavam armazenados de maneira padronizada, e podiam ser acessados de dentro da empresa em qualquer lugar do mundo;

- A integração da equipe local com a matriz e a familiaridade com a documentação foi expressivamente melhor no segundo grupo de projetos;

- A divulgação do modelo de referência em formato de figura facilitou a compreensão da cadência das atividades e da inter-relação entre as áreas funcionais envolvidas no projeto; as pastas de projetos na Intranet iniciavam sempre com a figura do modelo de referência e hiperlinks para cada atividade e sua respectiva documentação; 
- O documento PDP01 Source Document foi aos poucos assimilado pelas equipes e muito utilizado pelos gerentes dos projetos;

- Como característica negativa desta difusão, a documentação inteira na língua inglesa embora facilitasse a comunicação entre as unidades de todo o mundo dificultava o entendimento e gerava resistência na utilização para os funcionários que não tinham significativo domínio do idioma.

- No segundo grupo de projetos as equipes já tinham mais conhecimento sobre o modelo e suas atividades e com isso foi observada uma tendência de aumento do número de sugestões para melhorias do processo e das suas atividades;

- Alguns funcionários ainda enxergavam o modelo como burocrático, e pediam uma ferramenta mais adequada para a unidade local. Neste aspecto, durante a observação da documentação na pesquisa, observou-se que dos formulários padronizados (em inglês) sugeridos pela matriz, menos da metade das informações solicitadas eram preenchidas e em nenhum momento foi observado que a falta destas informações trouxeram penalidades aos desenvolvimentos; ao contrário, observou-se que muitas informações acabavam sendo duplicadas nos formulários utilizados e com o tempo, essa duplicidade gerava informações desatualizadas em algum documento. 


\section{Análise e Considerações Finais}

As primeiras considerações acerca da melhoria contínua aplicada ao processo de desenvolvimento de produtos referem-se aos modelos de melhoria contínua e de maturidade em desenvolvimento de produtos encontrados na literatura.

Como visto na revisão da literatura, a adequação de um modelo de referência para o processo de desenvolvimento de produtos faz-se necessária para torná-lo mais eficiente, permitindo desenvolvimentos mais rápidos, tornando a empresa mais competitiva.

Exemplos de modelo de PDP como Caffyn (1998) e Rozenfeld et al. (2006) demonstraram-se muito abrangentes pois não se referem a um segmento industrial, como é o caso do segmento automotivo. Faz-se necessário um modelo de melhoria contínua e de maturidade em desenvolvimento de produtos melhor explorado e ligado diretamente ao desempenho deste processo, de maneira que a necessidade de se melhorar o processo de desenvolvimento de produtos possa ser justificada pela melhoria do seu desempenho. Em adição, faz-se preciso aplicar estes modelos sem um caso prático para que possa ser analisada a eficácia da sua utilização e retiradas lições e oportunidades de melhoria.

Ainda, a premissa sugerida pela literatura de desenvolvimento de produtos de que é preciso melhorar e sistematizar o PDP para ganhos competitivos possui possui poucas evidências em dados de desempenho.

A proposta deste trabalho de pesquisa foi investigar estes dois aspectos, sistematização e melhoria contínua, para que a discussão acerca destes indicadores pudesse vir à tona, de maneira que os resultados representados servissem como uma primeira discussão sobre o assunto, ainda que limitada ao escopo deste trabalho.

Os resultados da pesquisa de campo indicam que a sistematização do processo de desenvolvimento de produtos teve resultados mais significativos nas atividades que são parte do PDP, ou seja, quando comparados às atividades dos projetos do primeiro grupo de projetos (antes da sistematização) com as do segundo grupo notou-se uma grande melhora no número de atividades formais do PDP e expressiva diminuição das atividades que aconteciam de maneira $a d-h o c$ ou ainda que não aconteciam. 
Em contrapartida, embora as atividades que contribuem para a melhoria contínua do PDP e fazem parte do PMC - processo que apóia a melhoria dos demais processos de negócios da empresa - também tenham tido significativa melhora quando comparados os primeiros projetos com os segundos, observou-se que esta melhora se deu no nível de atividades que não aconteciam nos primeiros projetos para as atividades que aconteciam de maneira ad-hoc no segundo grupo de projetos, como apresentado graficamente no capítulo anterior.

Significa dizer que embora o PDP tenha sido sistematizado na unidade de negócios estudada, o PMC ainda não foi sistematizado para funcionar como processo de apoio ao PDP. Portanto, o processo de melhoria contínua não foi considerado como um processo de apoio aos demais processos da empresa dentro do esforço de sistematização realizado, tal como sugere a literatura mais recente como Rozenfeld et al (2006).

Há também a indicação pelos dados de que a empresa já estava em um nível de maturidade nas atividades de PDP maior que nas atividades de PMC aplicadas ao PDP, o que é um cenário comum. Desta forma, a evolução das atividades de PMC que não existiam para atividades que aconteciam de maneira ad-hoc é positiva pois representa uma melhora no nível de maturidade do processo de melhoria contínua.

O próximo passo seria uma segunda evolução do nível de maturidade, transformando as atividades que acontecem ad-hoc para atividades formais, mas cabe a empresa analisar se esta unidade precisa evoluir mais este nível ou não, a partir de seus objetivos e estratégias de negócios, comparados com os resultados obtidos em seus desenvolvimentos.

Parte das atividades identificadas como de melhoria contínua pela literatura, implementadas no decorrer da sistematização do PDP no caso foi resultado do esforço de mudança (apresentadas no item 4 deste trabalho). Alguns exemplos são: estabelecimento do PSO, exclusão de atividades do modelo, etc.

Outra parte foi incorporada ao PDP da empresa, deixando de ser ad-hoc no início para se transformarem em atividades formais no segundo grupo de projetos, tais como estabelecimento de mapas para gestão do portfólio, definição e monitoramento de indicadores de desempenho e formalização da comunicação entre todos os níveis hierárquicos. 
Ainda, uma terça parte das atividades permaneceram ad-hoc e poderiam ser identificadas como PMC; citam-se a atividade de comparar e integrar os desenvolvimentos, de fomentar a melhoria contínua por ações da alta gerência e da adoção de melhores práticas pelo histórico de desenvolvimentos anteriores.

A implementação da sistematização do PDP não seria possível sem as demais atividades aqui descritas, sejam elas identificadas na literatura ou no caso estudado. Portanto, o caso sugere que tanto o processo de transformação como o de melhoria contínua precisam ser sistematizados para uma melhor gestão do PDP e a viabilização da visão por processos, para ganhos competitivos pelos resultados dos desenvolvimentos. A análise dos projetos evidencia que a sistematização trouxe resultados positivos. Portanto, o estudo sugere a hipótese de estruturação de processos complementares ao do PDP visando a sua efetiva implementação e desenvolvimento contínuo. Uma das hipóteses que esta pesquisa sugere é que pode ser de grande valia para a melhoria contínua do PDP que exista um processo de PMC sistematizado para o PDP, e não apenas um processo de apoio. Contudo, cabe a cada empresa identificar em qual nível de maturidade deseja estar para garantir suas fatias de mercado. Ainda, é um processo natural de evolução formalizar primeiramente o processo principal (PDP) para depois formalizar o processo de apoio (PMC)

Ainda com relação aos resultados do estudo de caso, observou-se que a categoria da complexidade dos projetos ainda não é suficiente para descrever o portfólio de projetos que a empresa possui, ou seja, não está claro para a equipe multifuncional como se enquadram os projetos que estão sendo desenvolvidos. Prova disso é que dos projetos analisados, dois tiveram suas categorias alteradas no decorrer do desenvolvimento e outros dois tiveram este assunto por diversas vezes discutidos, embora nenhuma ação tenha sido tomada. Isso demonstra que pode existir a necessidade de uma adequação das classificações sugeridas pela matriz americana, dadas as características particulares dos projetos locais.

A afirmação da literatura de que a classificação dos desenvolvimentos por tipo ou complexidade é necessária foi aferida para o caso. Contudo, ficou demonstrado que dentro de uma mesma empresa - ou de um mesmo modelo - pode haver a necessidade de se criar categorias distintas, de acordo com as características do projeto, do cliente ou no processo no qual o produto será produzido. 
O comportamento dos projetos, ainda que em diferentes categorias, mostrou-se similar quando comparados o primeiro e o segundo grupos. Isso demonstra que a evolução dos projetos foi independente do nível de complexidade dos mesmos.

O assunto da sistematização volta em discussão nesta pesquisa quando são observados os resultados de desempenho e qualidade dos projetos. Observou-se que as atividades implementadas influenciaram positivamente no desempenho dos projetos para tempo, custo e nível de aprendizado local. No entanto, com relação à qualidade dos produtos desenvolvidos não foram identificadas melhoria possivelmente por uma lacuna deste trabalho, que como citado anteriormente, utilizou apenas um indicador de desempenho - parcialmente disponível - para aferir este dado. Os dados coletados, portanto, não foram representativos.

O caso estudado demonstrou que a sistematização trouxe benefícios aos resultados de desempenho dos projetos analisados, porém houve uma transformação voltada à melhoria contínua deste processo; a carência pela sistematização do processo de melhoria contínua a ser aplicado ao PDP continua presente na unidade de negócios estudada. Este aspecto é positivo se pensarmos que o processo de desenvolvimento de produtos foi tomado como prioridade dentro dos objetivos de melhoria da empresa, que agora está apta para implementar um processo de melhoria contínua de apoio. De nada adiantaria ter um processo de apoio estruturado se o seu processo principal (PDP) apresentasse deficiências.

Uma continuidade para esta pesquisa poderia ser a validação desta hipótese de que o processo de melhoria contínua que apóia o PDP deve ser também sistematizado para este segundo processo, uma vez que se demonstrou que as atividades de melhoria contínua também influenciaram positivamente nos resultados dos desenvolvimentos analisados.

Ainda, a análise de outros casos do segmento automotivo ou a aplicação desta pesquisa em outros segmentos poderia enriquecer ou lapidar a lista compilada neste trabalho, tanto para a literatura quanto para os casos práticos. Finalmente, o acompanhamento deste novo nível de maturidade em melhoria contínua que a empresa sinalizou como objetivo futuro poderia analisar os resultados de novos projetos, verificando se realmente é necessário formalizar este processo de apoio para o PDP. 


\section{Referências}

ALLIPRANDINI, D.H.; RUY, M. (2002). Aprendizagem organizacional no processo de desenvolvimento de produtos: estudo de casos em três empresas brasileiras. In: SIMPÓSIO DE GESTÃO DA INOVAÇÃO TECNOLÓGICA, 22., 2002, Salvador. Anais... São Paulo: PGT/USP. 1 CD-ROM.

ALLIPRANDINI, D.H.; SILVA, M.M. (2003). Aprendizagem organizacional no processo de desenvolvimento de produto: investigação do conhecimento declarativo no contexto da sistemática de stagegates. In: CONGRESSO E EXPOSIÇÃO INTERNACIONAIS DE TECNOLOGIA DA MOBILIDADE: SAE BRASIL, 12., 2003, São Paulo. Anais... São Paulo: SAE Brasil.

ALLWORDS english dictionary. (2006). Disponível em:<http://www.allwords.com/word-mechanism.html $>$. Acesso em: 28 jul. 2006.

AMARAL, D.C. (1997). Colaboração cliente-fornecedor no desenvolvimento de produto: integração, escopo e qualidade do projeto do produto - estudos de casos na indústria automobilística brasileira. $195 \mathrm{p}$. Dissertação (Mestrado) - Universidade Federal de São Carlos, São Carlos, 1997.

(2002). Arquitetura para gerenciamento de conhecimentos explícitos sobre o processo de desenvolvimento de produtos. 214p. Tese (Doutorado) - Escola de Engenharia de São Carlos, Universidade de São Paulo, São Carlos, 2002.

AUTOMOTIVE INDUSTRY ACTION GROUP (1994). APQP - advanced product quality planning and control plan. Soulthfield: AIAG.

BERGER, A. (1997). Continuous improvement and Kaizen: standarization and organizational designs. Integrated Manufacturing Systems, Bradford, v.8, n.2, p.110-117.

BESSANT, J.; CAFFYN, S. (1997). High involvement innovation through continuous improvement. International Journal of Technology Management, Geneva, v.14, n.1, p.7-28.

BESSANT, J. et al. (1993). Continuous improvement in UK manufacturing. Technovation, Amsterdam, v.13, n.4, p.241-251, May.

Feb.

(1994). Rediscovering continuous improvement. Technovation, Amsterdam, v.14, n.1, p.17-29,

BRYMAN, A. (1989). Research method and organization studies. London: Unwin; Hyman.

BUSS, C.O. (2002). Cooperação interfuncional no desenvolvimento de novos produtos: a interface marketing-engenharia. 84p. Dissertação (Mestrado) - Universidade Federal do Rio Grande do Sul, Porto Alegre, 2002.

CAFFYN, S. (1997). Extending continuous improvement to the new product development. R\&D Management, Oxford, v.27, n.3, p.253-268, July.

(1998). The scope for the application of continuous improvement to the process of new product development. 327p. Thesis (PhD.) - University of Brighton, Brighton, 1998.

CAFFYN, S.; BESSANT, J. (1995). Continuous improvement as a strategic capability. In: EUROCINET CONFERENCE, 1995, Gatwick. Proceedings... Gatwuick: CiNet.

(1996). A capability-based model for continuous improvement. In: INTERNATIONAL

CONFERENCE OF THE EUROMA, 3., 1996, London. Proceedings... London: London Business School. 
CAFFYN, S.; GRANTHAM, A. (2003). Fostering continuous improvement within new product development process. International Journal of Technology Management, Geneva, v.26, n.8, p.843-856.

CHENG, L.C. et al. (1995). QFD - planejamento da qualidade. Belo Horizonte: QFCO.

CLARK, K.B.; FUJIMOTO, T. (1991). Product development performance: strategy, organization and management in the world auto industry. Boston-Mass: Harvard Business School.

CLARK, K.B.; WHEELWRIGHT, S.C. (1993). Managing new product and process development: texts and cases. Boston: Harvard Business School.

CLAUSING, D. (1994). Total quality development. New York: ASME. p.3-29

CAPABILITY MATURITY MODEL INTEGRATION. (2005). Pittsburgh: Carnegie Mellon University. Disponível em:<http://www.sei.cmu.edu/cmmi/adoption/pdf/cmmi-overview05.pdf.>. Acesso em: 12 Aug. 2005.

CONDOTTA, A. (2004). Melhoria do processo de desenvolvimento de produtos em uma empresa do setor automotivo. 156p. Dissertação (Mestrado Profissionalizante) - Escola de Engenharia, Universidade Federal do Rio Grande do Sul, Porto Alegre, 2004.

COOPER, R.G. (1993). Winning at new products: accelerating the process from idea to launch. Reading: Perseus Books.

(2001). Doing it right: winning with new products. Ancaster: Product Development Institute.

COOPER, R.G.; EDGETT, S.J.; KLEINSCHMIDT, E.J. (1999). New product portfolio management: practices and performance. Journal of Product Innovation Management, Malden, v.16, n.4., p.333-351, July.

CRAWFORD, J.K. (2002). The strategic project office: a guide to improving organizational performance. New York: Marcel Dekker.

CROSSAN, M.M.; LANE, H.W.; WHITE, R.E. (1999). A organizational learning framework: from intuition to institution. Academy of Management Review, Ohio, v.24, n.3, p.522-537, July.

DANE , F.C. (1990). Research methods. Belmont: Brooks/Cole.

DAVENPORT, T.; PRUSAK, L. (1998). Conhecimento empresarial. Rio de Janeiro: Campus.

DELPHI AUTOMOTIVE SYSTEMS (2001). Troy: DELPHI. Publicação interna

DESCHAMPS, J.; NAYAK, P.R. (1997). Produtos irresistíveis. São Paulo: Makron Books. DEVELIN, N. (1995). Kaizen II: acelerando a melhoria contínua. São Paulo: IMAM.

ECHEVESTE, M.E.S. (2003). Uma abordagem para estruturação e controle do processo de desenvolvimento integrado de produtos. 1v. Tese (Doutorado) - Universidade Federal do Rio Grande do Sul, Porto Alegre, 2003.

FREITAS, C.; ECHEVESTE, M.E.S.; CUNHA, J.D. (2003). Uma proposta de avaliação da reestruturação do processo de desenvolvimento de produtos baseada em métricas. In: CONGRESSO BRASILEIRO GESTÃO DE DESENVOLVIMENTO DE PRODUTOS, 4., 2003, Gramado. Anais... Porto Alegre: UFRGS.

GARVIN, D.A. (1993). Building a learning organization. Harvard Business Review, New York, July/Aug. 
GUERRERO, V. (2001). Análise do gerenciamento de informação em um ambiente colaborativo e distribuído de desenvolvimento de produto. 105p. Dissertação (Mestrado) - Escola de Engenharia de São Carlos, Universidade de São Paulo, São Carlos, 2001.

GIL, A.C. (1987). Métodos e técnicas de pesquisa social. São Paulo: Atlas.

IMAI, M. (1997). Gemba Kaizen: a commonsense, low-cost approach to management. New York: McGraw-Hill.

INSTITUTO DE PESOS E MEDIDAS DO ESTADO DE SÃO PAULO (2006). Informações ao empresário: programa 5 esses. Disponível em:<http://www.ipem.sp.gov.br/3emp/5esses.asp?vpro=abe $>$. Acesso em: 18 jul. 2006.

KARLSSON, C.; AHLTROM, P. (1996). The difficult path to lean product development. Journal of Product Innovation Management, Malden, v.13, n.4, p.296-310, July.

LAVILLE, C.; DIONE, J. (1999). A construção do saber: manual de metodologia de pesquisa em ciências humanas. Porto Alegre: Artes Médicas; Belo Horizonte: UFMG.

LEONARD-BARTON, D. (1995). Wellsprings of knowledge: building and sustaining the sources of innovation. Boston-Mass: Harvard Business School.

LYNN, G.S. (1998). New product team learning: development and profiting from your knowledge capital. California Management Review, Berkerley, v.40, n.4, p.74-94, Summer.

MARCONCIN, J.C. (2004). Melhorias no desenvolvimento de produto em uma empresa de manufatura de produtos eletroeletrônicos. 136p. Dissertação (Mestrado) - Escola de Engenharia, Universidade Federal do Rio Grande do Sul, Porto Alegre, 2004.

MARTINS, G.A. (1995). Epistemologia da pesquisa em administração. 1v. Tese (Livre-Docência) Faculdade de Economia, Administração e Contabilidade, Universidade de São Paulo, São Paulo, 1995.

MCMANUS, H.L. (2004). Product development value stream mapping (PDVSM) - manual. Cambridge: LAI - Lean Aerospace Initiative; Massachusetts Institute of Technology.

MESQUITA, M.; ALLIPRANDINI, D.H. (2003). Competências essenciais para melhoria contínua da produção: estudo de caso em empresas da indústria de autopeças. Gestão \& Produção, São Carlos, v.10, n.1, p.17-33.

NONAKA, I.; TAKEUCHI, H. (1997). Criação de conhecimento na empresa. 8.ed. Rio de Janeiro: Campus.

PALMA, R.F. (2005). Interações sobre técnicas de gerenciamento de projetos, competências do gerente de projetos e o desempenho do projeto. 78p. Dissertação (Mestrado) - Escola Politécnica, Universidade de São Paulo, São Paulo, 2005.

INTERNATIONAL AUTOMOTIVE SECTOR GROUP (2003). QS-9000: one world - one quality system. Disponível em:<http://www.qs-9000.org>. Acesso em 10 june 2006.

RENTES, A.F. (2000). TransMeth - proposta de uma metodologia para condução de processos de transformação de empresas. 1v. Tese (Livre-Docência) - Escola de Engenharia de São Carlos, Universidade de São Paulo, São Carlos, 2000.

ROSENAU JR., M.D. (2000). Successful product development: speeding from opportunity to profit. New York: John Wiley. 
ROZENFELD, H. et al. (2006). Gestão de desenvolvimento de produtos - uma referência para a melhoria do processo. São Paulo: Saraiva.

(2000). O processo de desenvolvimento de produtos. In: ROZENFELD, H.; BREMER, C.F. (Org.). Produtos \& Serviços - Fábrica do futuro: entenda hoje como sua indústria vai ser amanhã, São Carlos, n.312, p.55-64, dez. Edição especial.

RUY, M.; ALLIPRANDINI, D.H. (2005). Organizational learning in the context of product development management. Product Management \& Development = Brazilian Journal of Product Development Management, Florianópolis, v.3, n.2, p.133-145, Oct.

SENGE, P. (1999). A quinta disciplina. Rio de Janeiro: Campus.

SHIBA, S.; GRAHAM, A.; WALDEN, D. (1997). TQM - quatro revoluções da gestão da qualidade. Porto Alegre: Bookman. p.40-56.

SILVA, M.M. (2004). Aprendizagem organizacional no PDP: investigação do conhecimento declarativo no contexto da sistemática de stage-gates. 170p. Dissertação (Mestrado) - Universidade Federal de São Carlos, São Carlos, 2003.

SLACK, N. et al. (1997). Administração da produção. São Paulo: Atlas.

SPENDOLINI, M.J. (1993). Benchmarking. São Paulo: Makron Books. p.10-16.

TOLEDO, J.C. (2002). Modelo de referência para a gestão do processo de desenvolvimento de produto: aplicações na indústria brasileira de autopeças. São Carlos: GEPEQ. Relatório final de projeto de pesquisa.

TOLEDO, J.C. et al. (2001). Gestão do processo de desenvolvimento de produtos na indústria brasileira de autopeças: práticas correntes e principais problemas. In: CONGRESSO DE GESTÃO DE

DESENVOLVIMENTO DE PRODUTO, 3., 2001, Florianópolis. Anais eletrônicos... Florianópolis: [s.n.].

VERNADAT, F.B. (1996). Enterprise modeling and integration: principles and applications. London: Chapman \& Hall.

WHEELWRIGHT, S.C.; CLARK, K.B. (1992). Revolutionizing product development: quantum leaps in speed, efficiency and quality. New York: The Free Press.

(1995). Leading product development: the senior manager's guide to creating and shaping the enterprise. New York: The Free Press.

WOMACK, J.; JONES, D.T. (1998), Lean Thinking. New York: Free Press.

YIN, R.K. (2001). Estudo de caso: planejamento e métodos. Porto Alegre: Bookman. 


\section{Apêndices}

\section{Apêndice A - Roteiro de Entrevistas para Aplicação em Campo}

Este apêndice foi utilizado como referência para aplicação das entrevistas em campo. As questões foram aplicadas aos representantes de cada projeto analisado, em suas respectivas funções. Para questões relativas ao projeto (terceiro item deste apêndice) foi aplicado um questionário para cada projeto de desenvolvimento analisado.

\section{- Caracterizacão do Respondente}

1. Qual é o seu nome?

2. Qual é a sua função?

3. Há quanto tempo está nesta função na Delphi?

- Questionário sobre Modelo de Referência do PDP da Empresa e suas Práticas

1. Há quanto tempo o modelo de PDP da Delphi vem sendo utilizado nesta unidade?

2. Os clientes (montadoras) conhecem o modelo de PDP utilizado pela empresa? Se sim, como ele foi difundido?

3. Ocorreram mudanças na estrutura de DP desta unidade nos últimos anos (pessoas, práticas, etc.)? Quais fatores determinaram estas mudanças? Quando foi a última?

4. A unidade realiza auditorias de qualidade (internas ou externas)? Se sim, quando foram implementadas? Como é a comunicação dos resultados e como são tratadas as oportunidades de melhoria identificadas?

5. Existe algum tipo de workshop ou fórum para se discutir problemas nas linhas de produtos? Se sim, desde quando foram implementados?

6. Existem mapas ou painéis para facilitar o direcionamento estratégico? Quando eles surgiram? Dê um exemplo de utilização destes painéis.

7. Qual é a ferramenta para comunicação das estratégias da unidade a todas as pessoas da organização? Quando ela começou a ser utilizada? Que tipo de melhorias esta atividade de comunicação trouxe?

8. Existem indicadores de desempenho para o PDP da empresa?

\section{- Questionário sobre o Projeto de Desenvolvimento Analisado}

1. Sobre o modelo de referência empregado no projeto:

1.1. Do modelo de PDP seguido neste projeto, quanto do sugerido foi efetivamente utilizado? Deste modelo, quanto foi efetivamente utilizado?

1.2. O cliente (montadora) conhecia o modelo de PDP utilizado durante o desenvolvimento? 
1.3. Existia algum mapa, painel ou documento demonstrando a relação do projeto com a estratégia de negócios da empresa?

1.4. Ao término do projeto, foram utilizados indicadores de desempenho para medir a eficácia do processo de desenvolvimento de produtos?

2. Sobre a troca de informações e ferramentas:

2.1. Como foi a troca de informações com fornecedores e clientes durante o projeto? Em que momento eles foram envolvidos no desenvolvimento? Desde quando esta prática existe e por que ela foi adotada?

2.2. Como foi a troca de informações internamente, com a equipe de desenvolvimento? Como a equipe se mantinha informada e alinhada com as atualizações do projeto?

2.3. Alguma sugestão de melhoria nas atividades do PDP (ou no próprio modelo de referência) foi feita por algum cliente, fornecedor ou membro da equipe durante o projeto? Como foi tratada a sugestão?

2.4. Foram utilizadas ferramentas para desenvolvimentos virtuais, tais como: CAD, mockup digital, etc?

2.5. Foram utilizadas ferramentas para garantia da qualidade, como: FMEA, QFD, DFE, etc?

2.6. Existia um banco de dados compilado para capturar ou buscar o que foi aprendido?

3. Sobre Auditorias de processo e aprendizagem:

3.1. Foram realizadas auditorias durante o projeto?

3.2. No projeto que você participou a equipe (incluindo o líder) possuía acesso a desenvolvimentos similares para capturar experiências e aprendizado? Dê um exemplo de aprendizado adquirido e utilizado a partir de um desenvolvimento anterior no projeto em que você trabalhou.

3.3. Como a equipe tratou os problemas identificados durante os desenvolvimentos? Existia sistemática para isso? Que benefícios a sistemática trouxe?

3.4. Ocorreram alterações de escopo do desenvolvimento? Como foram tratadas? Existia sistemática para isso? Que benefícios ela trouxe?

3.5. Foram realizadas atividades de Benchmarking ou eventos Kaizen durante o projeto? Se sim, que benefícios eles trouxeram?

3.6. Os conceitos do Programa de 5S são utilizados pela equipe multifuncional?

4. Sobre a estrutura organizacional:

4.1. O conceito de equipe multifuncional foi utilizado? Como era a integração entre as atividades? Isso facilitou o seu trabalho dentro do projeto? Como?

4.2. Eram realizadas reuniões de stage-gates durante o projeto? Quem participava das reuniões? Eram capturadas as lições aprendidas durante essas reuniões? Alguma melhoria de processo já foi identificada e implementada a partir destas reuniões?

4.3. Os gerentes das demais áreas funcionais foram envolvidos com as atividades do PDP? Alguma sugestão de melhoria do PDP vinda de um gerente funcional foi implementada durante o desenvolvimento?

4.4. Idéias da equipe foram incorporadas às atividades do PDP? Como isso ocorreu? Você sugeriu alguma melhoria ao PDP durante o projeto? Foi implementada?

4.5. Você recebeu treinamentos para executar suas funções no projeto e para sugerir melhorias ao PDP? 
4.6. Como a alta gerência mediu o desempenho individual e dos times de desenvolvimento? Houve casos de baixos desempenhos demandarem novos treinamentos? Como foram tratadas estas dificuldades?

4.7. Existia estrutura organizacional específica para auxiliar a gestão do desenvolvimento de produtos? (ex. Escritório de projetos).

4.8. O líder do projeto tinha poder de decisão sobre o projeto? Em que nível?

4.9. Como era a integração entre as pessoas da equipe de desenvolvimento?

5. Sobre a análise de riscos:

5.1. Você se recorda de algum risco identificado antecipadamente e evitado durante o projeto? Como aconteceu? Havia sistemática?

6. Sobre indicadores de desempenho do projeto:

6.1. Vocês tiveram algum problema durante o desenvolvimento ou você vê algum aspecto negativo na padronização das atividades, seja ela na esfera local ou mundial? Na sua opinião, é bom ou não padronizar as atividades do PDP?

6.2. Houve problemas de comunicação entre as pessoas da equipe ou entre equipes de diferentes desenvolvimentos? Quais? Como vocês trataram estes problemas?

6.3. Na sua opinião, houve melhorias no PDP se compararmos o primeiro e o segundo desenvolvimento que você participou? Quais? Quais foram os benefícios destas melhorias? Como foram medidos os resultados da melhoria implementada? (específica aos entrevistados que participaram de dois projetos de mesma linha de produto).

6.4. Existia duração estimada para cada atividade do PDP? Como eram verificadas as causas e justificados os atrasos? Havia metodologia para re-planejamento das atividades?

6.5. Que outras possibilidades de melhoria do PDP você vê? 


\section{Apêndice B - Tabela Padrão de Atividades do PDP para Mapeamento dos Projetos}

\begin{tabular}{|c|c|c|c|}
\hline \multirow[t]{2}{*}{ Projeto "x" } & \multicolumn{3}{|c|}{ Prática da Atividade } \\
\hline & Formal & Ad hoc & $\begin{array}{c}\text { Não } \\
\text { Existe }\end{array}$ \\
\hline \multicolumn{4}{|l|}{$\begin{array}{l}\text { Utilizar ferramentas para desenvolvimentos virtuais, tais como: CAD, } \\
\text { mockup digital, etc. }\end{array}$} \\
\hline \multicolumn{4}{|l|}{ Definir mapas para auxílio na gestão estratégica de portfólio } \\
\hline \multicolumn{4}{|l|}{$\begin{array}{l}\text { Aplicar ferramentas que garantam a qualidade como: FMEA, QFD, } \\
\text { DFE, etc. }\end{array}$} \\
\hline \multicolumn{4}{|l|}{$\begin{array}{l}\text { Desenvolver e aplicar métodos, ferramentas e padrões para } \\
\text { planejamento, execução e controle dos desenvolvimentos incluindo } \\
\text { métricas para análise de desempenho. }\end{array}$} \\
\hline \multicolumn{4}{|l|}{$\begin{array}{l}\text { Estabelecer plano agregado de projetos: visão dos desenvolvimentos e } \\
\text { lançamentos nos próximos anos }\end{array}$} \\
\hline \multicolumn{4}{|l|}{$\begin{array}{l}\text { Criar estrutura organizacional específica para auxiliar a gestão do } \\
\text { desenvolvimento de produtos (ex. escritório de projetos) }\end{array}$} \\
\hline \multicolumn{4}{|l|}{$\begin{array}{l}\text { Definir categorias de desenvolvimento para padronizar ações } \\
\text { requeridas de acordo com a complexidade }\end{array}$} \\
\hline \multicolumn{4}{|l|}{$\begin{array}{l}\text { Estabelecer critérios de aprovação de mudanças significativas nos } \\
\text { desenvolvimentos }\end{array}$} \\
\hline \multicolumn{4}{|l|}{ Comparar e integrar desenvolvimentos } \\
\hline \multicolumn{4}{|l|}{ Envolver os fornecedores desde o início dos desenvolvimentos } \\
\hline \multicolumn{4}{|l|}{ Utilizar conceitos de engenharia simultânea } \\
\hline $\begin{array}{l}\text { Implementar e aplicar metodologia de "Stage-Gates" para aprovação } \\
\text { ou reprovação de fases do desenvolvimento. }\end{array}$ & & & \\
\hline
\end{tabular}




\section{Apêndice C - Tabela Padrão de Atividades do PMC para Mapeamento dos Projetos}

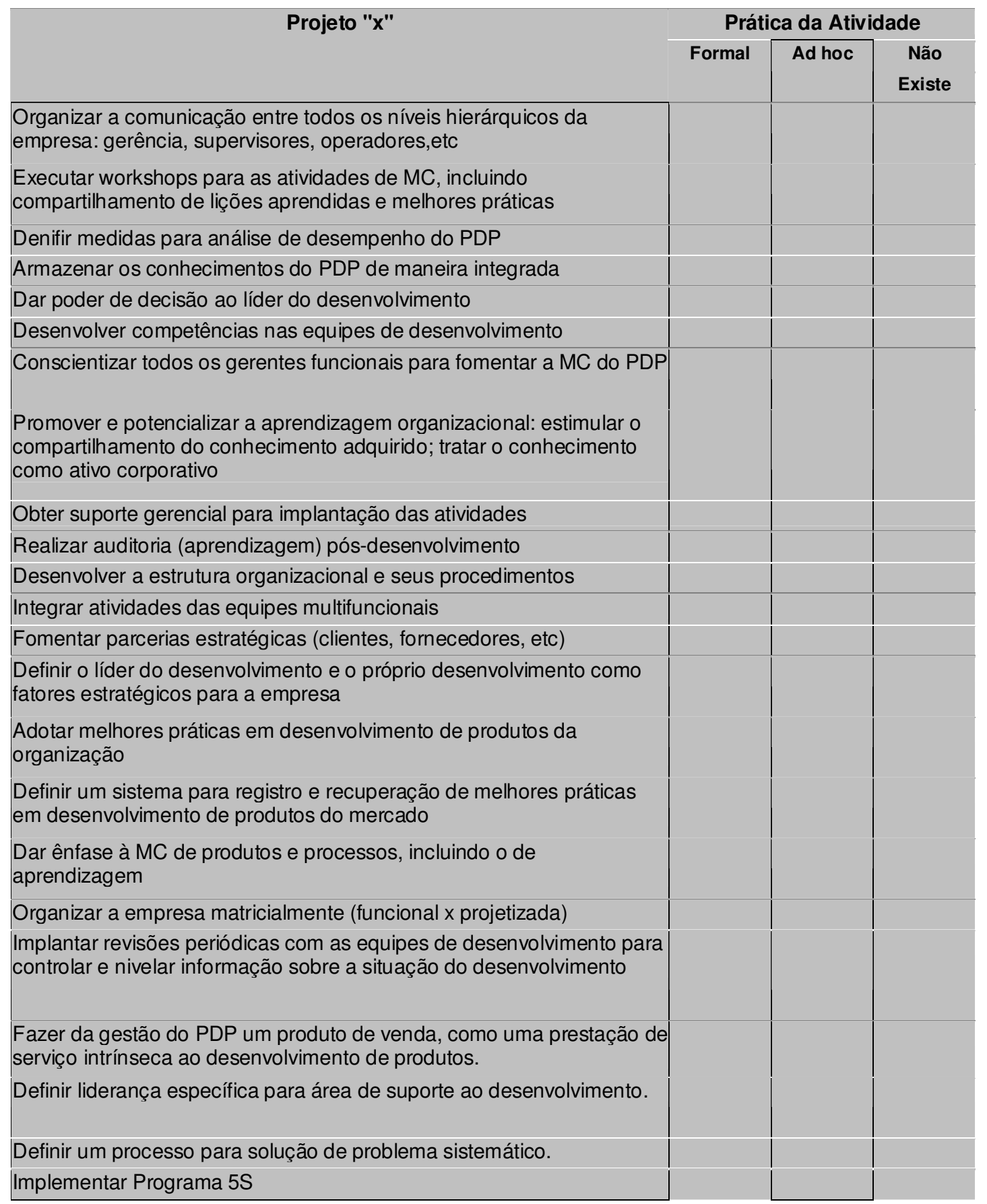




\section{Apêndice D - Roteiro de Observação para pesquisa em campo}

O roteiro abaixo descrito norteou o trabalho de observação em campo, incluindo a consulta a manuais, procedimentos e demais documentos históricos sobre os modelo de PDP da empresa e os projetos de desenvolvimento de produtos analisados.

1- Identificação da estrutura organizacional ( funcional, projetizada ou matricial);

2- Levantamento histórico da quantidade de revisões realizadas no modelo de PDP, a freqüência com que aconteceram e quais foram as alterações feitas;

3- Identificação dos treinamentos oferecidos nos últimos anos a todos os níveis da organização (incluindo treinamentos aos líderes dos projetos);

4- Identificação de painéis ou mapas para visualização do portfólio de projetos da empresa;

5- Identificação da divisão de responsabilidades entre a matriz e a unidade local (inclui nível de autonomia local);

6- Identificação do nível de padronização dos documentos e das atividades executadas durante os desenvolvimentos;

7- Verificação da existência / utilização de sistemática para gerenciamento de mudanças de escopo de projeto e resolução de problemas;

8- Verificação da existência / utilização de sistemática para capturar e implementar melhorias ao PDP e lições aprendidas nos desenvolvimentos;

9- Verificação da existência / utilização de sistemática para identificação e análise de indicadores de desempenho do PDP e ações corretivas a partir destes indicadores;

10- Verificação da existência / utilização de metodologia para gerenciamento de riscos;

11-Verificação de estrutura / ferramenta para facilitar a troca de informações entre os diferentes níveis hierárquicos;

12- Verificação da existência de auditorias (internas ou externas) para análise de conformidades no desenvolvimento a partir dos requisitos do cliente;

13-Verificação da existência de equipes multifuncionais nos projetos e como as atividades estão inter-relacionadas durante o desenvolvimento;

14-Levantamento de registros e saídas das revisões de stage-gates nos projetos;

15-Identificação de relação de parceira com centros de pesquisa ou universidades; O modelo de PDP adotado sugere estas parcerias?

16-Identificação de atividades de Benchmarking / eventos Kaizen / Programa 5S durante a execução dos projetos estudados;

17-Verificação de política de bonificação à idéia de funcionário implementada para melhoria do PDP;

18-Levantamento de dados que caracterizem cada projeto: complexidade, modelo de PDP utilizado, número de pessoas envolvidas, duração em meses, esforço, etc.

19-Levantamento dos resultados dos seis projetos de desenvolvimento de produtos para comparação posterior. 
Apêndice E - Identificação das atividades de PDP e PMC nos projetos A.1 e A.2

\begin{tabular}{|c|c|c|c|c|c|c|}
\hline \multirow{3}{*}{\begin{tabular}{|c|} 
Linha de Produto A \\
Atividades do PDP
\end{tabular}} & \multicolumn{3}{|c|}{ Projeto A.1 } & \multicolumn{3}{|c|}{ Projeto A.2 } \\
\hline & \multicolumn{6}{|c|}{ Prática da Atividade } \\
\hline & Formal & Ad hoc & $\begin{array}{l}\text { Não } \\
\text { Existe }\end{array}$ & Formal & Ad hoc & $\begin{array}{l}\text { Não } \\
\text { Existe }\end{array}$ \\
\hline $\begin{array}{l}\text { Utilizar ferramentas para desenvolvimentos } \\
\text { virtuais, tais como: CAD, mockup digital, etc. }\end{array}$ & $x$ & & & $x$ & & \\
\hline $\begin{array}{l}\text { Definir mapas para auxílio na gestão } \\
\text { estratégica de portfólio }\end{array}$ & & & $\mathrm{x}$ & $\mathrm{x}$ & & \\
\hline $\begin{array}{l}\text { Aplicar ferramentas que garantam a qualidade } \\
\text { como: FMEA, QFD, DFE, etc. }\end{array}$ & $\mathrm{x}$ & & & $x$ & & \\
\hline $\begin{array}{l}\text { Estabelecer plano agregado de projetos: visão } \\
\text { dos desenvolvimentos e lançamentos nos } \\
\text { próximos anos }\end{array}$ & & & $x$ & $x$ & & \\
\hline $\begin{array}{l}\text { Criar estrutura organizacional específica para } \\
\text { auxiliar a gestão do desenvolvimento de } \\
\text { produtos (ex. escritório de projetos) }\end{array}$ & & & $x$ & $x$ & & \\
\hline $\begin{array}{l}\text { Desenvolver e aplicar métodos, ferramentas e } \\
\text { padrões para planejamento, execução e } \\
\text { controle dos desenvolvimentos. }\end{array}$ & & $\mathrm{x}$ & & $x$ & & \\
\hline $\begin{array}{l}\text { Definir categorias de desenvolvimento para } \\
\text { padronizar ações requeridas de acordo com a } \\
\text { complexidade }\end{array}$ & & $\mathrm{x}$ & & $x$ & & \\
\hline $\begin{array}{l}\text { Estabelecer critérios de aprovação de } \\
\text { mudanças significativas nos desenvolvimentos }\end{array}$ & & $x$ & & $x$ & & \\
\hline Comparar e integrar desenvolvimentos & & $x$ & & & $x$ & \\
\hline $\begin{array}{l}\text { Envolver os fornecedores desde o início dos } \\
\text { desenvolvimentos }\end{array}$ & & $\mathrm{x}$ & & $\mathrm{x}$ & & \\
\hline Utilizar conceitos de engenharia simultânea & $x$ & & & $x$ & & \\
\hline \multirow[t]{2}{*}{$\begin{array}{l}\text { Implementar / praticar metodologia de "Stage- } \\
\text { Gates" para aprovação ou reprovação de fases } \\
\text { do desenvolvimento. }\end{array}$} & & $x$ & & $x$ & & \\
\hline & 3 & 6 & 3 & 11 & 1 & 0 \\
\hline \multirow[b]{2}{*}{ Atividades do PMC } & \multicolumn{6}{|c|}{ Prática da Atividade } \\
\hline & Formal & Ad hoc & $\begin{array}{c}\text { Não } \\
\text { Existe }\end{array}$ & Formal & Ad hoc & $\begin{array}{l}\text { Não } \\
\text { Existe }\end{array}$ \\
\hline $\begin{array}{l}\text { Organizar a comunicação entre todos os níveis } \\
\text { hierárquicos da empresa: gerência, } \\
\text { supervisores, operadores, etc. }\end{array}$ & & $x$ & & $x$ & & \\
\hline $\begin{array}{l}\text { Executar workshops para as atividades de MC, } \\
\text { incluindo compartilhamento de lições } \\
\text { aprendidas e melhores práticas }\end{array}$ & & & $x$ & & $x$ & \\
\hline $\begin{array}{l}\text { Denifir medidas para análise de desempenho } \\
\text { do PDP }\end{array}$ & & $\mathrm{x}$ & & $x$ & & \\
\hline $\begin{array}{l}\text { Armazenar os conhecimentos do PDP de } \\
\text { maneira integrada }\end{array}$ & & & $x$ & & $x$ & \\
\hline
\end{tabular}




\begin{tabular}{|c|c|c|c|c|c|c|}
\hline $\begin{array}{l}\text { Dar poder de decisão ao líder do } \\
\text { desenvolvimento }\end{array}$ & $\mathrm{x}$ & & & $\mathrm{x}$ & & \\
\hline $\begin{array}{l}\text { Desenvolver competências nas equipes de } \\
\text { desenvolvimento }\end{array}$ & & $x$ & & $\mathrm{x}$ & & \\
\hline $\begin{array}{l}\text { Conscientizar todos os gerentes funcionais } \\
\text { para fomentar a MC do PDP }\end{array}$ & & $\mathrm{x}$ & & & $\mathrm{x}$ & \\
\hline $\begin{array}{l}\text { Promover e potencializar a aprendizagem } \\
\text { organizacional: estimular o compartilhamento } \\
\text { do conhecimento adquirido; tratar o } \\
\text { conhecimento como ativo corporativo }\end{array}$ & & & $\mathrm{x}$ & & $x$ & \\
\hline $\begin{array}{l}\text { Obter suporte gerencial para implantação das } \\
\text { atividades }\end{array}$ & & $\mathrm{x}$ & & & $x$ & \\
\hline $\begin{array}{l}\text { Realizar auditoria (aprendizagem) pós- } \\
\text { desenvolvimento e utilizar os resultados como } \\
\text { aprendizado em projetos futuros }\end{array}$ & & & $\mathrm{x}$ & $x$ & & \\
\hline $\begin{array}{l}\text { Desenvolver a estrutura organizacional e seus } \\
\text { procedimentos }\end{array}$ & & $\mathrm{x}$ & & $\mathrm{x}$ & & \\
\hline Integrar atividades das equipes multifuncionais & $\mathrm{x}$ & & & $x$ & & \\
\hline $\begin{array}{l}\text { Fomentar parcerias estratégicas (clientes, } \\
\text { fornecedores, etc) }\end{array}$ & $\mathrm{x}$ & & & $x$ & & \\
\hline $\begin{array}{l}\text { Definir o líder do desenvolvimento e o próprio } \\
\text { desenvolvimento como fatores estratégicos } \\
\text { para a empresa }\end{array}$ & & & $\mathrm{x}$ & $\mathrm{x}$ & & \\
\hline $\begin{array}{l}\text { Adotar melhores práticas em desenvolvimento } \\
\text { de produtos da organização }\end{array}$ & & $x$ & & & $\mathrm{x}$ & \\
\hline $\begin{array}{l}\text { Definir um sistema para registro e recuperação } \\
\text { de melhores práticas em desenvolvimento de } \\
\text { produtos do mercado }\end{array}$ & & & $\mathrm{x}$ & & & $\mathrm{x}$ \\
\hline $\begin{array}{l}\text { Dar ênfase à MC de produtos e processos, } \\
\text { incluindo o de aprendizagem }\end{array}$ & & $\mathrm{x}$ & & $\mathrm{x}$ & & \\
\hline $\begin{array}{l}\text { Organizar a empresa matricialmente (funcional } \\
\text { x projetizada) }\end{array}$ & & $\mathrm{x}$ & & $\mathrm{x}$ & & \\
\hline $\begin{array}{l}\text { Implantar revisões periódicas com as equipes } \\
\text { de desenvolvimento para controlar e nivelar } \\
\text { informação sobre a situação do } \\
\text { desenvolvimento }\end{array}$ & & $x$ & & $\mathrm{x}$ & & \\
\hline $\begin{array}{l}\text { Fazer da gestão do PDP um produto de venda, } \\
\text { como uma prestação de serviço intrínseca ao } \\
\text { desenvolvimento de produtos. }\end{array}$ & & & $\mathrm{x}$ & & & $\mathrm{x}$ \\
\hline $\begin{array}{l}\text { Definir liderança específica para área de } \\
\text { suporte ao desenvolvimento com foco em MC. }\end{array}$ & & & $x$ & $x$ & & \\
\hline $\begin{array}{l}\text { Definir um processo para solução de problema } \\
\text { sistemático. }\end{array}$ & & $x$ & & $x$ & & \\
\hline \multirow[t]{2}{*}{ Implantar Programa 5S } & & $x$ & & & $x$ & \\
\hline & 3 & 12 & 8 & 14 & 7 & 2 \\
\hline TOTAL & 6 & 18 & 11 & 25 & 8 & 2 \\
\hline
\end{tabular}




\section{Apêndice F - Identificação das atividades de PDP e PMC nos projetos B.1 e B.2}

\begin{tabular}{|c|c|c|c|c|c|c|}
\hline \multirow{3}{*}{$\begin{array}{l}\text { Linha de Produto B } \\
\text { Atividades do PDP }\end{array}$} & \multicolumn{3}{|c|}{ Projeto B.1 } & \multicolumn{3}{|c|}{ Projeto B.2 } \\
\hline & \multicolumn{6}{|c|}{ Prática da Atividade } \\
\hline & Formal & Ad hoc & $\begin{array}{l}\text { Não } \\
\text { Existe }\end{array}$ & Formal & Ad hoc & $\begin{array}{c}\text { Não } \\
\text { Existe }\end{array}$ \\
\hline $\begin{array}{l}\text { Utilizar ferramentas para desenvolvimentos } \\
\text { virtuais, tais como: CAD, mockup digital, etc. }\end{array}$ & $x$ & & & $x$ & & \\
\hline $\begin{array}{l}\text { Definir mapas para auxílio na gestão } \\
\text { estratégica de portfólio }\end{array}$ & & $\mathrm{x}$ & & & $\mathrm{x}$ & \\
\hline $\begin{array}{l}\text { Aplicar ferramentas que garantam a qualidade } \\
\text { como: FMEA, QFD, DFE, etc. }\end{array}$ & $\mathrm{x}$ & & & $\mathrm{x}$ & & \\
\hline $\begin{array}{l}\text { Desenvolver e aplicar métodos, ferramentas e } \\
\text { padrões para planejamento, execução e } \\
\text { controle dos desenvolvimentos. }\end{array}$ & & $x$ & & $x$ & & \\
\hline $\begin{array}{l}\text { Estabelecer plano agregado de projetos: visão } \\
\text { dos desenvolvimentos e lançamentos nos } \\
\text { próximos anos }\end{array}$ & & & $\mathrm{x}$ & $x$ & & \\
\hline $\begin{array}{l}\text { Criar estrutura organizacional específica para } \\
\text { auxiliar a gestão do desenvolvimento de } \\
\text { produtos (ex. escritório de projetos) }\end{array}$ & & & $x$ & $x$ & & \\
\hline $\begin{array}{l}\text { Definir categorias de desenvolvimento para } \\
\text { padronizar ações requeridas de acordo com a } \\
\text { complexidade }\end{array}$ & & $x$ & & $x$ & & \\
\hline $\begin{array}{l}\text { Estabelecer critérios de aprovação de } \\
\text { mudanças significativas nos desenvolvimentos }\end{array}$ & $x$ & & & $x$ & & \\
\hline Comparar e integrar desenvolvimentos & & $x$ & & $x$ & & \\
\hline $\begin{array}{l}\text { Envolver os fornecedores desde o início dos } \\
\text { desenvolvimentos }\end{array}$ & & $\mathrm{x}$ & & $\mathrm{x}$ & & \\
\hline Utilizar conceitos de engenharia simultânea & $\mathrm{x}$ & & & $\mathrm{x}$ & & \\
\hline \multirow[t]{2}{*}{$\begin{array}{l}\text { Implementar / praticar metodologia de "Stage- } \\
\text { Gates" para aprovação ou reprovação de fases } \\
\text { do desenvolvimento. }\end{array}$} & & $\mathrm{x}$ & & $x$ & & \\
\hline & 4 & 6 & 2 & 11 & 1 & 0 \\
\hline \multirow[b]{2}{*}{ Atividades do PMC } & \multicolumn{6}{|c|}{ Prática da Atividade } \\
\hline & Formal & Ad hoc & $\begin{array}{l}\text { Não } \\
\text { Existe }\end{array}$ & Formal & Ad hoc & $\begin{array}{l}\text { Não } \\
\text { Existe }\end{array}$ \\
\hline $\begin{array}{l}\text { Organizar a comunicação entre todos os níveis } \\
\text { hierárquicos da empresa: gerência, } \\
\text { supervisores, operadores, etc. }\end{array}$ & & $x$ & & $x$ & & \\
\hline $\begin{array}{l}\text { Executar workshops para as atividades de MC, } \\
\text { incluindo compartilhamento de lições } \\
\text { aprendidas e melhores práticas }\end{array}$ & & $x$ & & & $\mathrm{x}$ & \\
\hline $\begin{array}{l}\text { Denifir medidas para análise de desempenho } \\
\text { do PDP }\end{array}$ & $\mathrm{x}$ & & & $x$ & & \\
\hline $\begin{array}{l}\text { Armazenar os conhecimentos do PDP de } \\
\text { maneira integrada }\end{array}$ & & & $\mathrm{x}$ & $\mathrm{x}$ & & \\
\hline $\begin{array}{l}\text { Dar poder de decisão ao líder do } \\
\text { desenvolvimento }\end{array}$ & $\mathrm{x}$ & & & $\mathrm{x}$ & & \\
\hline
\end{tabular}




\begin{tabular}{|c|c|c|c|c|c|c|}
\hline $\begin{array}{l}\text { Desenvolver competências nas equipes de } \\
\text { desenvolvimento }\end{array}$ & & $\mathrm{x}$ & & $\mathrm{x}$ & & \\
\hline $\begin{array}{l}\text { Conscientizar todos os gerentes funcionais } \\
\text { para fomentar a MC do PDP }\end{array}$ & & $\mathrm{x}$ & & & $\mathrm{x}$ & \\
\hline $\begin{array}{l}\text { Promover e potencializar a aprendizagem } \\
\text { organizacional: estimular o compartilhamento } \\
\text { do conhecimento adquirido; tratar o } \\
\text { conhecimento como ativo corporativo }\end{array}$ & & & $\mathrm{x}$ & & $x$ & \\
\hline $\begin{array}{l}\text { Obter suporte gerencial para implantação das } \\
\text { atividades }\end{array}$ & & $x$ & & & $x$ & \\
\hline $\begin{array}{l}\text { Realizar auditoria (aprendizagem) pós- } \\
\text { desenvolvimento e utilizar os resultados como } \\
\text { aprendizado em projetos futuros }\end{array}$ & & & $\mathrm{x}$ & $x$ & & \\
\hline $\begin{array}{l}\text { Desenvolver a estrutura organizacional e seus } \\
\text { procedimentos }\end{array}$ & & $x$ & & $x$ & & \\
\hline Integrar atividades das equipes multifuncionais & $x$ & & & $x$ & & \\
\hline $\begin{array}{l}\text { Fomentar parcerias estratégicas (clientes, } \\
\text { fornecedores, etc) }\end{array}$ & & $\mathrm{x}$ & & $\mathrm{x}$ & & \\
\hline $\begin{array}{l}\text { Definir o líder do desenvolvimento e o próprio } \\
\text { desenvolvimento como fatores estratégicos } \\
\text { para a empresa }\end{array}$ & & $x$ & & $x$ & & \\
\hline $\begin{array}{l}\text { Adotar melhores práticas em desenvolvimento } \\
\text { de produtos da organização }\end{array}$ & & $\mathrm{x}$ & & $\mathrm{x}$ & & \\
\hline $\begin{array}{l}\text { Definir um sistema para registro e recuperação } \\
\text { de melhores práticas em desenvolvimento de } \\
\text { produtos do mercado }\end{array}$ & & & $x$ & & & $\mathrm{x}$ \\
\hline $\begin{array}{l}\text { Dar ênfase à MC de produtos e processos, } \\
\text { incluindo o de aprendizagem }\end{array}$ & & $x$ & & $x$ & & \\
\hline $\begin{array}{l}\text { Organizar a empresa matricialmente (funcional } \\
\mathrm{x} \text { projetizada) }\end{array}$ & & $x$ & & $x$ & & \\
\hline $\begin{array}{l}\text { Implantar revisões periódicas com as equipes } \\
\text { de desenvolvimento para controlar e nivelar } \\
\text { informação sobre a situação do } \\
\text { desenvolvimento }\end{array}$ & & $x$ & & $x$ & & \\
\hline $\begin{array}{l}\text { Fazer da gestão do PDP um produto de venda, } \\
\text { como uma prestação de serviço intrínseca ao } \\
\text { desenvolvimento de produtos. }\end{array}$ & & & $\mathrm{x}$ & & & $\mathrm{x}$ \\
\hline $\begin{array}{l}\text { Definir liderança específica para área de } \\
\text { suporte ao desenvolvimento com foco em MC. }\end{array}$ & & & $x$ & $\mathrm{x}$ & & \\
\hline $\begin{array}{l}\text { Definir um processo para solução de problema } \\
\text { sistemático. }\end{array}$ & & $x$ & & $x$ & & \\
\hline \multirow[t]{2}{*}{ Implantar Programa 5S } & & $\mathrm{x}$ & & & $\mathrm{x}$ & \\
\hline & 3 & 14 & 6 & 16 & 5 & 2 \\
\hline TOTAL & 7 & 20 & 8 & 27 & 6 & 2 \\
\hline
\end{tabular}




\section{Apêndice G - Identificação das atividades de PDP e PMC nos projetos C.1 e} C.2

\begin{tabular}{|c|c|c|c|c|c|c|}
\hline \multirow{3}{*}{$\begin{array}{l}\text { Linha de Produto C } \\
\text { Atividades do PDP }\end{array}$} & \multicolumn{3}{|c|}{ Projeto C.1 } & \multicolumn{3}{|c|}{ Projeto C.2 } \\
\hline & \multicolumn{6}{|c|}{ Prática da Atividade } \\
\hline & Formal & Ad hoc & $\begin{array}{l}\text { Não } \\
\text { Existe }\end{array}$ & Formal & Ad hoc & $\begin{array}{l}\text { Não } \\
\text { Existe }\end{array}$ \\
\hline $\begin{array}{l}\text { Utilizar ferramentas para desenvolvimentos } \\
\text { virtuais, tais como: CAD, mockup digital, etc. }\end{array}$ & $\mathrm{x}$ & & & $\mathrm{x}$ & & \\
\hline $\begin{array}{l}\text { Definir mapas para auxílio na gestão } \\
\text { estratégica de portfólio }\end{array}$ & & $\mathrm{x}$ & & & $\mathrm{x}$ & \\
\hline $\begin{array}{l}\text { Aplicar ferramentas que garantam a qualidade } \\
\text { como: FMEA, QFD, DFE, etc. }\end{array}$ & $\mathrm{x}$ & & & $\mathrm{x}$ & & \\
\hline $\begin{array}{l}\text { Desenvolver e aplicar métodos, ferramentas e } \\
\text { padrões para planejamento, execução e } \\
\text { controle dos desenvolvimentos. }\end{array}$ & & & $\mathrm{x}$ & $\mathrm{x}$ & & \\
\hline $\begin{array}{l}\text { Estabelecer plano agregado de projetos: visão } \\
\text { dos desenvolvimentos e lançamentos nos } \\
\text { próximos anos }\end{array}$ & & & $\mathrm{x}$ & $x$ & & \\
\hline $\begin{array}{l}\text { Criar estrutura organizacional específica para } \\
\text { auxiliar a gestão do desenvolvimento de } \\
\text { produtos (ex. escritório de projetos) }\end{array}$ & & & $\mathrm{x}$ & $x$ & & \\
\hline $\begin{array}{l}\text { Definir categorias de desenvolvimento para } \\
\text { padronizar ações requeridas de acordo com a } \\
\text { complexidade }\end{array}$ & & & $\mathrm{x}$ & & $\mathrm{x}$ & \\
\hline $\begin{array}{l}\text { Estabelecer critérios de aprovação de } \\
\text { mudanças significativas nos desenvolvimentos }\end{array}$ & & & $\mathrm{x}$ & & $\mathrm{x}$ & \\
\hline Comparar e integrar desenvolvimentos & & $x$ & & $x$ & & \\
\hline $\begin{array}{l}\text { Envolver os fornecedores desde o início dos } \\
\text { desenvolvimentos }\end{array}$ & $\mathrm{x}$ & & & $\mathrm{x}$ & & \\
\hline Utilizar conceitos de engenharia simultânea & $\mathrm{x}$ & & & $x$ & & \\
\hline \multirow[t]{2}{*}{$\begin{array}{l}\text { Implementar / praticar metodologia de "Stage- } \\
\text { Gates" para aprovação ou reprovação de fases } \\
\text { do desenvolvimento. }\end{array}$} & & $\mathrm{x}$ & & & $x$ & \\
\hline & 4 & 3 & 5 & 8 & 4 & 0 \\
\hline \multirow[b]{2}{*}{ Atividades do PMC } & \multicolumn{6}{|c|}{ Prática da Atividade } \\
\hline & Formal & Ad hoc & $\begin{array}{c}\text { Não } \\
\text { Existe }\end{array}$ & Formal & Ad hoc & $\begin{array}{l}\text { Não } \\
\text { Existe }\end{array}$ \\
\hline $\begin{array}{l}\text { Organizar a comunicação entre todos os níveis } \\
\text { hierárquicos da empresa: gerência, } \\
\text { supervisores, operadores, etc. }\end{array}$ & & $x$ & & & $\mathrm{x}$ & \\
\hline $\begin{array}{l}\text { Executar workshops para as atividades de MC, } \\
\text { incluindo compartilhamento de lições } \\
\text { aprendidas e melhores práticas }\end{array}$ & & & $\mathrm{x}$ & & $x$ & \\
\hline $\begin{array}{l}\text { Denifir medidas para análise de desempenho } \\
\text { do PDP }\end{array}$ & & $x$ & & $x$ & & \\
\hline $\begin{array}{l}\text { Armazenar os conhecimentos do PDP de } \\
\text { maneira integrada }\end{array}$ & & & $x$ & & $x$ & \\
\hline $\begin{array}{l}\text { Dar poder de decisão ao líder do } \\
\text { desenvolvimento }\end{array}$ & & $x$ & & $x$ & & \\
\hline
\end{tabular}




\begin{tabular}{|c|c|c|c|c|c|c|}
\hline $\begin{array}{l}\text { Desenvolver competências nas equipes de } \\
\text { desenvolvimento }\end{array}$ & & $\mathrm{x}$ & & $\mathrm{x}$ & & \\
\hline $\begin{array}{l}\text { Conscientizar todos os gerentes funcionais } \\
\text { para fomentar a MC do PDP }\end{array}$ & & & $\mathrm{x}$ & & $\mathrm{x}$ & \\
\hline $\begin{array}{l}\text { Promover e potencializar a aprendizagem } \\
\text { organizacional: estimular o compartilhamento } \\
\text { do conhecimento adquirido; tratar o } \\
\text { conhecimento como ativo corporativo }\end{array}$ & & & $x$ & & $\mathrm{x}$ & \\
\hline $\begin{array}{l}\text { Obter suporte gerencial para implantação das } \\
\text { atividades }\end{array}$ & & $\mathrm{x}$ & & & $\mathrm{x}$ & \\
\hline $\begin{array}{l}\text { Realizar auditoria (aprendizagem) pós- } \\
\text { desenvolvimento e utilizar os resultados como } \\
\text { aprendizado em projetos futuros }\end{array}$ & & & $x$ & $\mathrm{x}$ & & \\
\hline $\begin{array}{l}\text { Desenvolver a estrutura organizacional e seus } \\
\text { procedimentos }\end{array}$ & & $x$ & & $x$ & & \\
\hline Integrar atividades das equipes multifuncionais & & $x$ & & $x$ & & \\
\hline $\begin{array}{l}\text { Fomentar parcerias estratégicas (clientes, } \\
\text { fornecedores, etc) }\end{array}$ & & $\mathrm{x}$ & & $\mathrm{x}$ & & \\
\hline $\begin{array}{l}\text { Definir o líder do desenvolvimento e o próprio } \\
\text { desenvolvimento como fatores estratégicos } \\
\text { para a empresa }\end{array}$ & & & $x$ & $x$ & & \\
\hline $\begin{array}{l}\text { Adotar melhores práticas em desenvolvimento } \\
\text { de produtos da organização }\end{array}$ & & $\mathrm{x}$ & & $x$ & & \\
\hline $\begin{array}{l}\text { Definir um sistema para registro e recuperação } \\
\text { de melhores práticas em desenvolvimento de } \\
\text { produtos do mercado }\end{array}$ & & & $x$ & & & $\mathrm{x}$ \\
\hline $\begin{array}{l}\text { Dar ênfase à MC de produtos e processos, } \\
\text { incluindo o de aprendizagem }\end{array}$ & & & $\mathrm{x}$ & & $\mathrm{x}$ & \\
\hline $\begin{array}{l}\text { Organizar a empresa matricialmente (funcional } \\
\text { x projetizada) }\end{array}$ & & $\mathrm{x}$ & & $\mathrm{x}$ & & \\
\hline $\begin{array}{l}\text { Implantar revisões periódicas com as equipes } \\
\text { de desenvolvimento para controlar e nivelar } \\
\text { informação sobre a situação do } \\
\text { desenvolvimento }\end{array}$ & & & $x$ & $\mathrm{x}$ & & \\
\hline $\begin{array}{l}\text { Fazer da gestão do PDP um produto de venda, } \\
\text { como uma prestação de serviço intrínseca ao } \\
\text { desenvolvimento de produtos. }\end{array}$ & & & $x$ & & $\mathrm{x}$ & \\
\hline $\begin{array}{l}\text { Definir liderança específica para área de } \\
\text { suporte ao desenvolvimento com foco em MC. }\end{array}$ & & & $x$ & $x$ & & \\
\hline $\begin{array}{l}\text { Definir um processo para solução de problema } \\
\text { sistemático. }\end{array}$ & & $\mathrm{x}$ & & & $\mathrm{x}$ & \\
\hline \multirow[t]{2}{*}{ Implantar Programa 5S } & & $\mathrm{x}$ & & & $\mathrm{x}$ & \\
\hline & 0 & 12 & 11 & 12 & 10 & 1 \\
\hline TOTAL & 4 & 15 & 16 & 20 & 14 & 1 \\
\hline
\end{tabular}


Anexo 1 - Diagrama de Tartaruga utilizado no mapeamento dos processos da unidade estudada

\section{DELPHI}

DIAGRAMA DA TARTARUGA

Automotive Systems

SO: Desenvolvimento de Produto e Processo

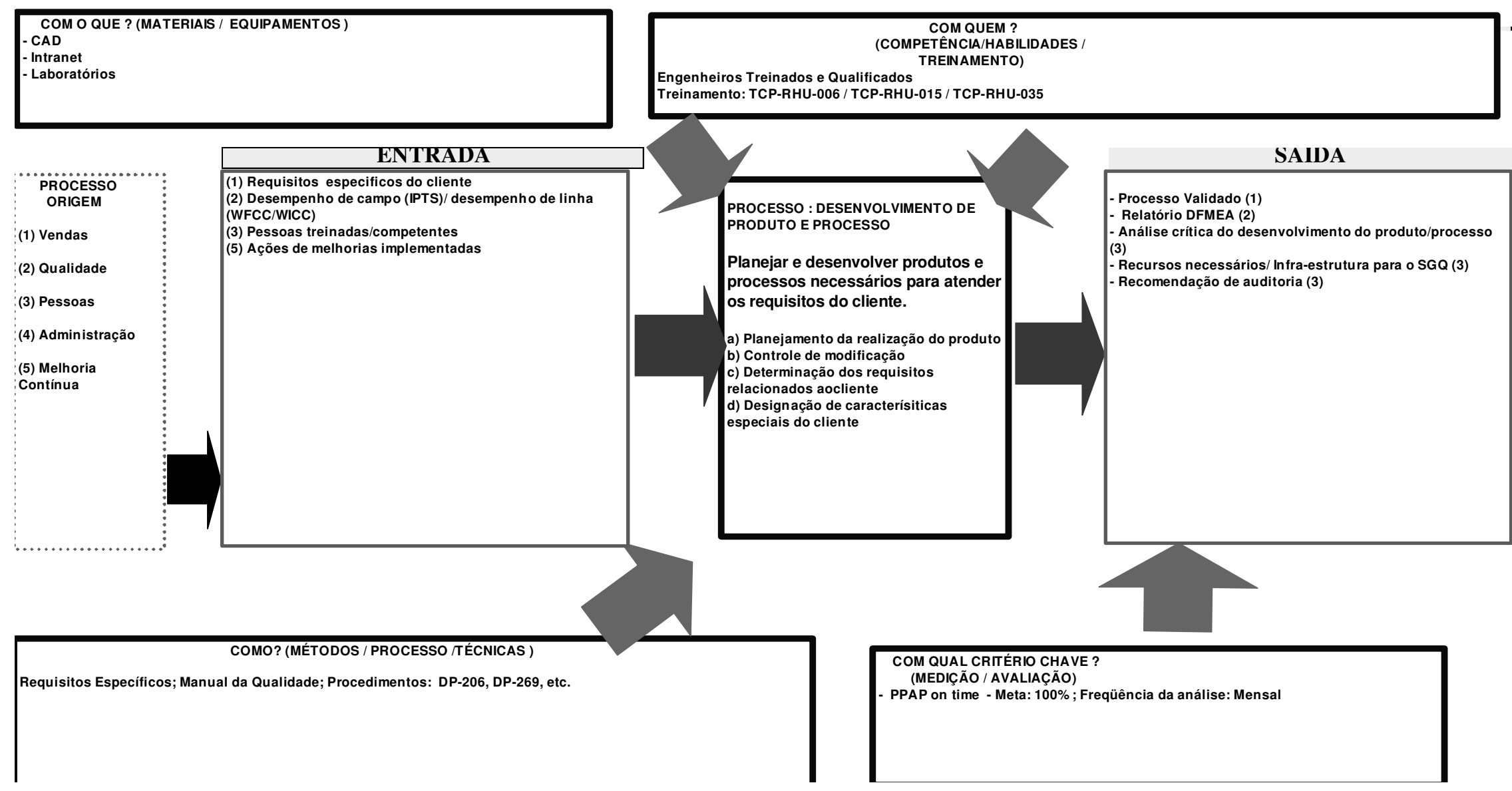

